\title{
Studies of the Systemic Inflammation in Psoriasis
}

Gunnpórunn Sigurđardóttir

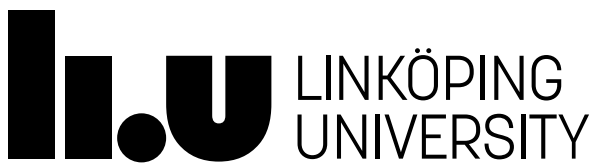

Ingrid Asp Psoriasis Research Center

Department of Clinical and Experimental Medicine

Faculty of Medicine and Health Sciences, Linköping University SE-581 83 Linköping, Sweden

Linköping 2018 
(C) 2018 Gunnpórunn Sigurðardóttir

ISBN: 978-91-7685-256-9

ISSN: 0345-0082

Front cover and illustration by Gunnpórunn Sigurðardóttir with graphic assistance from LiU-Tryck, Linköping.

Published articles have been reprinted with permission of the copyright holders.

Paper I Copyright remains with the authors. Journal Compilation (C) 2013 Acta Dermato- Venereologica

Paper II (C) 2014 American Academy of Dermatology, Inc. Mosby, Inc.

Paper III ㄷ 2018 S. Karger AG, Basel

Printed by LiU-Tryck, Linköping 2018 
"Nothing is so firmly believed as that which we least know" Michel de Montaigne 



\section{Abstract}

Psoriasis is a common immune-mediated disease, where an increased prevalence of extra cutaneous diseases and mortality is observed. Common inflammatory mechanisms are implicated. The general aim of this thesis was to investigate markers of inflammation and cardiovascular disease in psoriasis, now considered a systemic disease, assumed to reflect the systemic inflammation.

In Study I, Th1-, Th2- and Th17-associated chemokines were elevated in the blood of psoriasis patients in comparison to controls and, in Study II, six markers of cardiovascular risk were demonstrated to be systemically elevated. After adjustment for body mass index and waist: hip ratio in Study II, only one marker, the total plasminogen activator inhibitor-1, showed sustained elevated levels. The levels of the chemokines and the cardiovascular markers were unaffected after treatment with narrowband UVB therapy (NB-UVB), despite a significant improvement in skin lesions, indicating more local than systemic effects of NBUVB. This was further strengthened by the fact that the response to in-vitro stimulation in the peripheral blood mononuclear cells (PBMCs) of psoriasis patients before and after NB-UVB treatment was unaffected. In Study I, CCL20 was shown to correlate to the psoriasis area severity index (PASI), but this correlation was lost after phototherapy, suggesting sources of CCL20 other than the skin. Conversely, systemic treatment with TNF- $\alpha$ inhibition in Study II alleviated the elevated systemic levels of the cardiovascular risk markers. In Study III, the levels of 17 potential biomarkers, with the emphasis on endothelial and adipocyte dysfunction, soluble receptors and the innate mechanisms were studied. Endocan-1, CXCL16, and sVEGFR1, were found to be systemically decreased in psoriasis patients at baseline. Endocan-1 showed a negative correlation to the PASI. In contrast to the results in Studies I and II, NB-UVB therapy affected the systemic levels of investigated markers; Endocan-1 and CXCL16 were restored to normal levels, while sVEGF1, FABP3, FABP4 and sIL-1R1 showed a significant reduction following NB-UVB. In Study IV, the focus was on the contribution of innate immune mechanisms and the effects of the cytokines IL-17 and TNF- $\alpha$ on systemic inflammation. In keratinocytes, the gene and protein expression of inflammasome components was increased upon exposure to IL-17 and TNF- $\alpha$. Systemically, the constitutive expression of the inflammasome components NLRP1, NLRP3 and AIM2 was detected in neutrophils, classical monocytes, CD4+ lymphocytes and B-cell subsets from psoriasis patients. Upon exposure to IL-17 and TNF- $\alpha$, increased systemic caspase-1 levels were detected, confirming systemic inflammasome activity.

In conclusion, these studies support the hypothesis that there is a systemic inflammation in psoriasis to which both innate and adaptive immune mechanisms contribute. The systemic inflammation may be explained, to some extent, but not completely, by body weight and fat distribution. The different effects of NB-UVB therapy on the systemic levels of the investigated markers may reflect their different roles in psoriasis, but the ameliorating effects of the TNF- $\alpha$ inhibitor on the elevated cardiovascular markers suggests that systemic treatment should be evaluated in psoriasis patients with signs of a systemic inflammatory burden. 



\section{Popular science summary}

[in Swedish]

\section{Inflammation som uppmäts i blodet hos patienter med psoriasis är kopplad till övervikt och påverkas i mindre grad av ljus än av invärtes behandling}

Psoriasis är en kronisk inflammatorisk sjukdom som drabbar 2-3\% av befolkningen. Sjukdomen uttrycker sig i huden som röda, fjällande fläckar men kan även drabba naglar, senfästen och leder. Den exakta orsaken till sjukdomens uppkomst är okänd, men det krävs samspel mellan genetisk predisposition och utlösande faktorer i omgivningen. Flera studier har observerat en koppling mellan psoriasis och andra sjukdomar såsom övervikt, det metabola syndromet, diabetes samt hjärt-och kärlsjukdom men även leversjukdom och depression. Metabola syndromet är ett samlingsnamn som innebär att det finns flera och bestämda riskfaktorer för hjärt-och kärlsjukdom. Mycket talar för att det finns gemensamma mekanismer för uppkomst av psoriasis och denna samsjuklighet. Därför är karakterisering av den systemiska inflammationen i psoriasis av värde för att förstå hur mekanismerna är relaterade. Att identifera en mätbar markör i blodet hos psorsiasispatienter som kan förutsäga risk för utveckling av samsjuklighet är av vikt för behandlingsstrategin hos den enskilda individen.

Denna avhandling inkluderar fyra studier, där markörer för inflammation, men även hjärt-och kärlsjukdom har analyserats hos psoriasispatienter samt hur dessa markörer påverkas av behandling.

I första studien har inflammatoriska markörer, så kallade chemokiner (små proteinmolekyler som vägleder immunceller till områden med inflammation), representarande olika typer av immunförsvar påvisats vara förhöjda hos psoriasispatienter. I den andra studien har fem av sex undersökta riskmarkörer för hjärt-och kärlsjukdom påvisats förhöjda. Efter korrigering för kroppsmasseindex (body mass index; BMI) som mått på övervikt och midja-höft kvot som mått på midjemåttet i studie II, kvarstod endast en markör förhöjd. Detta talar för att inflammationen i blodet som markörerna representerar är till stor del, men inte enbart, kopplad till kroppsvikt och bukfetma.

I studie I och II studerades även effekten av den ljusbehandling som oftast används för behandling av psoriasis (ultraviolett ljus av typ B med våglängden $311 \mathrm{~nm}$ ). Markörerna kvarstod förhöjda, trots tillfredsställande förbättring av hudsymptomen. Däremot visade studie II att behandling med antiinflammatoriskt läkemedel i injektionsform ledde till sänkning av samtliga riskmarkörer för hjärt-och kärlsjukdom. Dessa resultat indikerar att ljusbehandlingen hämmar inflammationen i huden utan att i samma grad påverka inflammationen i blodet.

I studie III undersöktes ytterligare markörer relaterade till hjärt-och kärlsjukdom, nu utifrån aspekter såsom kärlpåverkan, inflammation i fettväv och fettomsättning. Till skillnad från tidigare resultat hittades en sänkning av markörer. Den ena är viktig för funktionen av endotelet, det innersta lagret i kroppens kärl, vars funktion är rubbad vid hjärt-och 
kärlsjukdom, den andra är av vikt i det tidiga immunförsvaret både i hjärt-och kärlsjukdom samt psoriasis och den tredje hämmar kärlnybildning. En av markörerna korrelerade till svårighetsgraden av psoriasis i huden och två av de tre markörerna normaliserades i samband med ljusbehandling. Möjligen kan markörerna som minskade vara mer specifika för hudinflammationen och en ökad koncentration i huden förklara sänkta värden i blodet.

Det finns ett ökat intresse för forskning kring tidiga immunmekanismer vid psoriasis. I studie fyra studerades komponenter av proteinkomplexer inuti celler som är av stor vikt i det tidiga eller medfödda immunförsvaret, så kallade inflammasomer. Ökat uttryck av inflammasomdelarna NLRP1, NLRP3 och AIM2 konstaterades i olika typer av vita blodkroppar hos psoriasispatienter med en koppling till nyckelcytokinet i psoriasis, IL-17 (ett protein som driver inflammation).

Sammanfattningsvis har dessa studier styrkt och närmare beskrivit förekomsten av systemisk inflammation hos psoriasispatienter. Inflammationen i blodet kan delvis kopplas till kroppsvikt och bukfetma. Resultaten talar för att ljusbehandling inte påverkar denna inflammation i samma grad som invärtes läkemedelsbehandling. 


\section{Table of contents}

LIST OF ORIGINAL PAPERS

ABBREVIATIONS

INTRODUCTION

Epidemiology

Classification

Aetiology

Genetic susceptibility

Epigenetic factors

Environmental factors

Pathogenesis

Innate immune mechanisms in psoriasis

Cytokines and chemokines in psoriasis

Cytokines

Chemokines

Psoriasis as a systemic disease $\quad 29$

Co-morbidities in psoriasis $\quad 30$

$\begin{array}{ll}\text { Obesity } & 30\end{array}$

Metabolic syndrome $\quad 31$

Vascular disease $\quad 31$

Non-alcoholic fatty liver disease (NAFLD) 33

Depression $\quad 34$

Investigating systemic inflammation in psoriasis

$\begin{array}{ll}\text { AIM OF THESIS } & 37\end{array}$

MATERIAL AND METHODS 39

$\begin{array}{ll}\text { Ethical principles } & 39\end{array}$

Patient and control study groups $\quad 39$

Patients and controls from Linköping University Hospital $\quad 40$

Patients and controls from Sahlgrenska University Hospital 41

Patients from Karolinska University Hospital $\quad 41$ 
Quantification of biomarkers (Studies I-III) 41

Biomarkers in clinical use $\quad 41$

$\begin{array}{ll}\text { Other biomarkers } & 42\end{array}$

Immunoassay procedures $\quad 42$

Cell cultures and stimulations (Studies I \& IV) 43

$\begin{array}{ll}\text { Study I } & 43\end{array}$

Study IV 43

Quantitative real-time PCR (Study IV) 44

$\begin{array}{ll}\text { Immunofluorescence (Study IV) } & 45\end{array}$

Flow cytometry (Study IV) 45

Detection of inflammasome expression $\quad 46$

Detection of caspase $1 \quad 46$

$\begin{array}{ll}\text { Statistical methods } & 47\end{array}$

RESULTS AND DISCUSSION

$\begin{array}{ll}\text { Paper I } & 49\end{array}$

$\begin{array}{lr}\text { Paper II } & 54\end{array}$

$\begin{array}{ll}\text { Paper III } & 59\end{array}$

Common considerations in Studies I-III 62

$\begin{array}{ll}\text { Studies of inflammatory mediators } & 62\end{array}$

$\begin{array}{ll}\text { Pursuing a biomarker } & 62\end{array}$

$\begin{array}{ll}\text { Measuring cytokine levels } & 63\end{array}$

$\begin{array}{ll}\text { Paper IV } & 65\end{array}$

Inflammasome expression in blood of psoriasis patients 65

The role of IL-17 in inflammasome expression $\quad 67$

$\begin{array}{ll}\text { CONCLUSIONS } & 71\end{array}$

$\begin{array}{ll}\text { PERSPECTIVE } & 73\end{array}$

$\begin{array}{ll}\text { ACKNOWLEDGEMENTS } & 75\end{array}$

$\begin{array}{ll}\text { REFERENCES } & 77\end{array}$ 


\section{List of original papers}

The thesis is based on the following original papers, which are referred to in the text by their respective Roman numerals:

I. Ekman A-K*, Sigurdardottir G*, Carlstrom M, Kartul N, Jenmalm MC, Enerbäck C Systemically elevated Th1-, Th2- and Th17-associated chemokines in psoriasis vulgaris before and after ultraviolet B treatment.

Acta Dermato- Venereologica. 2013;93(5):525-31. Epub 2013/04/10.

*Shared first authorship

II. Sigurdardottir G*, Ekman A-K*, Ståhle M, Bivik C, Enerbäck C

Systemic treatment and narrowband ultraviolet B differentially affect cardiovascular risk markers in psoriasis.

Journal of the American Academy of Dermatology. 2014;70(6):1067-75. Epub $2014 / 03 / 20$.

*Shared first authorship

III. Sigurdardottir G, Ekman A-K, Verma D, Enerbäck C

Decreased systemic levels of endocan-1 and CXCL16 in psoriasis are restored following narrowband UVB treatment.

Dermatology. 2018 Sep 3:1-7. Epub ahead of print.

IV. Sigurdardottir G, Verma D, Bivik.Eding C, Enerbäck C

Increased systemic activity of the NLRP1, NLRP3 and AIM2 inflammasomes in psoriasis is regulated by $I L-17$ and $T N F-\alpha$.

In manuscript 


\section{Abbreviations}

AIM

AMPs

ASC

BMI

CCL

cDNA

CRP

CXCL

CXCR

DAMPs

DCs

FABP

HEKn

HLA

ICAM-1

IF

IFN

IL

ILC

LPS

$\mathrm{mDCs}$

MHC

MMP

MPO

NAFLD

NB-UVB

$N F-\kappa B$

NK
Absent in melanoma

Antimicrobial peptides

Apoptosis-associated speck like protein containing a CARD

Body mass index

$\mathrm{CC}$ chemokine ligand

Complementary DNA

$\mathrm{C}$-reactive protein

CXC chemokine ligand

CXC chemokine receptor

Danger-associated molecular patterns

Dendritic cells

Fatty acid-binding protein

Human epidermal keratinocytes, neonatal

Human leukocyte antigen

Intercellular adhesion molecule 1

Immunofluorescence

Interferon

Interleukin

Innate lymphoid cells

Lipopolysaccharide

Myeloid dendritic cells

Major histocompatibility complex

Matrix metalloproteinase

Myeloperoxidase

Non-alcoholic fatty liver disease

Narrowband ultraviolet B

Nuclear factor-kappa beta

Natural killer 
NLRP1

NLRP3

OxLDL

PAI-1

PAMPs

PASI

PBMCs

pDCs

PPR

PUVA

RBC

ROS

sE-selectin

sICAM-1

SIL-1R

sIL-2Ra

sTNFR

sVCAM-1

sVEGFR

Tc

Th

tPAI-1

TNF- $\alpha$

TLR

VCAM-1

VEGF

WHR
NACHT, LRR and PYD domains-containing protein 1

NACHT, LRR and PYD domains-containing protein 3

Oxidised low-density lipoprotein

Plasminogen activator inhibitor 1

Pathogen-associated molecular patterns

Psoriasis area severity index

Peripheral blood mononuclear cells

Plasmacytoid dendritic cells

Pattern recognition receptor

Psoralen ultraviolet A

Red blood cell

Reactive oxygen species

Soluble E-selectin

Soluble intercellular adhesion molecule 1

Soluble interleukin 1 receptor

Soluble interleukin 2 receptor subunit alpha

Soluble tumour necrosis factor receptor

Soluble vascular cell adhesion molecule 1

Soluble vascular endothelial growth factor receptor

$\mathrm{T}$ cytotoxic (cytotoxic $\mathrm{T}$ cell)

$\mathrm{T}$ helper

Total plasminogen activator inhibitor 1

Tumour necrosis factor alpha

Toll-like receptor

Vascular cell adhesion molecule 1

Vascular endothelial growth factor

Waist: hip ratio 


\section{Introduction}

Psoriasis is a common immune-mediated disease that on average affects $2-3 \%$ of the population worldwide (1). Its incidence, in children and adults, is thought to have been increasing over a 30 -year period $(2,3)$. The aetiology of psoriasis is not fully understood, but it is well established that a genetic predisposition and epigenetic factors, together with environmental factors, play an important role. The disease has several phenotypes and the most common, plaque psoriasis, is characterised by chronic inflammation, manifesting in the skin as scaly red lesions, plaques, with or without the involvement of nails and joints. There is a difference in severity, ranging from a few plaques to the involvement of almost the entire body surface. The degree of severity depends on genetic and environmental factors and the disease may intermittently improve or progressively worsen. Histologically, there is an increase in the thickness of the epidermis, reflecting accelerated cell division, and parakeratosis, reflecting disordered differentiation, and angiogenesis in the dermis. Immunologically, there is cross-talk between immune cells and keratinocytes, where cytokines and chemokines are key factors. Clinically, the increased prevalence of extra cutaneous diseases, including obesity, the metabolic syndrome, cardiovascular disease and depression, is observed. Furthermore, there is an increase in mortality, especially in severe disease (4-6). With expanding knowledge of the immune system, it is becoming more evident that these diseases may have common inflammatory mechanisms. Studies of systemic inflammation in psoriasis therefore play an important part of identifying new aspects of the pathogenesis of the disease itself and the co-morbidities observed in many psoriasis patients. Identifying markers of the disease that could differentiate between different phenotypes and help in deciding on the most appropriate and cost-effective treatment for each individual is therefore of interest. In 2014, the World Health Organization (WHO) encouraged member states to raise awareness of psoriasis and its impact on general health, asserting the need for further research and a more holistic approach to the management of psoriasis patients $(7,8)$. Furthermore, in March 2018, the National Board of Health and Welfare (Socialstyrelsen) in Sweden published a preliminary version of national guidelines regarding the care of psoriasis patients, where psoriasis as a systemic disease is emphasised and screening for comorbidities, especially in severe disease, is recommended (9). 


\section{Epidemiology}

Psoriasis affects people of all ages and ethnicities, without any gender predisposition.

However, the disease occurs more frequently with advancing age and appears to be most common in populations of Northern Europe and least common in populations of Eastern Asia. According to published data, the prevalence of psoriasis varies between $0.09 \%$ and $11.4 \%$ in different countries. The estimated prevalence of psoriasis in the most developed countries has been estimated between $1.5 \%$ and $5 \%$. A significant variation in psoriasis prevalence between populations and countries has been demonstrated, but there are differences in the way data sampling has been accomplished and there are many gaps in the availability of data $(8,10$, 11).

\section{Classification}

Psoriasis can be classified according to age of onset, disease severity, pattern of distribution including anatomical site, morphology and whether it is stable or unstable. The diagnosis is first and foremost clinical. The disease can be divided into the following clinical phenotypes: 1) plaque psoriasis, 2) guttate psoriasis, 3) pustular psoriasis and 4) erythrodermic psoriasis. Inverse and nail psoriasis can be classified as separate phenotypes, as patients can present with lesions only on these anatomical sites. However, these sites are often also affected in the previously mentioned clinical phenotypes. Plaque psoriasis or psoriasis vulgaris is the most common form of psoriasis, presenting as pink or red plaques of different sizes and thicknesses. Guttate psoriasis has an acute onset and presents with droplet-like lesions less than $1 \mathrm{~cm}$ in diameter. It is more common in children and young individuals following streptococcal infection or upper respiratory tract infection, but even psoriasis vulgaris can worsen following infection or other stressful situations. Having guttate psoriasis, which is often self-limiting, increases the risk of developing plaque psoriasis, either in association with the guttate episode or later in life. Pustular psoriasis can be localised or generalised and presents as sterile pustules on an erythematous base. Palmoplantar pustulosis is a form of localised pustular psoriasis. Erythrodermic psoriasis presents as generalised erythema involving the majority of the skin surface and is often a presentation of the worsening of previously known psoriasis. Besides the importance of identifying the phenotype of psoriasis, assessing disease severity is meaningful with regard to the selection of treatment and 
follow-up. There are different ways of evaluating disease severity and one of them is the Psoriasis Area Severity Index (PASI). The PASI is currently the most appropriate instrument for grading psoriasis. It combines an evaluation of the severity of the skin lesions, with regard to infiltration, erythema and scaling, together with the distribution of the disease $(12,13)$. The PASI is presented as a number between 0-72, where a higher count indicates more severe psoriasis. The classification of the severity of psoriasis has changed and, at the present time (9), a PASI of less than 3 is interpreted as mild disease, PASI 3-10 as moderate disease and a PASI of more than 10 as severe disease. It should be mentioned that quality of life assessed with the Dermatology Life Quality Index (DLQI) is also a part of the holistic assessment of disease severity.

\section{Aetiology}

Psoriasis is a multifactorial condition where interaction between genetic susceptibility and environmental and epigenetic factors is fundamental regarding the risk of developing the disease (Figure 1). The exact cause of psoriasis is, however, still unknown, but different environmental and epigenetic factors may contribute differently to the different psoriasis phenotypes.

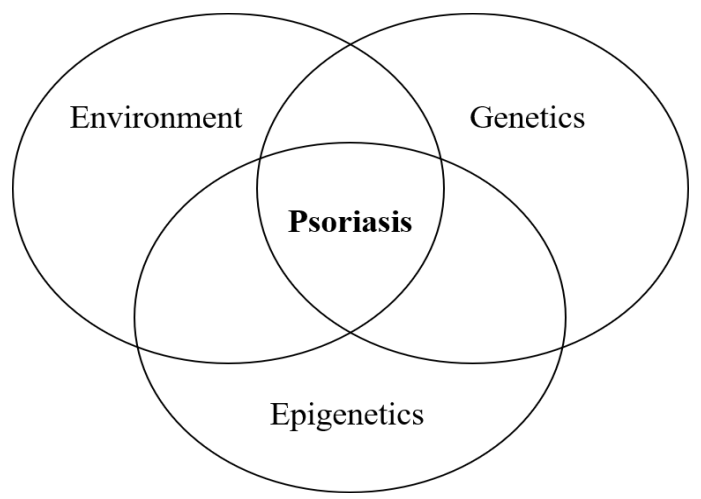

Figure 1. Aetiological factors in psoriasis. 


\section{Genetic susceptibility}

In psoriasis, familial recurrence is well documented and disease concordance is higher in monozygotic than in dizygotic twins $(14,15)$. Genetic studies have identified more than 60 psoriasis susceptibility loci, but all the underlying genes have not been definitely identified (16). Linkage analyses have identified chromosomal loci, Psoriasis Susceptibility (PSORS) 1-9 regions, where evidence of a linkage to psoriasis has been found in PSORS1 loci but also in PSORS 2 and PSORS4. Major histocompatibility complex (MHC) antigens are associated with psoriasis and the strongest association appears to be with the human leukocyte antigen (HLA)-Cw6 locus in PSORS1 (17).

In the PSORS2 region, mutations in the caspase recruitment domain family member/CARD14 gene, which encodes an adaptor protein highly expressed in keratinocytes, have been identified. These CARD14 mutations cause constitutive nuclear factor-kappa beta (NF- $\kappa \mathrm{B})$ activation and therefore enhanced production of pro-inflammatory cytokines $(18,19)$.

In the Epidermal Differentiation Cluster (EDC) in PSORS4, there are genes encoding proteins involved in terminal keratinocyte differentiation. The deletion of the EDC genes, late cornified envelope ( $L C E$ ) $3 B$ and $3 C$, has been found to be strongly associated with psoriasis (20).

The loss of function mutations in the IL-36 receptor antagonist gene, IL36RN, lead to uncontrolled IL-36 signalling by abolishing the inhibitory activity of the gene. These mutations are associated with generalised pustular psoriasis $(21,22)$.

Furthermore, certain polymorphisms in genes coding for major role players in the innate immune responses, the inflammasome sensor proteins, NACHT, LRR and PYD domaincontaining proteins (NLRP) 1 and 3, have been associated with psoriasis susceptibility and pathogenesis $(23,24)$. 


\section{Epigenetic factors}

As previously mentioned, the concordance of psoriasis in monozygotic twins is higher than in dizygotic twins. Studies have shown a concordance in monozygotic twins of between $36-64 \%$ $(14,25)$. This discordance suggests the possibility that epigenetic modifications, which have been identified in psoriasis, could affect initiation and the phenotype of the disease. Epigenetic modifications are potentially hereditary and include the regulation of gene expression extrinsic to DNA sequence by DNA methylation, histone modification and noncoding RNA. These modifications are also potentially reversible, making them highly interesting from the angle of possible therapeutic approaches. The epigenetic modifications found in psoriasis affect keratinocyte proliferation and differentiation, innate immune mechanisms, cytokine expression and the function of T regulatory cells (26-29).

\section{Environmental factors}

In psoriasis, interaction between environmental and genetic factors has been shown in connection with smoking and obesity. Moreover, it has been suggested that environmental factors induce epigenetic modifications and thereby affect gene expression leading to clinical manifestation (30).

Exogenous stimuli, such as trauma, infections, smoking, alcohol, drugs and psychogenic factors, have been linked to psoriasis and are implied to be trigger factors, with regard to both the initiation of the disease and progression but also to the aggravation of a pre-existing disease. Skin injury in any form, mechanical trauma or infectious agents, disrupting the skin barrier, induces inflammatory responses that could initiate psoriasis. The epidermal keratinocytes recognise mechanical trauma as danger-associated molecular patterns (DAMPs) and infectious agents as pathogen-associated molecule patterns (PAMPs) through toll-like receptors (TLR) and inflammasome complexes (31). Infections with $\beta$ haemolytic streptococcus, especially throat infections, are related to the initiation and recurrence of guttate psoriasis, the progression of guttate psoriasis to the chronic plaque form and the exacerbation of chronic plaque psoriasis (32-36). Moreover, it has been proposed that intestinal microbiota could affect the initiation of psoriasis disease (37). Smoking is overrepresented in psoriasis patients and has been suggested as a risk factor for psoriasis (38). 
The reason is not known, but, apart from nicotine, cigarettes contain many toxins and smoking increases oxidative stress (39). A relationship has been observed between carrying the HLA-Cw6 gene and smoking in psoriasis patients (40). Furthermore, nicotine binds to the nicotinic acetylcholine receptor (nAChR) and the nAChR pathway is able to regulate keratinocyte and T-cell function (41). As with smoking, alcohol is also suggested as a risk factor for psoriasis and alcohol-associated diseases are overrepresented in patients with moderate to severe disease (42). Chronic alcohol consumption may stimulate inflammatory responses in contrast to acute alcohol consumption. Alcohol intake correlates positively with inflammatory markers, Tumour necrosis factor-alpha converting enzyme (TACE) and soluble tumour necrosis factor receptor type I (sTNFR1), indicators of tumour necrosis factor alpha (TNF- $\alpha$ ) mediated inflammation (43). In addition, ethanol has been shown to affect keratinocyte proliferation in in-vitro models (44). 


\section{Pathogenesis}

In the pathogenesis of psoriasis, both the innate and the adaptive immune mechanisms are involved. The inflammatory infiltrate in psoriatic skin is composed of dendritic cells (DCs), neutrophils, macrophages and lymphocytes. The inflammation is driven by cytokines and chemokines. According to the model of psoriasis pathogenesis, psoriasis evolution starts with an injury to the keratinocytes. The keratinocytes then initiate an immune response through the release of self-DNA and the production of antimicrobial peptides (AMPs), chemokines and cytokines (45).

Keratinocytes and DCs are the hallmark of the initiation and early inflammatory phases of psoriasis. Keratinocyte-derived chemokines and cytokines are important for the recruitment of leukocytes, e.g. neutrophils. Different subsets of DCs play a role in psoriasis pathogenesis. They are plasmacytoid dendritic cells (pDCs), myeloid dendritic cells (mDCs) and 6-sulpho lacNAc + dendritic cells (SlanDCs). Plasmacytoid dendritic cells are recruited by the chemokine, chemerin, produced by dermal fibroblasts, endothelial cells and mast cells. Injured keratinocytes release DNA (self-DNA) and the cathelicidin-derived antimicrobial peptide LL-37. Complexes of DNA-LL-37 or RNA-LL-37 activate pDCs, through different TLRs, which in turn release interferon (IFN) $\alpha$. IFN- $\alpha$, but also RNA-LL-37 complexes, activate dermal mDCs $(46,47)$, (Figure $2 \mathrm{a})$.

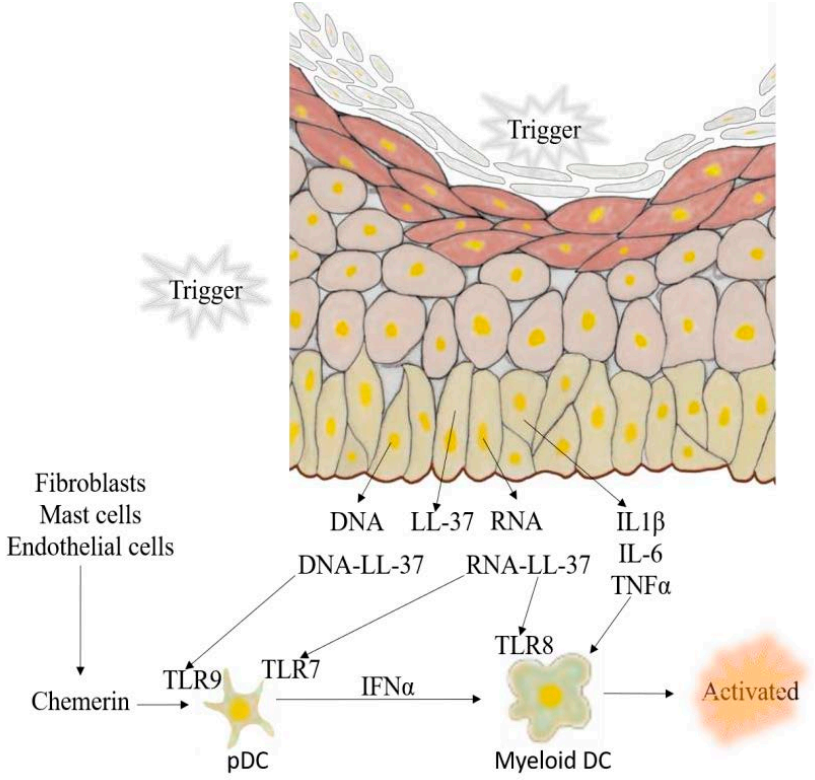

Figure 2a. The initiation phase in the pathogenesis of psoriasis. 
Dermal mDCs release TNF- $\alpha$, which induces the expression of cyto- and chemokines and the upregulation of adhesion molecules, and inducible nitric oxide synthase (iNOS), which leads to vasodilation, inflammation and antimicrobial effects. The mDCs also migrate into the draining lymph nodes where they induce the differentiation of naive $\mathrm{T}$ cells into $\mathrm{T}$ helper $(\mathrm{Th})$ 17 cells, type $17 \mathrm{~T}$ cytotoxic cells (Tc17), Th1 or Tc1 cells. These circulate to the skin and further affect the cytokine milieu. The mDCs produce the cytokines IL-12, which leads to a Th1 response with IFN- $\gamma$ production and IL-23 which leads to a Th17 response with IL-17 and IL-22 production. The SlanDC potentiates the activity of neutrophils and natural killer (NK) cells and also induces Th1 and Th17 responses (48), (Figures $2 \mathrm{~b}$ and 2c).

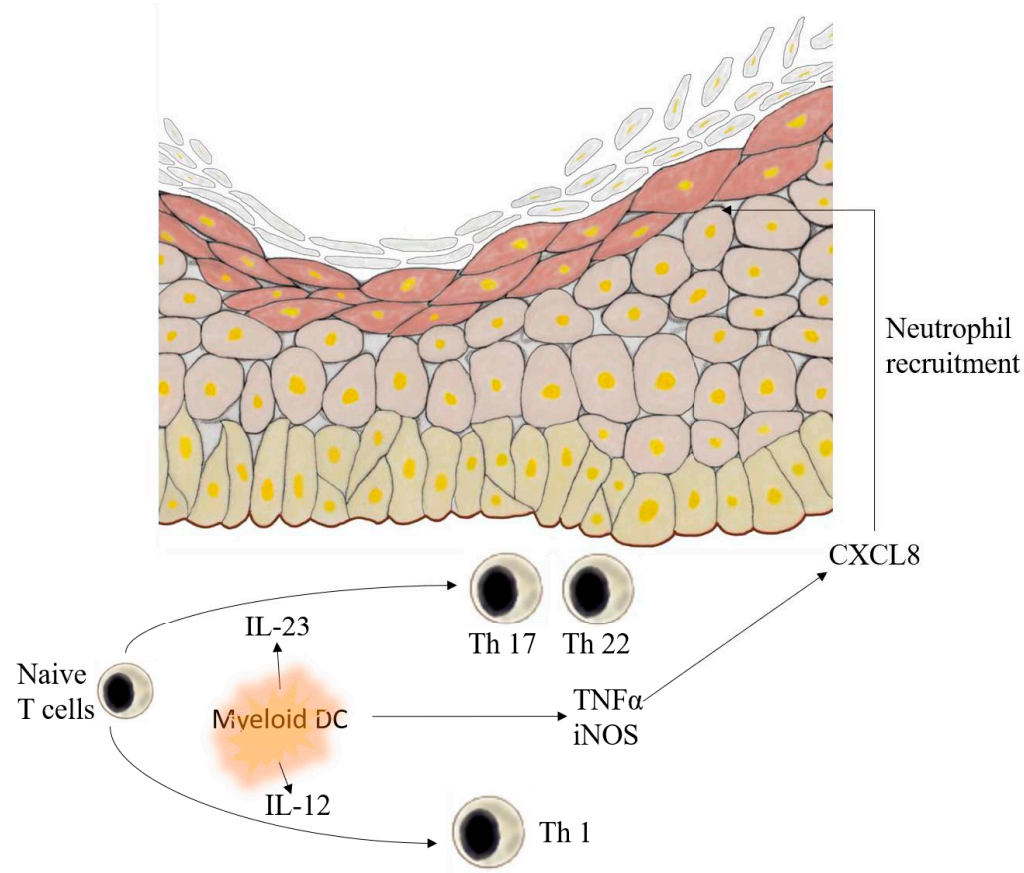

Figure 2b. The early inflammatory phase in psoriasis plaque formation. 
In psoriasis, the lesional skin contains an abundance of $\mathrm{T}$ cells, mainly activated memory $\mathrm{T}$ cells but also activated Th1, Th17, Tc1 and Tc17 cells $(49,50)$. The different T cell subsets produce different cytokines such as TNF- $\alpha$, IFN- $\gamma$, IL-17, IL.22 and IL-21 but also IL-10 and IL-4. The T cells mark the adaptive immune response and, in combination with an ongoing innate immune response, represent the second phase of the inflammatory reaction. The cytokines $\mathrm{T}$ cells produce, further affect the keratinocytes that respond with a change in intracellular signalling, leading to hyperplasia and disordered differentiation (Figure 2c).

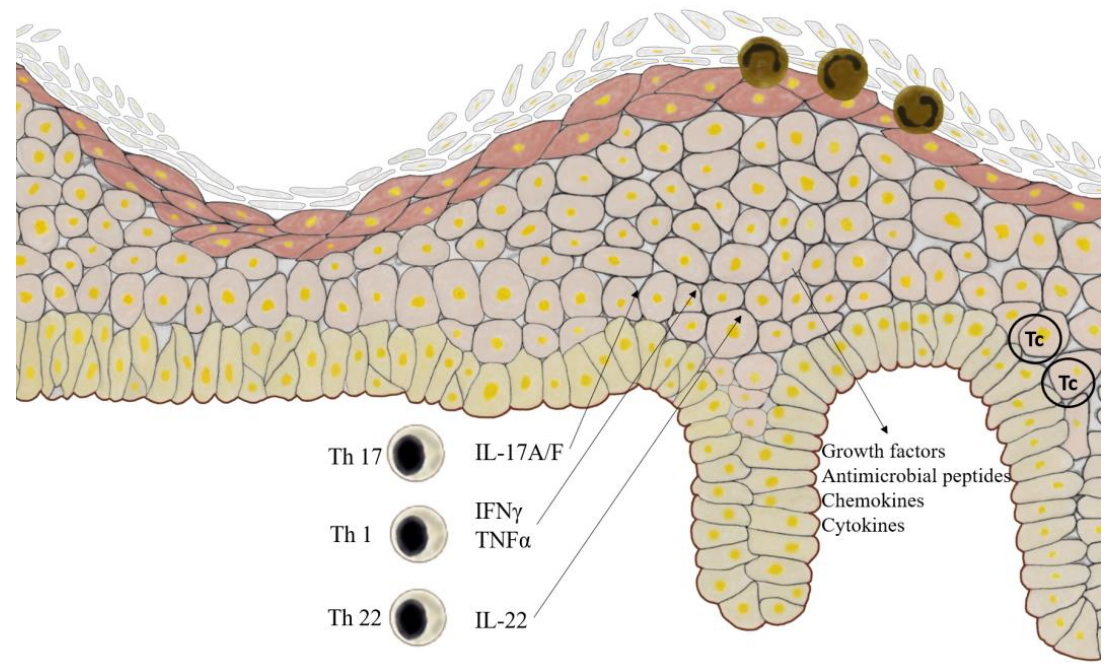

Figure 2c. The late inflammatory phase in psoriasis plaque formation. 


\section{Innate immune mechanisms in psoriasis}

A great deal of interest has focused on the adaptive immune system in psoriasis, with respect to both pathogenesis and treatment. However, possible treatments targeting early events in psoriasis pathogenesis, such as TLRs, are emerging (51). Other pattern recognition receptors (PPRs) like inflammasomes are also potential treatment targets. Inflammasomes are multiprotein cytoplasmic complexes with a central role in the innate immune response, consisting of a central scaffold and sensor protein, adaptor protein (ASC) and effector protein (caspase-1/5). They are abundantly expressed in macrophages and DCs. These proteins assemble upon sensing PAMPs or DAMPs which leads to an inflammatory response, resulting in IL-1 $\beta$ and IL-18 production. (Figure 3). The inflammasome sensor proteins NLRP 1 and 3 are expressed in psoriatic skin and certain polymorphisms in their respective gene have been associated with psoriasis susceptibility and pathogenesis $(23,24)$. Furthermore, an increase in expression in absent in melanoma 2 (AIM2), a cytosolic DNA sensor and part of an inflammasome, has been observed in keratinocytes in psoriatic lesions (52). In mice, constitutive IL-1 $\beta$ activation or the lack of an IL-1 receptor antagonist results in a Th17 response and psoriasis phenotype $(53,54)$. In psoriatic lesions, an increase in IL-18 expression has been demonstrated which significantly diminished after treatment (55). IL-18 can cause Th1 polarisation and synergise with IL-23 to induce IL-17 production $(56,57)$.

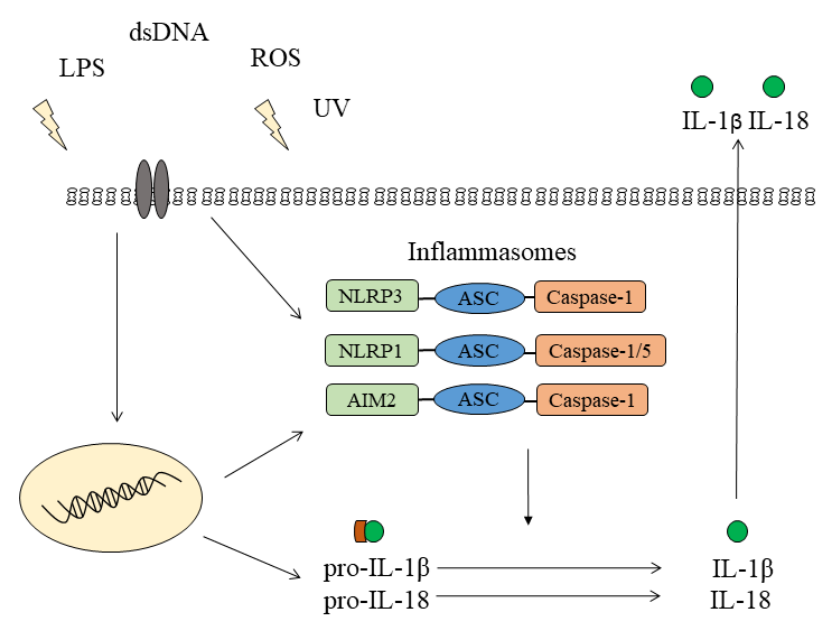

Figure 3. Inflammasome activation. (The picture has been modified with permission from Cecilia Bivik Eding). 


\section{Cytokines and chemokines in psoriasis}

The cytokine network in psoriasis is complex, involving many cytokines that work in autocrine and paracrine fashion, while some have synergic effects. Cytokines induce inflammatory signals and the production of chemokines, a subfamily of cell signalling cytokines. Cytokines and chemokines, together with DCs, form a link between the innate and adaptive immune mechanisms. In psoriasis, cytokines and chemokines act on the keratinocytes to promote inflammatory and antimicrobial responses but also on local fibroblasts, immune cells and endothelial cells. This leads to the increased recruitment of immune cells to the skin, a manifestation of the changes seen in psoriatic skin (disturbed keratinocyte differentiation, hyperproliferation and angiogenesis) and the maintenance of inflammation (58).

\section{Cytokines}

Many cytokines are involved in psoriasis (Table 1). IFN, $\alpha$ and $\beta$, play a role in the initiation of psoriasis pathogenesis. IFN- $\boldsymbol{\alpha}$, a type I IFN, is secreted by pDCs in early psoriasis, as previously described. IFN- $\boldsymbol{\gamma}$, a type II IFN, is an important immunoregulator, affecting the maturation and activation not only of T cells, macrophages and NK cells but also of B cells, endothelial cells and fibroblasts. Furthermore, it increases the expression of MHC class I and II molecules on antigen-presenting cells and of intercellular adhesion molecule (ICAM)-1 on keratinocytes $(59,60)$.

The IL-1 family of cytokines is important in the early pathogenesis of psoriasis. The IL-1 isoforms, IL-1 $\boldsymbol{\alpha}$ and IL-1及, are expressed in healthy epidermis as pro-proteins with different means of activation. When secreted, the function of the isoforms is similar (61). Sources of IL-1 in psoriasis are keratinocytes, monocytes or macrophages, fibroblasts, activated endothelial cells and Langerhans cells (62). In healthy skin, IL-1 $\alpha$ is mainly active, but in psoriatic skin, IL- $1 \beta$ becomes more prominent and increased levels of IL- $1 \beta$ in both the skin and peripheral blood mononuclear cells (PBMCs) have been observed (63). IL-1 $\beta$ induces a Th17 response in psoriasis but also stimulates the upregulation of antimicrobial responses and the expression of adhesion molecules such as ICAM 1 and vascular cell adhesion molecule (VCAM) 1. The severity of the disease has been shown to be reflected in IL-1 $\beta$ secretion from PBMCs (64). 
Another member of the IL-1 family, IL-18, stimulates the recruitment of DCs (65). Upregulation has been demonstrated in psoriatic lesions (66) and in the blood of psoriasis patients $(67,68)$. It has been proposed that IL-18 exert its effects in psoriasis through, both, IFN- $\gamma$ and pathways independent of IFN- $\gamma$, the latter then indicating a role for IL-18 in early psoriasis. IFN- $\gamma$ increases the Th1 response, but, interestingly, IL-18 is able to induce IL-4 and IL-13 production by both innate cells, such as NK cells, mast cells and basophils, and by T cells (69). Further, IL-18 is able to synergise with IL-23 to induce the production of IL-17 $(56,57)$. The IFN- $\gamma$ independent pathways include the induction of chemotaxis in pDCs and angiogenesis $(70,71)$.

IL-36 also belongs to the IL-1 family of cytokines. The IL-36 receptor is expressed on human epithelial and antigen-presenting cells. IL-36 leads to the upregulation of AMPs and chemokines, such as CXCL8, CCL20, CCL17 and CCL22, by keratinocytes and the activation of antigen-presenting cells. All the IL-36 receptor agonists, IL-36 $\alpha$, IL-36 $\beta$ and IL$36 \gamma$, have been demonstrated in psoriatic lesions, where IL-36 $\gamma$ has been shown to correlate with disease severity (72-74).

Psoriasis-associated genetic polymorphisms have been found in both cytokines and receptors of the members of the interleukin (IL) 12 family of cytokines, IL-12 and IL-23 (75). The IL12p40 and IL23p19 subunits are increased in psoriatic lesions (90). IL-12 induces the IFN- $\gamma$ producing cells and affects cutaneous lymphocyte-associated antigen (CLA) expression on memory T cells (76). IL-23 stimulates and affects the maintenance of Th17 cells (77).

Tumour necrosis factor alpha, TNF- $\alpha$, is a central cytokine in inflammation. Interestingly, TNF- $\alpha$ per se is not sufficient to elicit a substantial response in cultured keratinocytes but synergises with other cytokines. For example, it induces the effects of IL-17A and is able to stimulate the upregulation of the IL-17 receptor by keratinocytes $(78,79)$, but IL-17 plays a major role in psoriasis pathogenesis. IL-17 has been shown to be upregulated in the skin and blood of psoriasis patients $(80,81)$ and to be involved in the activation of innate cells. It also has regulatory effects on the chemokine and adhesion molecule expression of keratinocytes (82). The IL-17 family of cytokines includes the IL-17A-F isoforms. Furthermore, five receptors, IL-17RA- IL-17RE, are included in this family of cytokines (83). IL-17A is a key cytokine in psoriasis, but IL-17F is also known to play a role. These two cytokines bind to the same IL-17RA and IL-17RC receptor complex (84). There is a study reporting the stronger expression of IL-17C in psoriatic lesions than of IL-17A (85). IL-17C appears to be mainly 
expressed by keratinocytes in lesional skin (85), but IL-17A is produced by innate immune cells, such as neutrophils, mast cells, NK cells, $\gamma \delta$ T cells and innate lymphoid cells (ILCs) (86-88). As with TNF- $\alpha$, IL-17 itself may be insufficient to induce a significant inflammatory response and potentiates its effects by acting co-operatively or synergistically with other cytokines like TNF- $\alpha$, IL-1 $\beta$, IL-6, IL-23 and TGF- $\beta$ (89-91).

IL-22 is a cytokine which belongs to the IL-20 subfamily of the IL-10 family cytokines. Elevated levels of IL-22, mainly expressed by T cells and ILCs, have been detected in the skin and plasma of psoriasis patients. IL-22 synergises with cytokines such as TNF- $\alpha$, IFN- $\gamma$, IL-1 $\beta$ and IL-17. Its receptor is expressed on keratinocytes but not on immune cells and its primary effects are epidermal alterations seen in psoriasis, epidermal hyperplasia and disturbed differentiation, together with the upregulation of AMPs (92-96).

\section{Chemokines}

Chemokines are small molecular weight cytokines that represent a large group of chemotactic proteins that play a critical role in leukocyte trafficking. Chemokines also have nontrafficking functions, such as effects on lymphocyte proliferation and function and granulocyte release $(97,98)$. Furthermore, chemokines have non-immunological effects, such as promoting tumorigenesis through effects on angiogenesis, cell growth and apoptosis (99). Chemokines interact with cell-surface receptors which are members of seven-transmembrane domain G-protein-coupled receptors. They are grouped into four families based on the arrangement of the N-terminal cystein residues, $\mathrm{C}$ (XCL), CC (CCL), CXC (CXCL) and CX3C (CX3CL) $(100,101)$. The chemokine receptors have a certain chemokine specificity profile, most binding to more than one chemokine but restricted to one structural group of chemokines (100-102). The different chemokines also have a particular receptor specificity. Almost all chemokines are chemotactic agonists, but they can have both agonist and antagonistic effects because of their ability to bind to more than one chemokine receptor. At present, 24 subtypes of human chemokine receptors and 44 human chemokines have been recognised (103).

The chemokines and their receptors that have been shown to be implicated in psoriasis include the IFN- $\gamma$-inducible CXCL 9, 10 and 11 ligands to CXC receptor (CXCR) 3 expressed on dermal CD3+ lymphocytes $(104)$, the CXCL16 $(105,106)$ ligand to CXCR6 (107), the IL23 inducible CCL 20, also a ligand to CXCR6 expressed on Th17 cells (108) and epidermal 
Langerhans cells (54), and the IL-17-inducible CXCL8 ligand to CXCR1 and CXCR2 (101) (Table 1). Chemokines are also important factors in controlling vascular inflammation (109) which is interesting in the context of psoriasis, as the disease is associated with other diseases and an increase in mortality, as further discussed later on.

Table 1. Important cytokines and chemokines in psoriasis.

\begin{tabular}{|c|c|}
\hline Cytokine & Chemokine \\
\hline IFN- $\alpha$ & CXCL9 \\
IFN- $\gamma$ & CXCL10 \\
TNF- $\alpha$ & CXCL11 \\
IL-1 $\beta$ & CXCL8 \\
IL-18 & CXCL16 \\
IL-12 & CCL20 \\
IL-23 & \\
IL-17 & \\
IL-22 & \\
IL-36 & \\
\hline
\end{tabular}




\section{Psoriasis as a systemic disease}

Co-morbidities in psoriasis, such as cardiovascular disease, obesity, metabolic dysregulation, liver disorders and depression (Figure 4), are well recognised and have actually been observed in psoriasis for decades. The first publication describing the association with diabetes mellitus of which the author is aware dates from 1897 (110). A paper by Benton et al. (111), published in The Lancet in 1963, states:

"The cause of psoriasis remains unknown; but for many years it has been thought by some to be a disorder of metabolism, and fat metabolism has been most often incriminated.".

The authors discuss a study showing increased lipids in the lesions of psoriasis and conflicting studies of serum-cholesterol in psoriasis. They then report their own data where no differences in serum cholesterol were seen between 176 psoriasis patients and controls matched for age, gender and body weight. Furthermore, in 1973, a four-year retrospective observation was presented in which $11.5 \%$ of hospital-treated psoriasis patients had had one or more episodes of occlusive vascular disease (112). The topic is still being discussed and the exact relationship between psoriasis and its co-morbidities still remains to be elucidated.

There is evidence that, in psoriasis, there is a systemic inflammation that further affects other organs. Inflammation is also a key contributor to the pathogenesis in many of the comorbidities associated with psoriasis. Shared inflammatory pathways have been suggested as a possible explanation for these observations. It remains uncertain, however, whether the systemic inflammation in psoriasis patients reflects the disease activity in the skin and whether many of the associated diseases in psoriasis patients are related to an ongoing systemic inflammation due to the disease itself rather than other factors. In an animal model, psoriasis skin inflammation triggered aortic root changes which were ameliorated when the skin inflammation was treated, suggesting that skin inflammation alone could be the only factor driving cardiovascular changes in psoriasis (113). Furthermore, changes in activation patterns in the insulin signal pathway have been documented in psoriatic lesions, leading to insulin resistance in the skin affecting the normal differentiation of keratinocytes (114). Boehncke et al. have presented the concept of "The psoriasis march", which suggests that the skin contributes to the systemic inflammation in psoriasis. The inflammation can then induce insulin resistance, followed by endothelial dysfunction, which increases the risk of cardiovascular disease (115). Psoriasis patients with mild and moderate to severe psoriasis in 
the skin but otherwise asymptomatic have been shown to have subclinical, vascular and visceral inflammation $(116,117)$.

\section{Co-morbidities in psoriasis}

\section{Obesity}

Obesity is overrepresented in psoriasis patients $(118,119)$. It is uncertain whether obesity is a risk factor for psoriasis or psoriasis contributes to becoming obese because of ongoing inflammatory mechanisms or psychological effects of the disease and patient studies have shown controversial results (120-122). Obesity is associated with a state of chronic low-grade inflammation, mediated in part by macrophage infiltration into adipose tissue and an increase in the expression and secretion of pro-inflammatory cytokines, adipokines (123). Some of these cytokines are the same as those produced in the psoriatic plaque, whereas others are more restricted to the adipose tissue. In studies of obese mice, Th17 cells have been shown to infiltrate the adipose tissue, producing IL-17 and promoting inflammation $(124,125)$. Adipokines exert effects on insulin regulation, glucose and lipid metabolism and coagulation mechanisms (126). They play a role in the pathogenesis of insulin resistance which is thought to be related to endothelial dysfunction, an existing condition in psoriasis patients and predisposing for the development of atherosclerosis (115). It has been demonstrated that the adipokine, visfatin, enhances chemokine production consistent with the Th1 and Th17 response in human keratinocytes. Furthermore, it has been shown that patients with severe psoriasis have an increased expression of visfatin in their blood (127). Other adipokines like resistin and leptin can induce the production of inflammatory cytokines such as CXCL8 and TNF- $\alpha$, which are of relevance in the pathogenesis of psoriasis. Resistin has been shown to correlate positively with the severity of psoriasis (128). Moreover, increased serum levels of the adipokine chemerin have been demonstrated in psoriasis patients (129). Chemerin is mainly produced in white adipose tissue, but is also expressed in the skin where it recruits pDCs. 


\section{Metabolic syndrome}

Psoriasis patients are prone to develop the metabolic syndrome and the risk appears to be augmented with increasing psoriasis severity (130). The metabolic syndrome is an entity for metabolic dysregulation and includes several factors, an increased waist circumference, hypertension or treatment of hypertension, dyslipidaemia and elevated fasting glucose. For diagnoses of the metabolic syndrome, three of these five factors must be present, but the combination can vary $(131,132)$. It is unclear how the metabolic syndrome and psoriasis are linked. An increase in the incidence of the different components of the metabolic syndrome has been independently demonstrated in psoriasis patients. The strongest relationship is between psoriasis and obesity (133). The suggested explanations of the association between psoriasis and the metabolic syndrome include the increased levels of pro-inflammatory cytokines observed in obesity, as well as the dysfunction of adipocytes and chronically elevated levels of free fatty acids. Furthermore, hyperinsulinaemia also increases the adipocyte production of vascular endothelial growth factor (VEGF), also known to promote angiogenesis in the psoriatic skin and sustain the chronic skin inflammation (134-136). Genetic loci have been identified in patients with the metabolic syndrome and, interestingly, they are linked to lipid metabolism. According to assessments of published genome-wide association studies (GWAS) of the metabolic syndrome and psoriasis, only two genetic loci in psoriasis overlap with those in the metabolic syndrome. Furthermore, the clustering of susceptibility genes was separated in the two conditions. This points to the hypothesis that the genetic control of the conditions may be independent and some other common factor, such as obesity or factors leading to obesity, links them together. On the other hand, the MHC at $6 \mathrm{p} 21.33$ has been found to be common to both psoriasis and the metabolic syndrome, together with cardiovascular disease (137). Further, the CDKAL1 gene (CDK5 Regulatory Subunit Associated Protein 1-Like 1) has been associated to both psoriasis and diabetes type II (138).

\section{Vascular disease}

Epidemiological studies of psoriasis patients and the risk of cardiovascular disease have revealed an increase in the incidence of major adverse cardiovascular events in psoriasis patients, including myocardial infarction and stroke (139-141). A meta-analysis of nine observational studies has confirmed that both mild and severe disease are associated with an increased risk of myocardial infarction and stroke, although the association is stronger with severe psoriasis. Severe disease has also been linked to an elevated risk of cardiovascular 
mortality (142). In some studies, psoriasis has been observed to be an independent cardiovascular risk factor $(5,140,141,143)$. Furthermore, psoriasis patients have been shown to have subclinical atherosclerosis and global arterial and subcutaneous adipose tissue inflammation $(144,145)$. The causality is uncertain, but common inflammatory mechanisms are one explanation, as discussed previously for the psoriasis co-morbidities in general.

Genetic studies show only a weak association between psoriasis and coronary heart disease, also previously discussed in the context of the metabolic syndrome (137). Like psoriasis, atherosclerosis is regarded as a chronic inflammatory disease. These two diseases share inflammatory pathways with regard to cell types, cytokine network and angiogenesis. In both conditions, both innate and adaptive immune mechanisms with Th1 and Th17 responses are involved. At the beginning of the atherosclerosis process, as in psoriasis, pDCs are of importance in producing type I IFN (146). The hallmark of early-stage atherosclerosis is foam cells. Foam cells are macrophages that have taken up modified lipoproteins, such as oxidised low-density lipoprotein (OxLDL), rich in cholesterol esters, conveyed by PPRs. Further, reactive oxygen species and growth factors secreted in the tissue stimulate the uptake of modified lipoproteins and the proliferation of vascular smooth muscle cells which also are capable of accumulating cholesteryl esters. The recruitment of the monocytes to the subendothelium, where at least some become macrophages, is facilitated by P-selectins and Eselectins, together with the adhesion molecules, ICAM-1 and VCAM-1, as in the recruitment of immune cells to the skin in psoriasis. Foam cells secrete cytokines and chemokines which are critical for their maintenance and disease progression (147).

Many cytokines and chemokines involved in the pathogenesis of atherosclerosis are also of importance in psoriasis pathogenesis. For example, TNF- $\alpha$ is an important effector of vascular dysfunction and affects NO expression (148), promotes oxidative stress (149), increases tissue factor and suppresses thrombomodulin, thereby leading to an increased risk of thrombosis, and upregulates adhesion molecules like VCAM-1, ICAM-1, E-selectin and matrix metalloproteinase (MMP) 9. TNF- $\alpha$ exerts its effects by increasing the gene expression of various cytokines and chemokines either directly or by activating transcriptional factors such as NF- $\kappa \mathrm{B}$ (150). Moreover, the cytokines IL-6, IL-8 and IL-17 have been observed at increased levels in vascular disease (151) and, as in psoriasis, TNF- $\alpha$ and IL-17 enhance the upregulation of cytokines synergistically.

In the atherosclerotic plaque, the T-cell differentiation is skewed towards a Th1 and Th17 response, as in the psoriatic plaque. In Th1 cells, oxLDL induces IFN- $\gamma$ production (152), 
which in turn stimulates foam cell formation and maintenance $(153,154)$. IFN- $\gamma$ induces CXCL10 and ICAM-1 expression $(155,156)$, which is important for the recruitment of immune cells. Moreover, activated Th1 cells in the intima induce the expression of the CD40 ligand, which facilitates the ligation of CD40 on antigen-presenting cells and the release of matrix-degrading metalloproteinases $(157,158)$. Th17 cells and IL-17 have been demonstrated in early atherosclerotic plaques. IL-17, together with IFN- $\gamma$, has been shown to activate vascular smooth muscle cells through IL-6, CXCL8 and CXCL10 (159). Th22 cells are also implicated in atherosclerosis $(160,161)$, as in psoriasis.

In conclusion, psoriasis and atherosclerosis are two inflammatory diseases where the barrier between the tissue and its environment, the endothelium and the skin epithelium, becomes dysfunctional via trigger factors, leading to the activation of the immune system by cell recruitment and cytokine and chemokine production. In atherosclerosis, the foam cells, and, in psoriasis, the keratinocytes and neutrophils play a critical part in maintaining inflammation and enhancing plaque formation in both diseases.

\section{Non-alcoholic fatty liver disease (NAFLD)}

Non-alcoholic fatty liver disease (NAFLD), the most common liver disease worldwide, is overrepresented in psoriasis patients (162). NAFLD, like psoriasis, is also associated with other diseases including the cardiovascular system. NAFLD affects the regulation of metabolic and immunological pathways. One common feature in the pathogenesis of NAFLD and the metabolic syndrome is insulin resistance. Interestingly, nearly $50 \%$ of psoriasis patients have been found to have NAFLD, even after adjusting for metabolic factors and other possible confounders (163). Furthermore, experimental studies have demonstrated more severe induced skin inflammation in mice with NAFLD than in control mice (164). This points to shared mechanisms for psoriasis and NAFLD as well. Both diseases are associated with obesity which contributes to insulin resistance, possibly via the release of both proinflammatory cytokines and non-esterified fatty acids. These fatty acids are thought to promote liver injury by increasing oxidative stress and activating inflammatory pathways in the liver, a key regulator of glucose metabolism and a substantial source of many inflammatory and coagulation factors. Pro-inflammatory cytokines produced in psoriatic skin, for example, IL-6, TNF- $\alpha$ and IL-17 are also produced by the inflamed liver, together with C-reactive protein (CRP), plasminogen activator inhibitor 1(PAI-1), fibrinogen and others (165). The inhibition of IL-17 in a mice model of cholestatic liver fibrosis, was linked to 
significant improvements in liver function, decreased hepatocellular necrosis and inflammation (166).

\section{Depression}

Psoriasis can have substantial psychosocial effects and affects quality of life $(167,168)$. It is therefore not unexpected that depression is overrepresented in psoriasis patients (169). Stigmatisation and physical symptoms may not only be to blame, as pro-inflammatory cytokines have been found at higher levels in depressed individuals (170-172). Furthermore, in an animal model of depression, inhibiting Th17 cells was associated with diminished vulnerability to depression-like behaviour (173).

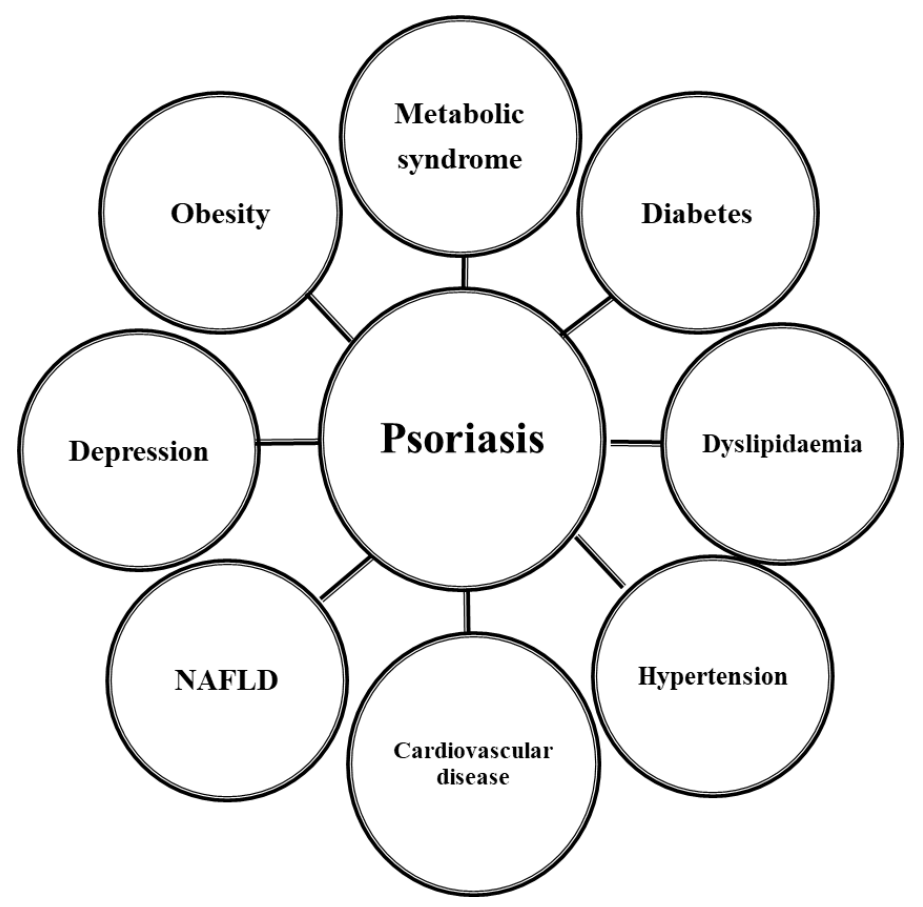

Figure 4. Co-morbidities in psoriasis. 


\section{Investigating systemic inflammation in psoriasis}

The characterisation of systemic inflammation in psoriasis is important to understand the extent of the disease and aid in better management. Biomarker research and investigating different aspects of the immune system in psoriasis are therefore extremely interesting. A biomarker can be a marker of susceptibility to a disease but also of the activity, severity and prognosis of the disease, together with treatment response. According to the US National Institutes of Health, the definition of a biomarker or a biological marker is (174):

\footnotetext{
"A characteristic that is objectively measured and evaluated as an indicator of normal biological processes, pathogenic processes, or pharmacologic responses to a therapeutic intervention.”.
}

Biomarkers can be genetic markers and patterns of gene or protein expression in different tissues. Furthermore, imaging, such as ultrasound, isotopes, positron emission tomography/computed tomography (PET/CT) and magnetic resonance imaging (MRI), can be a type of biomarker. Biomarkers that can be measured in peripheral blood, e.g. soluble biomarkers, are of interest, as a blood test is often more quantitative and can be more effective with regard to availability and overall costs and comfort for a patient.

With regard to the polygenicity of psoriasis, a relevant biomarker might be different for different psoriasis patients who can theoretically have different subtypes of the disease, despite having the same disease presentation in the skin. This calls for the evaluation of different potential biomarkers, chosen according to the different aspects of the disease pathogenesis. 


\section{Aim of thesis}

The general aim of this thesis was to investigate markers of inflammation and cardiovascular disease in psoriasis to obtain an improved understanding of the disease pathogenesis to aid in the search for a biomarker.

The specific aims of the studies presented in the included papers, I-IV, were:

I. To investigate circulating chemokines as possible markers of systemic inflammation in patients with psoriasis and the effects of narrowband ultraviolet B (NB-UVB) treatment on the potential systemic inflammation.

II. To measure markers of cardiovascular disease in psoriasis patients and study the effect of body weight on these markers. Furthermore, to evaluate whether NB-UVB therapy and systemic treatment affect the levels of these markers differently.

III. To further explore the systemic inflammation in psoriasis from the perspective of endothelial dysfunction, adipocyte contribution and soluble immune receptors. Furthermore, to evaluate the effects of NB-UVB treatment on the levels of these markers.

IV. To characterise the systemic expression of inflammasomes in psoriasis. Further, to explore whether IL-17, a key cytokine in psoriasis, could affect the expression and activity of these components in the skin and the blood. 


\section{Material and methods}

\section{Ethical principles}

Approval for the recruitment of patients was obtained from the regional ethics boards (Drn. S594-02, S242-03 and 2010/46-31). Participants gave informed consent and principles in accordance with the Declaration of Helsinki were followed.

\section{Patient and control study groups}

Patients and controls were recruited from three dermatology clinics in Sweden, the Departments of Dermatology at Linköping University Hospital, at Sahlgrenska University Hospital in Gothenburg and at Karolinska University Hospital in Stockholm (Table 2). The diagnosis of psoriasis was verified by a dermatologist in all patients and the severity of psoriasis was documented as the PASI. Individuals without inflammatory skin disease were recruited as controls. Information about gender and age was documented for all individuals. Blood tests were taken from all patients and controls at baseline. In patients receiving treatment with NB-UVB or TNF- $\alpha$ inhibitor given by their responsible dermatologist, further dermatological examination for PASI evaluation was performed and blood tests were taken at the point of assessment of treatment response. 
Table 2. Total number of patients and controls recruited from the different dermatology centres.

\begin{tabular}{|c|c|c|}
\hline Dermatology centre & $\begin{array}{c}\text { Number of } \\
\text { patients }\end{array}$ & $\begin{array}{c}\text { Number of } \\
\text { controls }\end{array}$ \\
\hline Linköping University Hospital & 71 & 50 \\
\hline Karolinska University Hospital & 20 & 0 \\
\hline Sahlgrenska University Hospital & 14 & 14 \\
\hline Total number of patients/controls & 105 & 64 \\
\hline
\end{tabular}

\section{Patients and controls from Linköping University Hospital}

At the Department of Dermatology at Linköping University Hospital, a total of 71 patients with psoriasis were enrolled for the studies. Information about the debut of the disease, joint symptoms, smoking, alcohol use, other co-existing health conditions, medication and family history was retrieved. Nails were then inspected and nail changes documented. The inspection of joints was carried out as needed. Furthermore, blood pressure was measured and weight and height, together with waist, and hip circumference, were documented to calculate body mass index (BMI) and waist: hip ratio (WHR). Blood samples were taken at baseline for the quantification of the markers to be investigated and more clinically used parameters including lipid profile (total cholesterol, triglycerides and apolipoproteins A1 and B), blood sugar, CRP, sedimentation rate and complete blood count. A total of 50 controls were enrolled (Studies I-IV) and information regarding the same variables as for the patients, was documented (Studies I-III). For patients and controls participating in Study IV, only information about height and weight 
for calculating BMI was retrieved and measurements of the clinically used parameters were not made.

\section{Patients and controls from Sahlgrenska University Hospital}

A total of fourteen patients and fourteen controls were recruited from the Department of Dermatology at Sahlgrenska University Hospital.

\section{Patients from Karolinska University Hospital}

A total of twenty patients receiving systemic treatment with TNF-alpha inhibitor were recruited from the Department of Dermatology at Karolinska University Hospital.

\section{Quantification of biomarkers [Studies I-III]}

\section{Biomarkers in clinical use}

Blood samples for the analysis of clinical markers were collected in gel-containing, lithiumheparin-coated plasma tubes to determine total cholesterol, triglycerides and apolipoproteins A1 and B, together with CRP, FC mixture (citrate, sodium fluoride and EDTA-Na2)containing tubes to determine blood glucose levels, sodium citrate-containing tubes to determine the sedimentation rate and EDTA-K2-containing tubes to determine the complete blood count. These samples were collected according to the standard recommendations of the Department of Clinical Chemistry at the University Hospital in Linköping, Sweden, where they were analysed. 


\section{Other biomarkers}

A multi-analyte profiling immunoassay using Luminex technology was used for the quantification of biomarkers. This is a bead-based assay in which polystyrene nonmagnetic or magnetic microspheres are coated with a capture antibody to a desired analyte. Each microsphere set has a unique fluorescent signature, making it possible to evaluate multiple analytes in one assay. The microspheres are added to the biological sample, followed by the addition of detection antibodies and reporter dye. The proportion of bound reporter dye depends on the analyte concentration in the original biological sample.

\section{Immunoassay procedures}

Blood samples were collected in sodium-heparin-coated cell preparation tubes, $\mathrm{CPT}^{\mathrm{TM}}$ tubes (Vacutainer ${ }^{\circledR}$, Becton Dickinson, Stockholm, Sweden), containing a Ficoll ${ }^{\mathrm{TM}}$ Hypaque $^{\mathrm{TM}}$ cushion for the isolation of plasma and PBMCs or in serum tubes with clot activator (Terumo Europe, Västra Frölunda, Sweden) for the isolation of serum. Plasma and serum were stored at $-80^{\circ} \mathrm{C}$ until analysis.

Multi-analyte profiling was conducted with Milliplex ${ }^{\circledR}$ MAP kits (Millipore Corporation, Billerica, MA, USA) on plasma or serum, according to the manufacturer's instructions. Data collection was performed on a Luminex 200 instrument (Biosource, Nivelles, Belgium) using xPONENT software (Luminexcorp, Austin, TX). The obtained data were analysed in StarStation 3.0 (Applied Cytometry, Sheffield, United Kingdom) or MasterPlex QT (MiraiBio, Alameda, CA). 


\section{Cell cultures and stimulations [Studies I \& IV]}

Peripheral blood mononuclear cells (PBMCs), neonatal human epidermal keratinocytes (HEKn) and whole blood were used in cell cultures and stimulations in Studies I and IV.

\section{Study I}

PBMCs were treated for 24 hours with lipopolysaccharides (LPS, $100 \mathrm{ng} / \mathrm{mL}$ ) or cultured for 72 hours in plates coated with mouse monoclonal anti-human CD3 antibody $(5 \mu \mathrm{g} / \mathrm{mL})$ with the addition of rat monoclonal anti-human CD28 antibody $(5 \mu \mathrm{g} / \mathrm{mL})$.

\section{Study IV}

Culture and stimulation of neonatal human epidermal keratinocytes

HEKn were cultured in EpiLife medium supplemented with 1\% EpiLife defined growth supplement (EDGS), $0.06 \mu \mathrm{M} \mathrm{CaCl}_{2}, 1 \%$ Amphotericin B and $1 \%$ penicillin/streptomycin. The cells were treated with IL-17 (10 ng/mL), in combination with TNF- $\alpha(10 \mathrm{ng} / \mathrm{mL})$, for 24 and 48 hours.

\section{Stimulation of whole blood before caspase 1 detection}

Peripheral blood was collected in EDTA-containing vacutainer tubes. Immediately after collection, the blood was treated with IL-17 $(200 \mathrm{ng} / \mathrm{mL})$ and TNF- $\alpha(10 \mathrm{ng} / \mathrm{mL})$ for one hour at $37^{\circ} \mathrm{C}$ before further processing for the caspase 1 assay. 


\section{Quantitative real-time PCR [Study IV]}

Quantitative real-time (RT) polymerase chain reaction (PCR) is a method to quantify genespecific mRNA expression (175). It unites the polymerase chain reaction with the use of fluorescent reporter molecules. The amplification of products during each cycle of the reaction is followed, in real time. First, RNA extraction of the test samples must be carried out. Complementary DNA (cDNA) is then synthesised by the reverse transcription of mRNA. The detection of DNA can be specific, using the fluorescent reporter probe method, or nonspecific, using double-stranded (ds) DNA-binding dyes that emit fluorescence when bound to dsDNA in general. When using non-specific DNA detection, as in Study IV, dissociation curves are used to ensure the absence of non-specific products. Furthermore, a housekeeping gene is used as an internal control for correcting minor variations in cDNA quantity between samples. The PCR reaction consists of four phases, the lag phase, the logarithmic (log) phase, the retardation phase and, lastly, the stationary phase. In the log phase, a fluorescence signal above the background level becomes measurable with the exponential increase in amplification product with a doubling in every cycle (assuming 100\% efficacy) of the reaction (176, 177).

In Study IV, RNA extraction was accomplished using an RNeasy mini kit (Qiagen, Hilden, Germany). The concentration and purity of each RNA sample was quantified with a Nanodrop ND-1000 Spectrophotometer. The synthesis of cDNA was accomplished using a Maxima First Strand cDNA Synthesis Kit (Thermo Scientific, Fermentas, Vilnius, Lithuania). The quantitative real-time PCR was performed with SYBR green PCR Master Mix (Applied Biosystems, Foster City, CA, USA) on a real-time 7500HT PCR (Applied Biosystems). The sequence-specific primers of the target genes, $N L R P 1, N L R P 3, A I M 2, I L-1 \beta$, Caspase 5 and Caspase 1, and the internal control, glyceraldehyde-3-phosphate dehydrogenase (GAPDH), were designed using Primer Express Software version 3.0 (Applied Biosystems). The gene expression was normalised to the internal control (GAPDH) using the $C_{t}\left(2^{-\Delta \Delta C t}\right)$ method and presented as the fold change relative to untreated controls (178). 


\section{Immunofluorescence [Study IV]}

Immunofluorescence (IF) is a method where antibodies are used to label specific target antigens with a fluorescent dye. The technique is based on using specific antibodies conjugated directly (primary IF) or indirectly (secondary IF) to fluorescent dyes. In primary IF, the antibody binding to the target of interest, the primary antibody is directly conjugated to a fluorescent dye, whereas, in secondary IF, an antibody recognising the unlabelled primary antibody is conjugated to the fluorescent dye.

In Study IV, secondary or indirect IF was used to assess protein production in the HEKn cell cultures.

Keratinocytes were fixed in $4 \%$ formaldehyde and permeabilised with $0.1 \%$ saponin. The cells were then incubated with the primary IL-1 $\beta$, NLRP 3 antibody or NLRP 1 at $4{ }^{\circ} \mathrm{C}$ over night. The secondary Alexa Fluor 488 conjugated goat antibody was then added. Nuclei were counterstained with DAPI (4', 6-diamidino-2-phenylindole). Negative controls were only incubated with the secondary antibody. Staining was analysed in an AxioVert.A1 Microscope (Zeiss, Oberkochen, Germany).

\section{Flow cytometry [Study IV]}

Flow cytometry is a technique (179) that facilitates the simultaneous analysis of multiple parameters regarding the physical and chemical characteristics of different particles, e.g. cells, at the same time. It is used for cell counting, cell sorting, identifying cell subsets, stage of cell differentiation or activation and clonality and intracellular evaluations of proteins. Different physical characteristics, such as size and granularity, together with fluorescent features, are parameters used to facilitate the analysis of different components. 
The flow cytometry technique is based on the following components. 1) A flow cell, where the particles in a specimen are carried in a liquid stream of sheath fluid to enable the measurement of the characteristics of a single particle. 2) Light sources, e.g. lasers, which generate light signals from the particles. 3) An optical system which directs light signals to photodetectors that convert light into electronic signals. 4) A computer system linked to the flow cytometer, which analyses the electronic signals.

In Study IV, flow cytometry was used to evaluate the expression of inflammasome components and the detection of caspase 1 in different white cell subsets.

\section{Detection of inflammasome expression}

Fresh whole blood samples were used for the detection of inflammasome expression. White blood cells, following red blood cell (RBC) lysis, were incubated for 10 minutes at room temperature with antibodies coupled to a fluorochrome for surface staining. The following fluorochrome-conjugated antibodies were used: CD14-Pacific Blue, CD16APC H7, CD4- PE Cy7, CD8- V500, CD209- PCP Cy5.5 and CD19-FITC. Following staining, the cells were fixed for 30 minutes at $4{ }^{\circ} \mathrm{C}$ and then washed. Intracellular staining was performed for 40 minutes at $4{ }^{\circ} \mathrm{C}$ using antibodies for the respective inflammasome components, coupled to a fluorochrome NLRP1-AF700, NLRP3-PE or AIM2-AF647.

\section{Detection of caspase 1}

For the detection of caspase 1 in lymphoid and myeloid populations, whole blood samples were first treated with IL-17 (200 ng/ml) and TNF- $\alpha(10 \mathrm{ng} / \mathrm{ml})$, as previously described. After RBC lysis, staining with CD3-Pacific blue, CD14-APC-Cy7 and CD16PE-Cy7 was then carried out. Caspase 1 activity was determined with flow cytometry using a caspase 1 FAM-FLICA ${ }^{\circledR}$ kit (ImmunoChemistry Technologies). FLICA ${ }^{\circledR}$ probes are non-cytotoxic fluorescent labelled inhibitors of caspases. They bind covalently to active caspases. To identify active caspase 1 , the FLICA $^{\circledR}$ probe contains the amino acid sequence, YVAD, which caspase 1 recognises, between a green fluorescent label, carboxyfluorescein (FAM), and a fluoromethyl ketone (FMK). The FAM-YVAD-FMK 
FLICA $^{\circledR}$ reagent enters each cell and becomes covalently coupled to activated caspase 1 , after which it is retained within the cell. Unbound FAM-YVAD-FMK FLICA ${ }^{\circledR}$ reagent diffuses out of the cell and is washed away during the preparation of the samples. The fluorescent signal is a direct measurement of the active caspase- 1 enzyme activity present in the cell at the time the reagent was added.

All flow cytometric analyses were performed on a Gallios ${ }^{\mathrm{TM}}$ flow cytometer (Beckman Coulter, LS). The acquisition, that is the collection of data from samples and analyses was performed using Kaluza Analys 1.3 software.

To define the cells of interest, the different cell populations were gated depending on the known characteristic of the different cell populations regarding expressed antigens, size and granularity. Clumps or doublets were eliminated by gating the single cells.

\section{Statistical methods}

In Studies I-III, data were compared using the non-parametric Mann-Whitney U test or Wilcoxon's matched-pairs signed rank test. The Mann-Whitney U test was used when comparing data between patients and controls and the Wilcoxon's matched-pairs signed rank test was used when comparing data before and after treatment in the patients. In Study IV, an unpaired $t$ test was administered for comparisons. For comparisons of the expression of the different inflammasome components in psoriasis patients versus controls, the Welch correction was applied. Correlations were determined by Spearman's test. A p value of less than or even up to 0.05 was considered significant. The analyses were performed in GraphPad Prism ${ }^{\circledR}$ (GraphPad Software, San Diego, CA). In Study I, GraphPad Prism 4.0 was used, in Study II, GraphPad Prism 5.0 was used and, in Studies III and IV, GraphPad Prism 6.01 was used. 


\section{Results and discussion}

\section{Paper I}

Previous studies have reported increased cytokine levels in the blood of psoriasis patients (180). Certain chemokines are increased in psoriatic lesions, as previously discussed. The levels of chemokines in peripheral blood are often higher than those of cytokines, making them more appropriate for reliable quantification (181) and therefore more appealing for the study of systemic inflammation. Chemokines are studied as therapy targets $(100,182)$, but, because many chemokine receptors have more than one ligand and different chemokines can bind to different receptors, a further understanding of the chemokine network is required.

In Study I, the systemic levels of Th1-, Th2- and Th17-associated chemokines were studied in 27 psoriasis patients and age- gender- matched controls.

The Th1-associated chemokines, CXCL 9 and CXCL 10, but not CXCL 11, were elevated in the blood of psoriasis patients in comparison to controls. Furthermore, the Th17-associated chemokine, CCL20, but not CXCL8, was significantly higher in the psoriasis patients than in the controls. These chemokines have been shown to be expressed in psoriatic lesions (104) and it could therefore be expected that they would be increased in the peripheral blood of psoriasis patients, at least correlated with the PASI.

The expression of CXCL 9, like the expression of CXCL10, has been shown to be confined to dermal endothelium and monocytes infiltrating the skin in psoriasis $(104,183)$, making it theoretically likely that they are elevated in the peripheral blood in the disease state. Regarding CXCL 11, there is a study showing only the epidermal expression of CXCL11 in psoriatic skin (184), which could possibly explain lower systemic levels. Moreover, CXCL 11 has been shown to exert its effects at much lower concentrations than CXCL 9 and 10 (185). Furthermore, there is more similarity between promoter regions and stimuli for CXCL 10 and 11 than CXCL9 (186) and it can be hypothesised that one of them is more dominant in different tissues. CXCL 10 has been shown to antagonise CXCL $9(187,188)$, but these 
chemokines have also been shown to have synergistic effects (189). It is also important to remember that, although these chemokines are all CXCR3 ligands, they can be differently regulated and there may be transient differences in their expression in different tissues, e.g. blood and skin, in the same disease (190).

CXCL8 or IL 8 is a potent neutrophil chemoattractant and it stimulates the degranulation of neutrophils. Neutrophils are important in psoriasis pathogenesis and are prevalent at least in early disease or exacerbations. They are found in pustular variants of psoriasis and in plaque psoriasis as Munro abscesses. CXCL8 further stimulates angiogenesis and the proliferation of keratinocytes which even produce CXCL8. The decreased systemic levels of CXCL8 in Paper I possibly reflect that the skin lesion to blood levels ratio for CXCL 8 is high in psoriasis. Previous studies of CXCL8 in psoriasis show conflicting data (128, 191-193).

According to the existing knowledge of psoriasis pathogenesis, the elevation of Th1- and Th17-mediated chemokines was not unexpected. The elevation of the Th2-mediated chemokines, CCL 17 and CCL 22, was more surprising. Psoriasis is seen as Th17- and Th1mediated disease, while atopic dermatitis is seen as Th2-mediated disease and it is well accepted that the Th1 response antagonises the Th2 response and conversely. However, increased CCL17 and CCL22 mRNA levels have been demonstrated in psoriatic lesions (104). 
The levels of the chemokines were measured again after treatment with NB-UVB therapy. There were no significant differences in the systemic levels of the respective chemokines (Figure 5), despite a significant improvement in the PASI (mean 67\%, median 75\%).

CXCL8

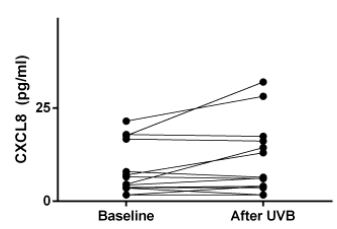

CCL17

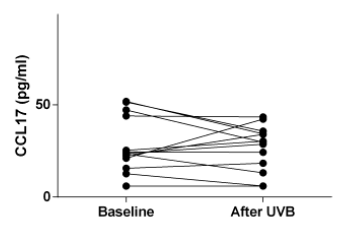

CCL20

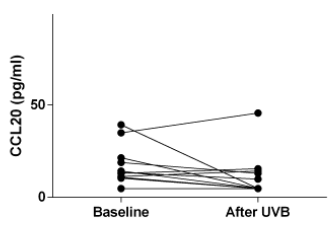

CCL22

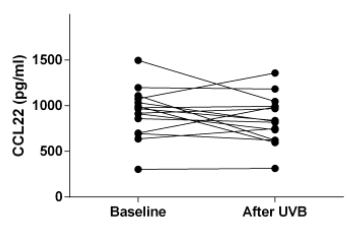

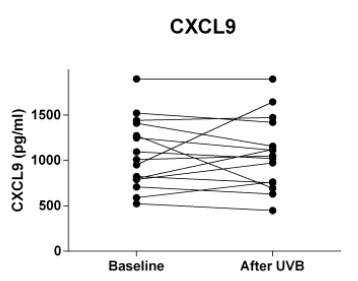
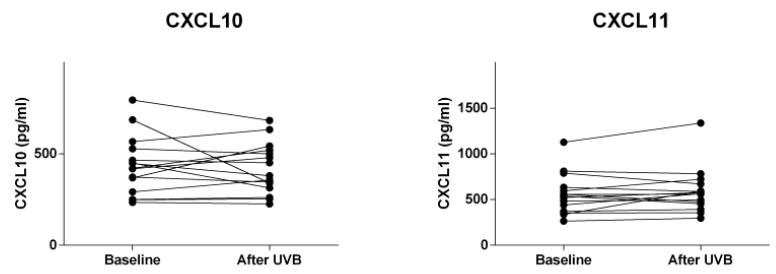

Figure 5. The levels of the Th17 chemokines, CXCL8 and CCL20, the Th2 chemokines, CCL17 and CCL22, and the Th1 chemokines, CXCL9, CXCL10 and CXCL11 before and after NB-UVB treatment, $\mathrm{n}=15$.

As in another study (194), CCL20 was shown to correlate to the PASI. Interestingly, this correlation was lost after NB-UVB treatment. The sustained systemic chemokine levels after NB-UVB therapy indicate that there may be sources for the production of the studied chemokines other than the psoriatic lesions themselves. The evaluation of these chemokines in a group of psoriasis patients receiving systemic treatment with immunomodulatory agents or biologics could have been an interesting enrichment to this study.

The source of the systemic elevation of the chemokines therefore remained unclear. To explore whether the peripheral blood immune cells were more reactive to stimuli in psoriasis patients than controls, PBMCs from 10 controls and 10 patients before and after UVB therapy 
were stimulated with LPS or anti-CD3 and anti-CD28 antibodies. LPS was chosen to activate antigen-presenting cells, e.g. DCs and monocytes, whereas anti-CD3 and anti-CD28 antibodies were selected for the antigen-independent activation of T-lymphocytes. Upstream cytokines were then measured. Following LPS stimulation, cytokines involved in the innate immune mechanisms were quantified, the Th1-inducing cytokine, IL-12p(70), and the Th17inducing cytokines, IL-1 $\beta$ and IL-23. For the evaluation of adaptive immune responses following anti-CD3 and anti-CD28 activation, the concentrations of the Th1 cytokine, IFN- $\gamma$, the Th17 cytokine, IL-17, and the Th2 cytokine, IL-13, were determined. Moreover, after LPS and anti-CD3 and anti-CD28 stimulation, both the chemokine, CCL20, and the antiinflammatory cytokine, IL-10, were measured. Patients with severe psoriasis are more likely to suffer from the co-morbidities linked to the disease and are therefore more likely to possess a higher level of systemic inflammation. The patients with the highest PASI in the cohort (median $=9.6$, range 5.1-16.0) were therefore selected for this experiment. The levels of the cytokines were not differently affected by the stimulation of PBMC from psoriasis patients in comparison to controls, except for the higher secretion of IL-13 in the patient group. IL-13 has been referred to as Th2 cytokine, but IL-13 may perform roles other than only driving the Th2 response. IL-13 is able to exert anti-inflammatory effects and has been shown to stimulate IL-6 production in cultured keratinocytes. Interestingly, another Th2 cytokine, IL-4, has been shown to be downregulated in psoriatic lesions but upregulated in the plasma of psoriasis patients. The IL-13 receptor, IL-13Ra1, has been shown to be upregulated in psoriatic lesions. Heterogeneity in the gene expression of IL-13 in psoriatic lesions has been demonstrated and it correlated to the composition of the inflammatory infiltrate (195-198). IL13 and IFN- $\gamma$, a Th1 cytokine with a central role in psoriasis, have been shown to have synergistic effects. Moreover, IFN- $\gamma$ together with IL-13 and/or IL-4 is able to induce IL-6 and CCL5 $(195,199)$. On the other hand, there are data suggesting that IL-13 may be involved in psoriasis arthritis but not cutaneous psoriasis (200). The role of IL-13 in psoriasis is unclear, but it may have some kind of regulatory effect in the chronic disease, as it has been proposed that, in psoriasis, there may be a shift towards a Th2 immunological response with increased disease duration (201). While discussing regulatory mechanisms, it is interesting that, in Study I, there were no statistical differences between the IL-10 secretion of stimulated PBMCs either in controls or patients or for the Th1 and Th17 cytokines.

NB-UVB therapy did not significantly influence the stimulation response of the PBMCs, again emphasising that this kind of phototherapy may not be able to target the systemic 
inflammation. The gene expression of cytokines involved in the pathogenesis of psoriasis in PBMCs has, however, been shown to be decreased following NB-UVB therapy (202).

In Study I, the aim was to investigate the systemic levels of chemokines involved in psoriasis. Th1- and Th17-mediated chemokines in psoriatic lesions have been demonstrated elsewhere $(104,194,203,204)$. As there were chemokines evaluated in Study I that were not elevated in the blood of the patients, it would have been valuable also to quantify the chemokines in biopsies from their psoriatic lesions. This could have provided information about the chemotactic gradient (205) between lesional skin tissue and blood (plasma), reflecting the role of the respective chemokine at the time of sampling, but, as discussed before, there may be transient differences in chemokine expression in different tissues. 


\section{Paper II}

Studying cardiovascular markers in the peripheral blood of psoriasis patients became extremely interesting after demonstrating elevated chemokines in the blood of this patient group. The elevated chemokines indicated systemic inflammation in psoriasis patients that is believed to be linked to the increased cardiovascular disease observed in psoriasis.

In Study II, six markers, strongly associated with cardiovascular risk, were evaluated, soluble vascular cell adhesion molecule (sVCAM) 1, soluble intercellular adhesion molecule (sICAM) 1, soluble E-selectin (sE-selectin), MMP-9, myeloperoxidase (MPO) and total plasminogen activator inhibitor 1 (tPAI-1).

First, the six markers were measured in 28 psoriasis patients and 28 age- and gender-matched controls. The levels of all the markers, except sVCAM-1, were significantly higher in the patients than in the controls.

Second, as overweight and obesity are linked to cardiovascular morbidity and mortality, it was interesting to analyse the association between these six markers and BMI, an indicator of general obesity, and WHR, an indicator of abdominal obesity. A correlation between the concentration of SICAM-1, sE-selectin, MMP-9 and tPAI-1 and BMI and WHR was identified (Figure 6). 
a)
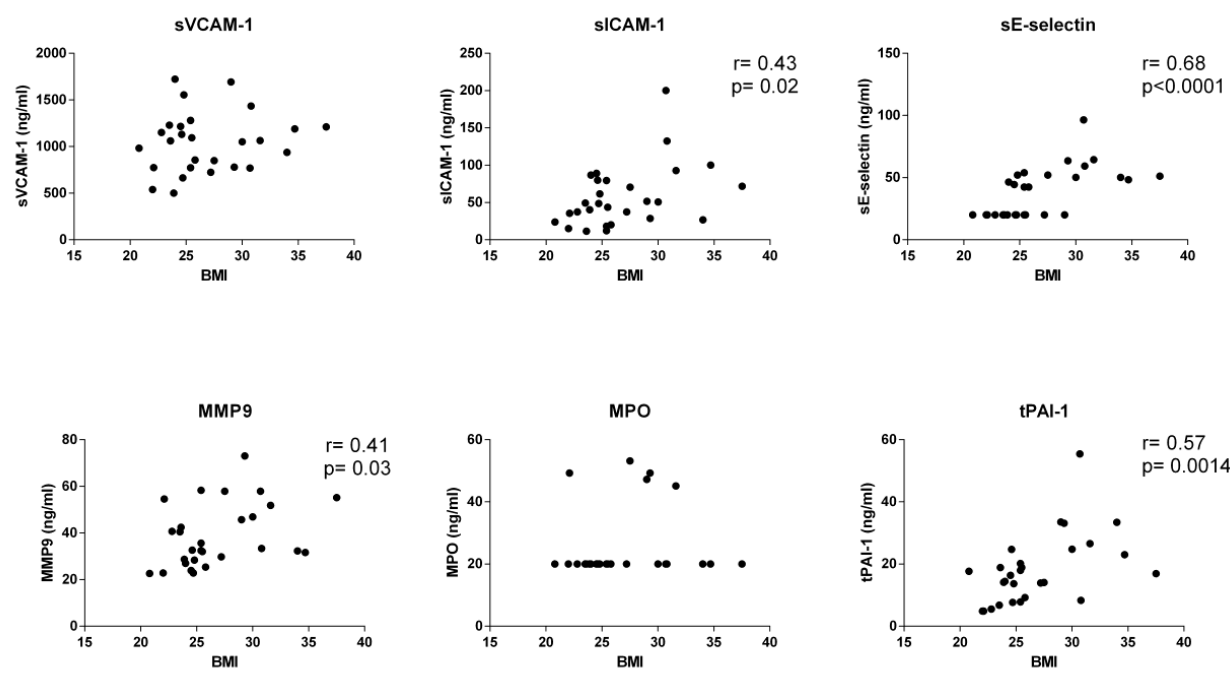

b)
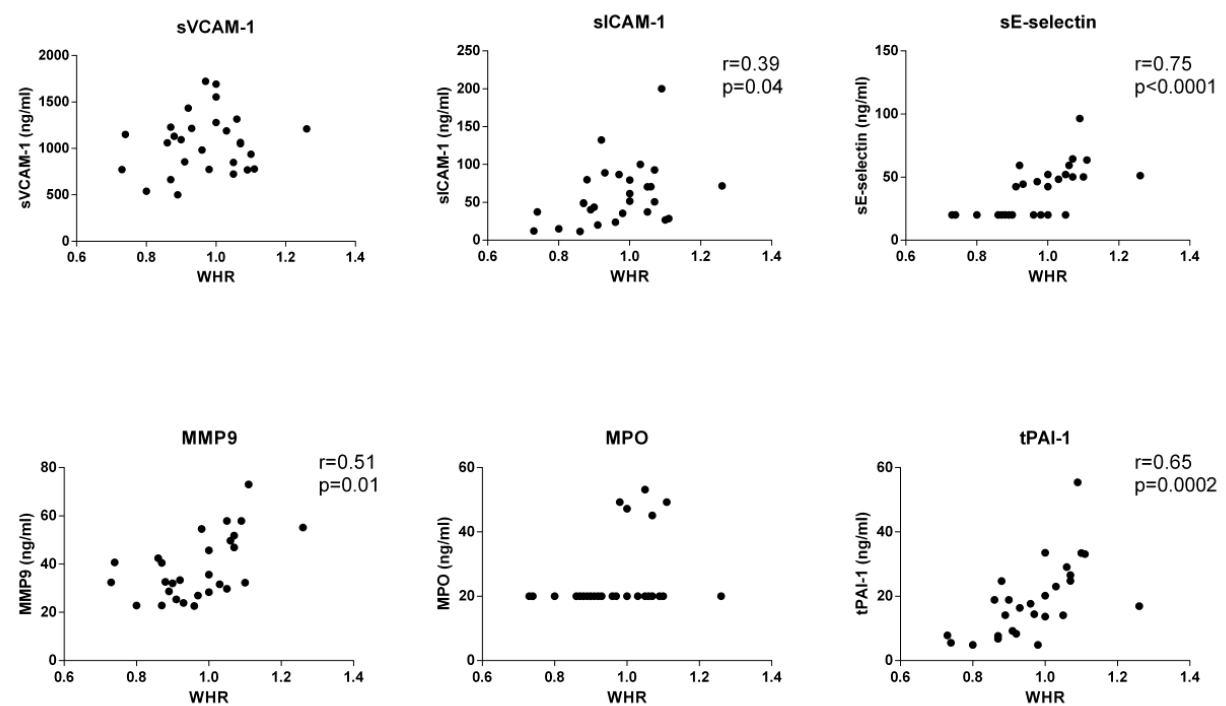

Figure 6. Correlation of a) body mass index (BMI), $n=28$, and b) waist: hip ratio (WHR), $n=28$, to sVCAM-1, sICAM-1, sE-selectin, MMP-9, MPO and tPAI-1 in psoriasis patients. The $r$ denotes the Spearman correlation coefficient. 
Further analysis of the markers was then carried out in 26 psoriasis patients and 26 age-, genderand BMI-matched controls. The BMI matching was within the range of $+/-1.0 \mathrm{~kg} / \mathrm{m}^{2}$. Taking BMI into consideration, only one marker, the tPAI-1, was elevated $(p=0.01)$ (Figure 7). Looking at the graph for tPAI-1, two assumed outliers were noted. When these two patients were excluded from the psoriasis group, there was still a significant difference between the levels of tPAI-1 in controls and patients $(p=0.04)$.

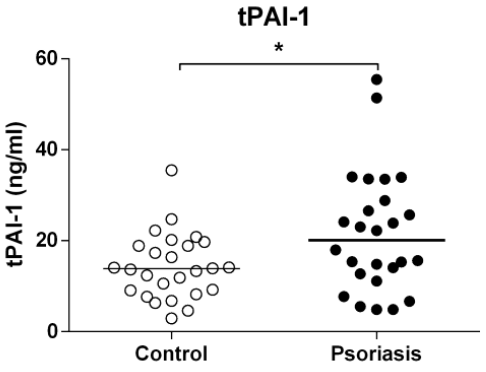

Figure 7. The levels of total plasminogen activator inhibitor-1 in the plasma of age-, gender- and body mass index-matched psoriasis patients and controls, $n=26$. The line shows the median. ${ }^{*} p=0.01$.

Increased visceral adipose tissue is associated with features of the metabolic syndrome such as decreased glucose tolerance, insulin resistance and divergent lipid profiles. Consequently, it has been suggested that measurements involving waist circumference are superior to BMI in predicting cardiovascular risk, although WHR and BMI measurements often correlate (206).

The six investigated markers were therefore also analysed in 13 psoriasis patients and 13 age-, gender- and WHR-matched controls. Here, as after the BMI matching, only the tPAI-1 was significantly elevated in the patients (Figure 8). The WHR matching was within the range of +/0.05. In each matched pair, both the patient and the control had a WHR either within the normal range or in the range defined as abdominal obesity.

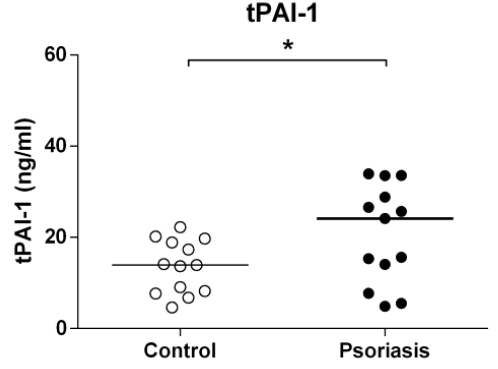

Figure 8. The levels of total plasminogen activator inhibitor-1 in the plasma of age-, gender-, and waist: hip ratio-matched psoriasis patients and controls, $\mathrm{n}=13$. The line shows the median, $* p=0.048$. 
Third, it was important to evaluate the effect of different treatment principles on the elevated markers. As suggested in Paper I, it is possible that NB-UVB treatment acts more locally and should therefore not affect the elevated cardiovascular risk factors. Here, the psoriasis patients had sustained levels of the investigated markers in plasma, after successful NB-UVB therapy. On the other hand, treatment with the TNF $\alpha$ inhibitor, etanercept (Enbrel $\left.{ }^{\circledR}\right)$, significantly improved the levels of the markers in the serum of psoriasis patients.

It should be noted that the markers were measured in plasma in patients receiving phototherapy but in serum in those receiving etanercept. Soluble markers show higher concentration variability in serum than plasma and are often measured at higher levels in serum. This can be explained by ex vivo platelet degranulation and release of mediators during the clotting process $(207,208)$. In study II the treatment groups were separate and only internal comparisons with regard to concentrations of markers were made.

Similar results regarding the effect of systemic treatment on cardiovascular risk markers in psoriasis patients have been demonstrated in other studies. Boehncke at al. demonstrated decreased levels of cardiovascular risk markers in patients receiving diverse systemic treatments for psoriasis, where the reduction was more pronounced in responders (209). A study of the effects of TNF- $\alpha$ blockade with etanercept on inflammatory markers such as fibrinogen and high-sensitivity $\mathrm{C}$-reactive protein (hs-CRP), in psoriasis patients with severe disease, demonstrated lowering effects (210). In patients with psoriatic arthritis, treatment with TNF- $\alpha$ inhibitors had lowering effects on PAI-1 (211). Furthermore, anti-TNF- $\alpha$ therapy has been shown to decrease systemic MMP-9 levels in psoriasis patients (212). Interestingly, Campanati et al. found that etanercept treatment was more effective than tablet psoralen ultraviolet A (PUVA) treatment in decreasing the systemic levels of markers for hepatic fibrosis in psoriasis patients. Furthermore, etanercept also caused a significant decrease in serum fasting insulin levels (213). In a study of patients exhibiting mild and moderate to severe psoriasis, the latter group had more divergent lipid profiles in comparison to controls. Increased oxLDL/LDL was, however, seen in all the patient groups. After topical treatment (calcipotriol or betamethasone dipropionate or a combination of both) or NB-UVB treatment, oxLDL/LDL ratios were continually higher than in the controls. On the other hand, patients treated with tablet PUVA displayed elevated adiponectin levels and a tendency towards both a reduction in oxLDL and an increase in apolipoprotein-B (214). In addition, Romaní et al. were unable to demonstrate any differences in the lipid profiles of 50 psoriasis patients before and after NB-UVB treatment (215). Regarding the effects of phototherapy on adipokine 
levels, Kawashima et al. reported reduced levels of the adipokine resistin but not leptin, which was also elevated at the start of treatment, in relation to treatment with NB-UVB and bath PUVA (216). Inversely, other studies have not reported any effect of phototherapy on resistin levels $(128,217)$. In a study conducted by Coimbra et al., systemic resistin levels were not affected by NB-UVB or tablet PUVA. However, PUVA had a lowering effect on IL-6 and TNF- $\alpha$, while NB-UVB only had this effect on TNF- $\alpha$. Moreover, only PUVA treatment had favourable effects on adiponectin. Despite these effects, there was a persistent significant difference between the levels in controls and patients after phototherapy (217).

The results of Study II indicate that, in psoriasis, the increased cardiovascular risk may, at least in part, be independent of the metabolic syndrome, suggesting other possible mechanisms, as the tPAI-1 concentrations were not affected by adjustments for body weight and abdominal obesity. This is interesting, as independent cardiovascular risk in psoriasis patients has been observed in some studies $(5,140,141,143)$. Nevertheless, these adjustments levelled out the differences between patients and controls in relation to other markers. Irrespective of whether or not the risk in psoriasis patients is independent of other known risk factors, this emphasises the need to identify psoriasis patients with or susceptible to comorbidities, thereby enabling the appropriate prevention and initiation of suitable treatment. Moreover, as NB-UVB therapy did not lower the levels of the cardiovascular risk markers in Study II, systemic treatment should be considered at an early stage in patients with severe disease and risk factors for cardiovascular disease. An investigation of the effects of phototherapy and systemic treatment in the same study, as was done in Study II, is lacking. More studies of different effects and comparing phototherapy and systemic treatment in a larger number of patients are warranted. 


\section{Paper III}

In Study II, the tPAI-1 was the only marker observed to be independent of body weight and abdominal fat. PAI-1 is overproduced in the diseased vessel wall, while plasmin production falls. This affects the homeostasis of the vessel wall, as plasmin has fibrinolytic activity, but PAI-1 is a fibrinolytic suppressor. This leads to the dysfunction of the endothelium, a fundamental sign of the pathogenesis of atherosclerosis (218). Moreover, the plasma levels of PAI-1 have been found to correlate to insulin resistance, which can precede endothelial dysfunction (219). In addition, psoriasis patients as well as patients with an increased BMI have been shown to be in a prothrombotic state $(220,221)$.

It was therefore intriguing to further study different biomarkers of metabolic and cardiovascular disease in psoriasis patients. In 37 age- and gender-matched patients and controls markers of endothelial dysfunction, thrombomodulin, Pecam-1, Endocan-1 and Pentraxin 3 (PTX 3), the adipokines, oncostatin M and FABP4, together with another fatty acid-binding protein, FABP3, the chemokines, CXCL 16 and CXCL6, together with the soluble IL receptors, (sIL)-1R1, sIL-1R2, sIL-2Ra, the soluble TNF receptors, sTNFR1 and sTNFR2, and the soluble vascular endothelial growth factor receptors, (VEGFR)1, sVEGFR2 and sVEGFR3, were measured.

The levels of endocan-1, CXCL16 and sVEGFR1 were reduced in psoriasis patients in comparison to controls, $p=0.009, p=0.02$ and $p=0.05$ respectively. Furthermore, a negative correlation was observed between endocan- 1 concentrations and the PASI $(\mathrm{r}=-0.3, p=0.05)$. This may indicate that reduced endocan-1 levels in psoriasis could represent more severe skin disease and possibly a systemic involvement. Decreased levels of endocan-1 are also observed in overweight and NAFLD $(222,223)$, both seen as co-morbidities in psoriasis patients. Interestingly, when matched for body composition, the significant differences between the concentrations of these markers in patients and controls were lost.

Endocan-1 levels, on the other hand, are markedly increased in highly inflammatory states such as sepsis and hypervascular states such as cardiovascular disease and certain cancer states (224-228). It has been hypothesised that increased levels might be a protective response, as endocan-1 is vasoprotective in normal physiological conditions (229). Low levels might therefore be indicative of insufficient vasoprotective capability, thereby explaining 
decreased concentrations in chronic low inflammatory conditions. The results of other studies of endocan-1 in psoriasis have been paradoxical $(230,231)$.

It has been confirmed that CXCL16 is increased in lesional psoriatic skin and induces the migration of neutrophils $(105,106,232)$. Conversely, previous studies have not found any connection between the systemic levels of CXCL16 and psoriasis (232). In atherosclerosis, CXCL16 is increased in the atherosclerotic plaque $(233,234)$ and, systemically, both decreased and elevated levels have been demonstrated $(235,236)$. Interestingly, it has been suggested that CXCL16 possesses both pro-atherogenic and anti-atherogenic effects, associated with its role in different blood vessel compartments and the evolution of atherosclerosis (237).

In Study III, the levels of endocan-1 and CXCL16 were restored after NB-UVB therapy. Furthermore, unaffected levels of sVEGF1, FABP3, FABP4 and sIL-1R1 at baseline were significantly decreased after NB-UVB treatment, indicating that systemic levels of soluble mediators can be affected by NB-UVB irradiation of the skin.

The fact that endocan-1 inhibits leukocyte extravasation by hindering the leukocyte functionassociated antigen (LFA)-1 connection with ICAM-1 (238), shown to be elevated in psoriasis patients (239), might indicate a mechanism for lowered endocan-1. However, this contradicts the fact that in Study II, sICAM-1 levels were not lowered after NB-UVB treatment, but, according to PASI scores, the skin symptoms diminished. This and the negative correlation of endocan-1 concentration to the PASI could suggest that endocan-1 is a marker of skin inflammation and healing. Future studies of endocan-1 in psoriatic skin could therefore be of interest. Suzuki et al. have reported reduced systemic endocan-1 levels in patients with atopic dermatitis, as well as an increment in endocan-1 in atopic dermatitis skin lesions, where it was expressed by keratinocytes and dermal endothelial cells (240). This is interesting in relation to the decreased sVEGFR1 levels seen in Study III. Soluble VEGFR1 binds VEGF and has an inhibitory effect on the VEGF response (241). VEGF is overexpressed both in the serum of psoriasis patients and in psoriatic skin, where it affects angiogenesis (242). Further, in contexts other than psoriasis, VEGF has been shown to induce endocan-1 levels, which can in turn potentiate the mitogenic and angiogenic effects of VEGF (243). 
The decrease in the systemic levels of endocan-1 and CXLC16 in the psoriasis cohort in Study III and the fact that they were affected by NB-UVB therapy may indicate that they are more suitable as markers of tissue or local inflammation rather than systemic inflammation in psoriasis. Circulating levels and tissue expression may not have to correlate and further studies of these markers in psoriatic skin could therefore be of interest with regard to the possible development of new topical treatments. 


\section{Common considerations in Studies I-III}

\section{Studies of inflammatory mediators}

Investigating different inflammatory markers in psoriasis, many of which are cytokines, is of importance to obtain a deeper understanding of the pathogenesis of the disease and to aid in the search for a possible biomarker. It would be interesting to determine whether psoriasis in itself contributes to the systemic inflammation in psoriasis, unrelated to the presence of other factors such as obesity and the metabolic syndrome, known risk factors for cardiovascular disease. Cytokines reflect local or systemic inflammation. As changes in circulating cytokine levels, including chemokine levels, are observed in many human diseases, the characterisation of their behaviour in healthy individuals and in different diseases and their interplay with other mediators is highly interesting. This could also be informative regarding similarities in the inflammatory cascade in different diseases like psoriasis and atherosclerosis, which possibly belong to the same category of immune-mediated diseases and are, at least theoretically, possibly not that different. Immunomodulatory treatments in psoriasis affect cytokines including chemokines and soluble molecules, directly or indirectly, and thereby the inflammatory cascade of the disease. Cytokines including chemokines and many soluble molecules can therefore be evaluated as biomarkers of a disease.

\section{Pursuing a biomarker}

A biomarker can be a marker of susceptibility to a disease but also of the activity, severity and prognosis of the disease, together with treatment response. The multiplicity in clinical phenotypes and also possible subclinical phenotypes of psoriasis can, however, make the search as difficult as it is important. The author's concept of subclinical phenotypes refers to patients with the same clinical presentation that may differ in terms of the consequences of the disease over time; for example, co-morbidities and treatment response. This may also underscore the need for more than one biomarker for the same disease.

An optimal biomarker is easy to measure, adds information about the prognosis of the disease and affects the management of patients. Many potential biomarkers may therefore have an 
insignificant impact as such. Together with the need for more than one biomarker in a disease, this underscores the need to evaluate multiple markers.

In Studies I-III in this thesis, the screening of different potential soluble biomarkers in psoriasis patients and evaluations of how they are affected by body composition and treatment have been performed. These studies can be seen more as an attempt to characterise the role of these markers in psoriasis and generate a hypothesis. For further evaluations of whether there is an optimal biomarker, a larger population and possibly a longer study period would be needed.

\section{Measuring cytokine levels}

In the studies in this thesis, it was decided to measure many cytokines and chemokines, together with other soluble molecules. As cytokines construct complex networks, this was assumed to be more informative than measuring only a single or very few inflammatory mediators.

There are factors to acknowledge regarding sampling procedures for studies of systemic cytokine levels, such as the types of tube for blood sampling, whether plasma or serum are used for measurements, the storing of samples and freeze-thawing cycles that may affect the measured levels and therefore possibly explain conflicting results in studies. Certain sampling procedures may be difficult to influence. There is a diurnal rhythm in the concentrations of many cytokines, with early morning peaks (244). Furthermore, exercise can also lead to temporarily elevated cytokine levels (245-247). In this context, the immunomodulatory effects of UVB therapy should also be discussed. UV treatment, including UVB treatment, has immunomodulatory effects and affects cytokine levels. After UVB irradiation, the levels of pro-inflammatory cytokines can rise, but UVB also exerts immune regulatory effects. UVB treatment with the longer wavelengths on the UVB scale, e.g. 310-311 nm corresponding to NB-UVB, lowers the risk of sunburn and the Koebner effect of the UVB radiation, which are more correlated to the shorter wavelengths of the UVB scale (248). There has been some discussion about whether it is the trauma of sunburn that induces pro-inflammatory cytokines and this has also been measured in plasma. IL-6 levels were shown to increase after single total body UV exposure of four minimal erythematous doses with peaks in plasma levels at 12 hours. The IL-6 levels were also seen to be correlated to clinical symptoms (249). NB-UVB 
therapy has been shown to be effective in suberythemogenic doses $(250,251)$ and may exert more pronounced immunomodulatory effects than broadband UVB therapy (252). NB-UVB suppresses the production of pro-inflammatory cytokines such as IFN- $\gamma$ and increases the expression of IL-1R2 that binds IL-1 and limits its effects. On the other hand, NB-UVB increases anti-inflammatory cytokines such as IL-10 (253-256). Furthermore, it inhibits the adhesion molecule, ICAM-1, but this inhibition is transient in nature, as ICAM-1 levels rise again 24 hours after UVB irradiation (257). The patients in the studies in this thesis received only NB-UVB treatment and the risk of a systemic increase in pro-inflammatory cytokines because of the treatment were assumed to be minimal.

There are hypotheses that the effect of NB-UVB therapy in psoriasis is of both local and systemic character $(202,258)$. However, indirectly exposed plaques have been shown to clear significantly less than directly exposed plaques, pinpointing that the NB-UVB may exert a much stronger local than systemic effect (259). NB-UVB did not have a significant effect on the systemic levels of the different inflammatory mediators investigated in Studies I and II, whereas, in Study III, there were significant differences. This may be indicative of different roles for the investigated markers in psoriasis. Further, a cytokine is able to exert different effects depending on the target cell. Moreover, the presence and concentrations of other cytokines which can have synergistic or counteracting influences at the time of blood sampling and quantification may also affect the results. This pleiotropy in cytokine networks further underscores the need to investigate multiple mediators. 


\section{Paper IV}

Psoriasis has been described as an autoinflammatory disease. Although autoantigens have been proposed in psoriasis (260-262), the disease has not been defined as autoimmune and exhibits more mixed autoinflammatory and autoimmune features. Inflammasomes are of great importance in many autoinflammatory diseases and, in some of them, blocking one of the end products of the inflammasomes, IL-1 $\beta$, has dramatic effects on disease symptoms (263). Inflammasomes have also been indicated in other inflammatory diseases or states, such as in psoriasis and hidradenitis suppurativa, where the effect of inhibiting IL-1 $\beta$ gives more diverse results (264-270).

It has been shown that the inflammasome components are upregulated in psoriatic skin (271, 272) but how this is regulated and if there is a systemic upregulation is unclear. Interestingly, an increase in the systemic expression of inflammasome components has been observed in autoimmune diseases such as systemic lupus erythematosus (273), Sjögren's syndrome (274) and multiple sclerosis (275).

In Paper IV, the aim was to explore a potential role for inflammasomes in psoriasis, as they have only been scarcely described in psoriasis. The expression levels and activity of components of the inflammasomes in the blood of psoriasis patients were evaluated and the effects of IL-17, a key cytokine in psoriasis, were explored.

\section{Inflammasome expression in blood of psoriasis patients}

RBC-lysed whole blood from twelve psoriasis patients and five controls was analysed with multicolour flow cytometry. The patients exhibited variations in disease severity with a PASI ranging from 0 to 25 . In the group presenting mild disease, the mean PASI was $1.9(n=5)$. In the group presenting moderate/severe disease, the mean PASI was $10.8(n=7)$. The protein expression of the inflammasome proteins, NLRP1, AIM2 and NLRP3, in different white blood cell subtypes was determined by gating different cell populations. A significant increase in the expression of NLRP1, NLRP3 and AIM2 was noted in neutrophils ( $p=0.007,0.01$ and 
0.0007), classical monocytes ( $p=0.009,0.005$ and 0.01$)$, CD4+ lymphocytes $(p=0.01,0.009$ and 0.05$)$ and B cells ( $p=0.01,0.04$ and 0.03$)$ in patient samples in comparison to controls.

Previous studies in this thesis have shown that, even if psoriasis patients obtain a significant improvement in their skin lesions, they nevertheless experience systemic inflammation. It was therefore of interest to analyse whether the systemic expression of the inflammasome components in the cohort was correlated to the PASI.

The expression of NLRP1, NLRP3 and AIM2 inflammasomes correlated with the PASI in some but not all white blood cell subtypes. In neutrophils, a positive correlation between the PASI and NLRP1, NLRP3 and AIM2 was observed. Furthermore, in B cells, AIM2 was positively correlated to the PASI, while NLRP3 in B cells showed negative correlation to the PASI. A correlation between the PASI and inflammasome expression in monocytes, CD4+ and CD8+ lymphocytes was not observed. Furthermore, the increased expression of inflammasomes was not found to correlate to BMI.

The small sample size should, however, be taken to consideration when drawing conclusions, but the increased expression of the three inflammasome components suggests their role in psoriasis pathogenesis. It can be hypothesised that the correlation of the expression of the different inflammasomes with the PASI in the different cell types could indicate different roles for the respective inflammasomes in psoriasis. The increased expression of NLRP1, NLRP 3 and AIM2 in neutrophils, also positively correlated to the PASI, may indicate their importance as a marker or target in early disease. As neutrophils have been shown to have functional inflammasome components, further studies of inflammasome components in pustular psoriasis and streptococcal-induced psoriasis and comparisons with chronic plaque psoriasis would be interesting. The expression of the inflammasome components in lymphoid cell populations indicates that inflammasomes may not only play a role in innate immunity. An increase in the activity of NLRP3 has previously been demonstrated in peripheral CD4+ cells (276). The increased expression of the inflammasomes in the B cells of psoriasis patients is particularly interesting. An increase in circulating B lymphocytes and CD19+ B cell ratios in PBMCs, positively correlated to the PASI, has been described in psoriasis patients in comparison to controls $(277,278)$. Furthermore, B-cell depletion has been connected to the development of psoriasis in patients undergoing treatment with rituximab (279). Inversely, a positive treatment response to rituximab has been described in palmoplantar pustulosis and 
psoriasis arthritis, where the PASI score was not affected in the latter patient group (280, 281). Yanaba et al. have also demonstrated more severe imiquimod skin inflammation in CD19-/- mice than in wild type (WT) mice. When transferring splenic regulatory B cells, absent in CD19-/- mice, from WT mice to CD19-/- mice, the skin inflammation was reduced (282). The spleen is a lymphoid organ rich in various subsets of B cells but also other immune cells such as T-cell subsets, DCs and macrophages. B cells in the marginal zone of the spleen produce large amounts of IL-10. Overweight psoriasis patients have been shown to have a larger spleen diameter than normal-weight psoriasis patients (283). A study based on a murine model demonstrated that obesity suppresses IL-10 production in the spleen (284), while another study reported a decrease in IL-10-producing regulatory B cells in the blood of patients with psoriasis but an increase in the number their progenitor cells (285). In atherosclerosis, both pro-atherosclerotic and atheroprotective B cells are described (286). Splenectomy in apolipoprotein $\mathrm{E}$ deficient $\left(\mathrm{apoE}^{-/-}\right)$mice has been shown to worsen vascular disease (287). Moreover, it has been suggested that the spleen plays a role in the progression of atherosclerotic disease and the concept of a "cardio-splenic axis" does in fact exist (288). Interestingly, Hjuler et al. demonstrated splenic inflammation in a small sample of psoriasis patients after adjustment for BMI, assessed by ${ }^{18} \mathrm{~F}$-fluorodeoxyglucose-positron emission tomography (FDG-PET/CT). The splenic inflammation was further associated with aortic inflammation (289). Other studies of B cells in psoriasis show conflicting results $(277,290$, 291), which warrants further attention.

\section{The role of IL-17 in inflammasome expression}

The efficacy of IL-17 inhibitors in treating psoriasis disease is well documented (292) and, in psoriasis, adaptive immune responses have been associated with IL-17 production (293). The expression of IL-17 has been observed in the psoriasis infiltrate (80) and elevated serum and plasma levels have been documented $(81,294,295)$. In addition, circulating levels of IL-17 have also been linked to the pathogenesis of many of the psoriasis co-morbidities (296). In another skin disease, hidradenitis suppurativa, where co-morbidities such as obesity and the metabolic syndrome are also observed, it has also been suggested that the inflammasomes play a role $(268,297,298)$. Increased levels of IL-17 are found in hidradenitis suppurativa lesions in both the skin and serum of patients with the condition. It has been hypothesised that IL-17 could be an initiation factor in the pathogenesis of hidradenitis suppurativa by driving 
the inflammasome, leading to IL-1 $\beta$ and IL-18 release $(299,300)$. As IL-17 is a central cytokine in psoriasis disease and there are data supporting the hypothesis that part of the IL17 released during inflammation is derived from innate immune cells (88), it was of interest to investigate its role in the increased inflammasome protein expression.

First, HEKn were stimulated with IL-17 and TNF- $\alpha$. After stimulation for 24 hours, the mRNA expression of NLRP1, NLRP3, caspase 5 and IL-1 $\beta$ was increased in comparison to unstimulated cells. The stimulation of HEKn with IL-17 and TNF- $\alpha$ did not alter the gene expression of AIM2 and caspase 1. After 48 hours of stimulation, only the mRNA expression of NLRP3 and IL-1 $\beta$ was increased in comparison to unstimulated cells, but the differences were smaller than after 24 hours of stimulation.

Even if an increase in mRNA expression was evident for different inflammasome components in the HEKn, it did not provide any information on functional importance. An immunofluorescence technique, on fixed cultures with HEKn, was therefore used to assess the protein expression in HEKn. An increase in the protein production of NLRP1, NLRP3 and IL$1 \beta$ was confirmed in cell cultures stimulated with IL-17 and TNF- $\alpha$.

Second, the effects of IL-17 on caspase-1 activity in different white blood cell subtypes were investigated. Caspase-1 is a marker of inflammasome activity, as it is needed to cleave procaspase- 1 to active capsase- 1 , which is then able to cleave pro-IL-1 $\beta$ and pro-IL-18 to IL-1 $\beta$ and IL-18. Freshly isolated white blood cells from healthy controls were stimulated with IL17 and TNF- $\alpha$ for one hour. The FAM-FLICA method was then used to detect caspase-1 analysed on a flow cytometer. A significant increase in caspase-1 activity was observed in classical monocytes. Neutrophils exhibited an increase in caspase-1 activity, which did not reach statistical significance. The stimulation did not affect caspase-1 activity in CD3+ lymphocytes.

These results indicate that IL-17, in combination with TNF- $\alpha$, induces inflammasome activity, both locally in the skin but also systemically. IL-17 has also been shown to be increased in psoriasis co-morbid diseases and the inflammasomes have been demonstrated to be active in these conditions. In atherosclerosis, it has also been suggested that inflammasomes induce macrophage retention into the arterial wall, together with their predisposition for lipid accumulation (301). Furthermore, inflammasomes have been related to obesity and the 
metabolic syndrome. The activation of NLRP3 plays a role in fatty tissue-mediated inflammation being expressed in adipose tissue macrophages and even affecting adipocyte differentiation and insulin sensitivity $(302,303)$. In patients with the metabolic syndrome, increases in the PAI-1 have been encountered. This is mediated through the activation of the $\mathrm{P} 2 \mathrm{X} 7$ receptor, an ATP-sensitive ionotropic $\mathrm{P} 2 \mathrm{X}$ receptor, which has been suggested to induce the assembly of inflammasomes (304). Again, it is of interest that, in Study II, the tPAI-1 was the only marker with sustained elevation after the BMI and WHR matching of patients and controls. 


\section{Conclusions}

The main conclusions in this thesis are as follows.

- The systemic inflammatory burden in psoriasis may be explained, to a certain extent, by body weight and fat distribution. Sustained levels of tPAI-1, despite adjustments for BMI and WHR and an increase in systemic inflammasome expression without correlation to BMI, suggest that there may also be an increased risk of systemic inflammation and cardiovascular risk independently of BMI in psoriasis.

- Sustained elevated levels of chemokines and cardiovascular markers after NB-UVB therapy, the lost correlation of CCL20 to the PASI after successful NB-UVB therapy and the unaffected stimulation response in the PBMCs of psoriasis patients before and after NB-UVB treatment indicate that the skin or psoriatic lesions may not be the only source of the systemically elevated markers that were studied.

- Sustained elevated levels of chemokines and cardiovascular markers after NB-UVB treatment, contrary to the lowering effect of treatment with the TNF- $\alpha$ inhibitor on the cardiovascular markers, point to more local effects of this kind of phototherapy. This further suggests that psoriasis patients with signs of a systemic inflammatory burden should be evaluated for systemic rather than local treatment.

- NB-UVB exerts different effects on the investigated markers, which may reflect different roles for these markers in psoriasis and may suggest that certain biomarkers are more indicative of systemic inflammation in psoriasis, whereas others may represent more local inflammation.

- An increase in the expression of Th2 chemokines and the cytokine, IL-13, together with systemic inflammasome expression in B cells, may mirror regulatory mechanisms in psoriasis. 


\section{Perspective}

This thesis has focused on systemic inflammation in psoriasis. It demonstrates that, in the psoriasis population studied, there is in fact systemic inflammation which appears, at least in part, to be unrelated to the inflammation in the skin. Previously, it has been suggested that an increase in the incidence of other inflammatory diseases in psoriasis was due to the lifestyle of psoriasis patients, with overweight and smoking overrepresented in this patient population. After psoriasis was defined as a systemic disease, sharing many inflammatory pathways with the co-morbid diseases, it has been suggested that the inflammation in the skin contributes to the systemic inflammation. This is interesting in the context of what has been observed in the studies of this thesis that, despite improvements in skin symptoms, there still is measurable inflammation in the blood. This could question the idea that the skin is the only contributor to the systemic inflammation in psoriasis and suggest that it instead initiates a systemic inflammation that then induces inflammation in other organs that then maintains itself independently of the skin status. Questions then arise about the patient population diagnosed with co-morbid diseases before the psoriasis disease, which could then affect the skin in the same way. Finding biomarkers for different psoriasis phenotypes could facilitate more customised care in the future, with regard to both preventive and treatment strategies. Conflicting results of studies investigating soluble markers in psoriasis mark the need for an analysis of larger samples and longitudinal studies. As genotype and possibly epigenetic factors affect the phenotype and could therefore affect the response to different treatment regimens and correlate differently to co-morbid diseases, research in this area is clearly of value in the search for psoriasis biomarkers. 


\section{Acknowledgements}

Many people have contributed to and supported the work this thesis encompasses in different ways.

I would like to express my gratitude to:

The entire research group at the Ingrid Asp Psoriasis Research Center, for this teamwork. Furthermore, thanks to the rest of you at the Division of Cell Biology for your friendly attitude.

All the participants in the studies, who were willing to give their time and without whom there would not have been any results.

All my colleagues and co-workers at the Dermatology Department at Linköping University Hospital, who have helped me with my clinical work when I have been away conducting the work behind this thesis.

I would especially like to mention the following individuals.

My main supervisor, Charlotta Enerbäck, for giving me the opportunity to engage in psoriasis research. Furthermore, for your guidance, encouragement, help in overcoming obstacles, being open-minded and, last but not least, your patience.

My co-supervisor, Cecilia Bivik Eding, for guiding me in many ways in the laboratory, always friendly, willing to listen and help, even when you are fully occupied. Furthermore, I want to thank you for your experimental help, comments on my work and help with editing.

My co-supervisor, Ingrid Synnerstad, for your encouragement and discussions. A friendlier and more positive person, but at the same time realistic, is hard to find.

Deepti Verma, for guiding me in the laboratory with your calm and encouraging attitude, your experimental help, participation in the writing process and for making comments on my work.

Anna-Karin Ekman, for your guidance and experimental help in the work with the Luminex, your linguistic skills and other valuable involvement in the writing processes and comments on my work.

Charlotta Sandin, for your important contribution to the work with flow cytometry.

Natalja Jacobsson, for your collaboration on patient sampling. 
My other co-authors, Maria Carlström, Maria C. Jenmalm and Mona Ståhle, for your valuable contribution and co-operation.

Ingemar Rundquist, for your positive attitude and showing interest in the progress of my thesis.

Birgitta Stymne, for giving me the opportunity to become a resident in dermatology and venereology.

Inger Rosdahl, for supporting the idea of my engaging in research and your guidance at the beginning of that journey.

My boss, Eva Ljunggren, for your understanding, helpfulness and support, giving me generous time to complete my thesis.

My friends, Kyriakos Orfanidis and Ines Köhler, for rewarding discussions and support.

Emelie Stenhammar, Lars Stenhammar, Jenny Blomberg and Hannes Jón Lárusson, for your linguistic consultation.

My family, who regularly remind me that mind-set and limitations are only applied by oneself. In particular, I want to thank my best friend and partner, Beggi, for your companionship, encouragement, support and help. It is invaluable! And then my gemstones, Hilda and Viktor, the only people who can make me smile, no matter what!

The studies in this thesis have been funded by the Ingrid Asp Foundation, the Welander Foundation, the Medical Research Council and the Swedish Psoriasis Association. 


\section{References}

1. Langley RG, Krueger GG, Griffiths CE. Psoriasis: epidemiology, clinical features, and quality of life. Annals of the rheumatic diseases. 2005;64 Suppl 2:ii18-23; discussion ii4-5. Epub $2005 / 02 / 15$.

2. Icen M, Crowson CS, McEvoy MT, Dann FJ, Gabriel SE, Maradit Kremers H. Trends in incidence of adult-onset psoriasis over three decades: a population-based study. Journal of the American Academy of Dermatology. 2009;60(3):394-401. Epub 2009/02/24.

3 . Tollefson MM, Crowson CS, McEvoy MT, Maradit Kremers H. Incidence of psoriasis in children: a population-based study. Journal of the American Academy of Dermatology. 2010;62(6):979-87. Epub 2009/12/08.

4. Gelfand JM, Troxel AB, Lewis JD, Kurd SK, Shin DB, Wang X, et al. The risk of mortality in patients with psoriasis: results from a population-based study. Archives of dermatology. 2007;143(12):1493-9. Epub 2007/12/19.

5. $\quad$ Prodanovich S, Kirsner RS, Kravetz JD, Ma F, Martinez L, Federman DG. Association of psoriasis with coronary artery, cerebrovascular, and peripheral vascular diseases and mortality. Archives of dermatology. 2009;145(6):700-3. Epub 2009/06/17.

6. Skov L, Thomsen SF, Kristensen LE, Dodge R, Hedegaard MS, Kjellberg J. Causespecific mortality in patients with psoriasis and psoriatic arthritis. The British journal of dermatology. 2018. Epub 2018/06/28.

7. Organization WH. World Health Assembly, 67. Psoriasis. Geneva: World Health Organization; 2014; Available from: http://www.who.int/iris/handle/10665/162768

8. Organization WH. Global report on psoriasis. Geneva: World Health Organization, 2016 .

9. Socialstyrelsen. Nationella riktlinjer för vård vid psoriasis. Stöd för styrning och ledning. Remissversion. Stockholm: Socialstyrelsen; 2018; Available from:

http://www.socialstyrelsen.se/publikationer2018/2018-3-15.

10. Parisi R, Symmons DP, Griffiths CE, Ashcroft DM. Global epidemiology of psoriasis: a systematic review of incidence and prevalence. The Journal of investigative dermatology. 2013;133(2):377-85. Epub 2012/09/28.

11. Michalek IM, Loring B, John SM. A systematic review of worldwide epidemiology of psoriasis. Journal of the European Academy of Dermatology and Venereology : JEADV. 2017;31(2):205-12. Epub 2016/08/31.

12. Fredriksson T, Pettersson U. Severe psoriasis--oral therapy with a new retinoid. Dermatologica. 1978;157(4):238-44. Epub 1978/01/01.

13. Schmitt J, Wozel G. The psoriasis area and severity index is the adequate criterion to define severity in chronic plaque-type psoriasis. Dermatology. 2005;210(3):194-9. Epub 2005/03/24.

14. Duffy DL, Spelman LS, Martin NG. Psoriasis in Australian twins. Journal of the American Academy of Dermatology. 1993;29(3):428-34. Epub 1993/09/01.

15. Generali E, Ceribelli A, Stazi MA, Selmi C. Lessons learned from twins in autoimmune and chronic inflammatory diseases. Journal of autoimmunity. 2017;83:51-61. Epub 2017/04/23.

16. Capon F. The Genetic Basis of Psoriasis. International journal of molecular sciences. 2017;18(12). Epub 2017/12/01.

$17 . \quad$ Tiilikainen A, Lassus A, Karvonen J, Vartiainen P, Julin M. Psoriasis and HLA-Cw6. The British journal of dermatology. 1980;102(2):179-84. Epub 1980/02/01.

18. Jordan CT, Cao L, Roberson ED, Duan S, Helms CA, Nair RP, et al. Rare and common variants in CARD14, encoding an epidermal regulator of NF-kappaB, in psoriasis. American journal of human genetics. 2012;90(5):796-808. Epub 2012/04/24.

19. Jordan CT, Cao L, Roberson ED, Pierson KC, Yang CF, Joyce CE, et al. PSORS2 is due to mutations in CARD14. American journal of human genetics. 2012;90(5):784-95. Epub 2012/04/24. 
20.

de Cid R, Riveira-Munoz E, Zeeuwen PL, Robarge J, Liao W, Dannhauser EN, et al.

Deletion of the late cornified envelope LCE3B and LCE3C genes as a susceptibility factor for psoriasis. Nature genetics. 2009;41(2):211-5. Epub 2009/01/27.

21. Onoufriadis A, Simpson MA, Pink AE, Di Meglio P, Smith CH, Pullabhatla V, et al. Mutations in IL36RN/IL1F5 are associated with the severe episodic inflammatory skin disease known as generalized pustular psoriasis. American journal of human genetics. 2011;89(3):432-7. Epub 2011/08/16.

22. Marrakchi S, Guigue P, Renshaw BR, Puel A, Pei XY, Fraitag S, et al. Interleukin-36receptor antagonist deficiency and generalized pustular psoriasis. The New England journal of medicine. 2011;365(7):620-8. Epub 2011/08/19.

23. Carlstrom M, Ekman AK, Petersson S, Soderkvist P, Enerback C. Genetic support for the role of the NLRP3 inflammasome in psoriasis susceptibility. Experimental dermatology. 2012;21(12):932-7. Epub 2012/11/23.

24. Ekman AK, Verma D, Fredrikson M, Bivik C, Enerback C. Genetic variations of NLRP1: susceptibility in psoriasis. The British journal of dermatology. 2014;171(6):1517-20. Epub 2014/06/10.

25. Grjibovski AM, Olsen AO, Magnus P, Harris JR. Psoriasis in Norwegian twins: contribution of genetic and environmental effects. Journal of the European Academy of Dermatology and Venereology : JEADV. 2007;21(10):1337-43. Epub 2007/10/26.

26. Zhou F, Wang W, Shen C, Li H, Zuo X, Zheng X, et al. Epigenome-Wide Association Analysis Identified Nine Skin DNA Methylation Loci for Psoriasis. The Journal of investigative dermatology. 2016;136(4):779-87. Epub 2016/01/09.

27. Zhang P, Su Y, Zhao M, Huang W, Lu Q. Abnormal histone modifications in PBMCs from patients with psoriasis vulgaris. European journal of dermatology : EJD. 2011;21(4):552-7. Epub $2011 / 07 / 01$.

28. Sonkoly E, Wei T, Janson PC, Saaf A, Lundeberg L, Tengvall-Linder M, et al. MicroRNAs: novel regulators involved in the pathogenesis of psoriasis? PloS one. 2007;2(7):e610. Epub 2007/07/12.

29. Tsoi LC, Iyer MK, Stuart PE, Swindell WR, Gudjonsson JE, Tejasvi T, et al. Analysis of long non-coding RNAs highlights tissue-specific expression patterns and epigenetic profiles in normal and psoriatic skin. Genome biology. 2015;16:24. Epub 2015/02/28.

30. Zeng J, Luo S, Huang Y, Lu Q. Critical role of environmental factors in the pathogenesis of psoriasis. The Journal of dermatology. 2017;44(8):863-72. Epub 2017/03/30.

31. Danilenko DM. An Overview of the Pathogenesis of Immune-mediated Skin Injury. Toxicologic pathology. 2016;44(4):536-44. Epub 2016/03/20.

32. Gudjonsson JE, Thorarinsson AM, Sigurgeirsson B, Kristinsson KG, Valdimarsson H. Streptococcal throat infections and exacerbation of chronic plaque psoriasis: a prospective study. The British journal of dermatology. 2003;149(3):530-4. Epub 2003/09/27.

33. Leung DY, Travers JB, Giorno R, Norris DA, Skinner R, Aelion J, et al. Evidence for a streptococcal superantigen-driven process in acute guttate psoriasis. The Journal of clinical investigation. 1995;96(5):2106-12. Epub 1995/11/01.

34. Telfer NR, Chalmers RJ, Whale K, Colman G. The role of streptococcal infection in the initiation of guttate psoriasis. Archives of dermatology. 1992;128(1):39-42. Epub 1992/01/01.

35. Wardrop P, Weller R, Marais J, Kavanagh G. Tonsillitis and chronic psoriasis. Clinical otolaryngology and allied sciences. 1998;23(1):67-8. Epub 1998/05/01.

36. Martin BA, Chalmers RJ, Telfer NR. How great is the risk of further psoriasis following a single episode of acute guttate psoriasis? Archives of dermatology. 1996;132(6):717-8. Epub 1996/06/01.

37. Zakostelska Z, Malkova J, Klimesova K, Rossmann P, Hornova M, Novosadova I, et al. Intestinal Microbiota Promotes Psoriasis-Like Skin Inflammation by Enhancing Th17 Response. PloS one. 2016;11(7):e0159539. Epub 2016/07/21.

38. Armstrong AW, Harskamp CT, Dhillon JS, Armstrong EJ. Psoriasis and smoking: a systematic review and meta-analysis. The British journal of dermatology. 2014;170(2):304-14. Epub 2013/10/15. 
39.

Attwa E, Swelam E. Relationship between smoking-induced oxidative stress and the

clinical severity of psoriasis. Journal of the European Academy of Dermatology and Venereology : JEADV. 2011;25(7):782-7. Epub 2010/11/03.

40. Jin Y, Yang S, Zhang F, Kong Y, Xiao F, Hou Y, et al. Combined effects of HLA-Cw6 and cigarette smoking in psoriasis vulgaris: a hospital-based case-control study in China. Journal of the European Academy of Dermatology and Venereology : JEADV. 2009;23(2):132-7. Epub 2008/08/16.

41. Grando SA, Horton RM, Mauro TM, Kist DA, Lee TX, Dahl MV. Activation of keratinocyte nicotinic cholinergic receptors stimulates calcium influx and enhances cell differentiation. The Journal of investigative dermatology. 1996;107(3):412-8. Epub 1996/09/01.

42. Brenaut E, Horreau C, Pouplard C, Barnetche T, Paul C, Richard MA, et al. Alcohol consumption and psoriasis: a systematic literature review. Journal of the European Academy of Dermatology and Venereology : JEADV. 2013;27 Suppl 3:30-5. Epub 2013/07/17.

43. Serwin AB, Sokolowska M, Dylejko E, Chodynicka B. Tumour necrosis factor (TNFalpha) alpha converting enzyme and soluble TNF-alpha receptor type 1 in psoriasis patients in relation to the chronic alcohol consumption. Journal of the European Academy of Dermatology and Venereology : JEADV. 2008;22(6):712-7. Epub 2008/03/04.

44. Farkas A, Kemeny L, Szell M, Dobozy A, Bata-Csorgo Z. Ethanol and acetone stimulate the proliferation of $\mathrm{HaCaT}$ keratinocytes: the possible role of alcohol in exacerbating psoriasis. Archives of dermatological research. 2003;295(2):56-62. Epub 2003/04/30.

45. Albanesi C. Immunology of Psoriasis. In: RR. R, editor. Clinical Immunology Principles and Practice. Fifth Edition. ed: ELSEVIER; 2018. p. 871-8.

46. Fujita H, Shemer A, Suarez-Farinas M, Johnson-Huang LM, Tintle S, Cardinale I, et al. Lesional dendritic cells in patients with chronic atopic dermatitis and psoriasis exhibit parallel ability to activate T-cell subsets. J Allergy Clin Immunol. 2011;128(3):574-82 e1-12. Epub 2011/06/28.

47. Lowes MA, Bowcock AM, Krueger JG. Pathogenesis and therapy of psoriasis. Nature. 2007;445(7130):866-73. Epub 2007/02/23.

48. Costantini C, Calzetti F, Perbellini O, Micheletti A, Scarponi C, Lonardi S, et al. Human neutrophils interact with both 6-sulfo LacNAc+ DC and NK cells to amplify NK-derived IFN \{gamma\}: role of CD18, ICAM-1, and ICAM-3. Blood. 2011;117(5):1677-86. Epub 2010/11/26. 49. Griffiths CE. The immunological basis of psoriasis. Journal of the European Academy of Dermatology and Venereology : JEADV. 2003;17 Suppl 2:1-5. Epub 2003/06/11.

50. Lowes MA, Kikuchi T, Fuentes-Duculan J, Cardinale I, Zaba LC, Haider AS, et al. Psoriasis vulgaris lesions contain discrete populations of Th1 and Th17 T cells. The Journal of investigative dermatology. 2008;128(5):1207-11. Epub 2008/01/18.

51. Balak DM, van Doorn MB, Arbeit RD, Rijneveld R, Klaassen E, Sullivan T, et al. IMO-8400, a toll-like receptor 7, 8, and 9 antagonist, demonstrates clinical activity in a phase 2a, randomized, placebo-controlled trial in patients with moderate-to-severe plaque psoriasis. Clin Immunol. 2017;174:63-72. Epub 2016/11/24.

52. Dombrowski Y, Peric M, Koglin S, Kammerbauer C, Goss C, Anz D, et al. Cytosolic DNA triggers inflammasome activation in keratinocytes in psoriatic lesions. Science translational medicine. 2011;3(82):82ra38. Epub 2011/05/13.

53. Guo L, Wei G, Zhu J, Liao W, Leonard WJ, Zhao K, et al. IL-1 family members and STAT activators induce cytokine production by Th2, Th17, and Th1 cells. Proceedings of the National Academy of Sciences of the United States of America. 2009;106(32):13463-8. Epub 2009/08/12. 54. Shepherd J, Little MC, Nicklin MJ. Psoriasis-like cutaneous inflammation in mice lacking interleukin-1 receptor antagonist. The Journal of investigative dermatology. 2004;122(3):6659. Epub 2004/04/17.

55. Rasmy H, Mikhael N, Ismail S. Interleukin-18 expression and the response to treatment in patients with psoriasis. Archives of medical science : AMS. 2011;7(4):713-9. Epub 2012/02/01.

56. Smith DE. The biological paths of IL-1 family members IL-18 and IL-33. Journal of leukocyte biology. 2011;89(3):383-92. Epub 2010/10/19.

57. Waite JC, Skokos D. Th17 response and inflammatory autoimmune diseases. International journal of inflammation. 2012;2012:819467. Epub 2012/01/10. 
58. 2015/01/15.

59. Adorini L. Cytokine-based immunointervention in the treatment of autoimmune diseases. Clinical and experimental immunology. 2003;132(2):185-92. Epub 2003/04/18.

60. Little MC, Gawkrodger DJ, Mac Neil S. Differentiation of human keratinocytes is associated with a progressive loss of interferon gamma-induced intercellular adhesion molecule-1 expression. The British journal of dermatology. 1996;135(1):24-31. Epub 1996/07/01.

61. Murphy JE, Robert C, Kupper TS. Interleukin-1 and cutaneous inflammation: a crucial link between innate and acquired immunity. The Journal of investigative dermatology. 2000;114(3):602-8. Epub 2000/02/26.

62. Pietrzak AT, Zalewska A, Chodorowska G, Krasowska D, Michalak-Stoma A, Nockowski P, et al. Cytokines and anticytokines in psoriasis. Clinica chimica acta; international journal of clinical chemistry. 2008;394(1-2):7-21. Epub 2008/05/01.

63. Debets R, Hegmans JP, Troost RJ, Benner R, Prens EP. Enhanced production of biologically active interleukin-1 alpha and interleukin-1 beta by psoriatic epidermal cells ex vivo: evidence of increased cytosolic interleukin-1 beta levels and facilitated interleukin-1 release. European journal of immunology. 1995;25(6):1624-30. Epub 1995/06/01.

64. Mizutani H, Ohmoto Y, Mizutani T, Murata M, Shimizu M. Role of increased production of monocytes TNF-alpha, IL-1beta and IL-6 in psoriasis: relation to focal infection, disease activity and responses to treatments. Journal of dermatological science. 1997;14(2):145-53. Epub 1997/02/01.

65. Gutzmer R, Langer K, Mommert S, Wittmann M, Kapp A, Werfel T. Human dendritic cells express the IL-18R and are chemoattracted to IL-18. J Immunol. 2003;171(12):6363-71. Epub 2003/12/10.

66. Ohta Y, Hamada Y, Katsuoka K. Expression of IL-18 in psoriasis. Archives of dermatological research. 2001;293(7):334-42. Epub 2001/09/12.

67. Flisiak I, Klepacki A, Chodynicka B. Plasma and scales levels of interleukin 18 in comparison with other possible clinical and laboratory biomarkers of psoriasis activity. Biomarkers : biochemical indicators of exposure, response, and susceptibility to chemicals. 2006;11(2):194-200. Epub 2006/06/13.

68. Pietrzak A, Lecewicz-Torun B, Chodorowska G, Rolinski J. Interleukin-18 levels in the plasma of psoriatic patients correlate with the extent of skin lesions and the PASI score. Acta dermatovenereologica. 2003;83(4):262-5. Epub 2003/08/21.

69. Nakanishi K, Yoshimoto T, Tsutsui H, Okamura H. Interleukin-18 is a unique cytokine that stimulates both Th1 and Th2 responses depending on its cytokine milieu. Cytokine \& growth factor reviews. 2001;12(1):53-72. Epub 2001/04/20.

70. Park CC, Morel JC, Amin MA, Connors MA, Harlow LA, Koch AE. Evidence of IL-18 as a novel angiogenic mediator. J Immunol. 2001;167(3):1644-53. Epub 2001/07/24.

71. Kaser A, Kaser S, Kaneider NC, Enrich B, Wiedermann CJ, Tilg H. Interleukin-18 attracts plasmacytoid dendritic cells (DC2s) and promotes Th1 induction by DC2s through IL-18 receptor expression. Blood. 2004;103(2):648-55. Epub 2003/09/25.

72. D'Erme AM, Wilsmann-Theis D, Wagenpfeil J, Holzel M, Ferring-Schmitt S, Sternberg $\mathrm{S}$, et al. IL-36gamma (IL-1F9) is a biomarker for psoriasis skin lesions. The Journal of investigative dermatology. 2015;135(4):1025-32. Epub 2014/12/20.

73. Johnston A, Xing X, Guzman AM, Riblett M, Loyd CM, Ward NL, et al. IL-1F5, -F6, F8, and -F9: a novel IL-1 family signaling system that is active in psoriasis and promotes keratinocyte antimicrobial peptide expression. J Immunol. 2011;186(4):2613-22. Epub 2011/01/19.

74. Foster AM, Baliwag J, Chen CS, Guzman AM, Stoll SW, Gudjonsson JE, et al. IL-36 promotes myeloid cell infiltration, activation, and inflammatory activity in skin. J Immunol. 2014;192(12):6053-61. Epub 2014/05/16.

75. Nair RP, Ruether A, Stuart PE, Jenisch S, Tejasvi T, Hiremagalore R, et al. Polymorphisms of the IL12B and IL23R genes are associated with psoriasis. The Journal of investigative dermatology. 2008;128(7):1653-61. Epub 2008/01/26.

76. Sigmundsdottir H, Johnston A, Gudjonsson JE, Valdimarsson H. Differential effects of interleukin 12 and interleukin 10 on superantigen-induced expression of cutaneous lymphocyte- 
associated antigen (CLA) and alphaEbeta7 integrin (CD103) by CD8+ T cells. Clin Immunol. 2004;111(1):119-25. Epub 2004/04/20.

77. Wilson NJ, Boniface K, Chan JR, McKenzie BS, Blumenschein WM, Mattson JD, et al. Development, cytokine profile and function of human interleukin 17-producing helper T cells. Nature immunology. 2007;8(9):950-7. Epub 2007/08/07.

78. Johnston A, Guzman AM, Swindell WR, Wang F, Kang S, Gudjonsson JE. Early tissue responses in psoriasis to the antitumour necrosis factor-alpha biologic etanercept suggest reduced interleukin-17 receptor expression and signalling. The British journal of dermatology. 2014;171(1):97107. Epub 2014/03/08.

79. Chiricozzi A, Guttman-Yassky E, Suarez-Farinas M, Nograles KE, Tian S, Cardinale I, et al. Integrative responses to IL-17 and TNF-alpha in human keratinocytes account for key inflammatory pathogenic circuits in psoriasis. The Journal of investigative dermatology. 2011;131(3):677-87. Epub 2010/11/19.

80. Johansen C, Usher PA, Kjellerup RB, Lundsgaard D, Iversen L, Kragballe K. Characterization of the interleukin-17 isoforms and receptors in lesional psoriatic skin. The British journal of dermatology. 2009;160(2):319-24. Epub 2008/11/20.

81. Zhou XY, Bao J, Huang B, Jin Y. Association between plasma interleukin-17 levels and risk of psoriasis: a meta-analysis. Clinical and experimental dermatology. 2017;42(2):161-6. Epub $2016 / 12 / 08$.

82. Teunissen MB, Koomen CW, de Waal Malefyt R, Wierenga EA, Bos JD. Interleukin17 and interferon-gamma synergize in the enhancement of proinflammatory cytokine production by human keratinocytes. The Journal of investigative dermatology. 1998;111(4):645-9. Epub 1998/10/09. 83.

Gu C, Wu L, Li X. IL-17 family: cytokines, receptors and signaling. Cytokine. 2013;64(2):477-85. Epub 2013/09/10.

84. Toy D, Kugler D, Wolfson M, Vanden Bos T, Gurgel J, Derry J, et al. Cutting edge: interleukin 17 signals through a heteromeric receptor complex. J Immunol. 2006;177(1):36-9. Epub 2006/06/21.

85. Johnston A, Fritz Y, Dawes SM, Diaconu D, Al-Attar PM, Guzman AM, et al. Keratinocyte overexpression of IL-17C promotes psoriasiform skin inflammation. J Immunol. 2013;190(5):2252-62. Epub 2013/01/30.

86. Villanova F, Flutter B, Tosi I, Grys K, Sreeneebus H, Perera GK, et al. Characterization of innate lymphoid cells in human skin and blood demonstrates increase of NKp44+ ILC3 in psoriasis. The Journal of investigative dermatology. 2014;134(4):984-91. Epub 2013/12/20.

87. Keijsers R, Hendriks AGM, van Erp PEJ, van Cranenbroek B, van de Kerkhof PCM, Koenen $\mathrm{H}$, et al. In vivo induction of cutaneous inflammation results in the accumulation of extracellular trap-forming neutrophils expressing RORgammat and IL-17. The Journal of investigative dermatology. 2014;134(5):1276-84. Epub 2013/12/10.

88. Cua DJ, Tato CM. Innate IL-17-producing cells: the sentinels of the immune system. Nature reviews Immunology. 2010;10(7):479-89. Epub 2010/06/19.

89. Katz Y, Nadiv O, Beer Y. Interleukin-17 enhances tumor necrosis factor alpha-induced synthesis of interleukins 1,6, and 8 in skin and synovial fibroblasts: a possible role as a "fine-tuning cytokine" in inflammation processes. Arthritis and rheumatism. 2001;44(9):2176-84. Epub 2001/10/11.

90. Griffin GK, Newton G, Tarrio ML, Bu DX, Maganto-Garcia E, Azcutia V, et al. IL-17 and TNF-alpha sustain neutrophil recruitment during inflammation through synergistic effects on endothelial activation. J Immunol. 2012;188(12):6287-99. Epub 2012/05/09.

91. Onishi RM, Gaffen SL. Interleukin-17 and its target genes: mechanisms of interleukin17 function in disease. Immunology. 2010;129(3):311-21. Epub 2010/04/23.

92. Sa SM, Valdez PA, Wu J, Jung K, Zhong F, Hall L, et al. The effects of IL-20 subfamily cytokines on reconstituted human epidermis suggest potential roles in cutaneous innate defense and pathogenic adaptive immunity in psoriasis. J Immunol. 2007;178(4):2229-40. Epub 2007/02/06.

93. Wolk K, Witte E, Wallace E, Docke WD, Kunz S, Asadullah K, et al. IL-22 regulates the expression of genes responsible for antimicrobial defense, cellular differentiation, and mobility in 
keratinocytes: a potential role in psoriasis. European journal of immunology. 2006;36(5):1309-23. Epub 2006/04/19.

94. Teunissen MBM, Munneke JM, Bernink JH, Spuls PI, Res PCM, Te Velde A, et al. Composition of innate lymphoid cell subsets in the human skin: enrichment of NCR(+) ILC3 in lesional skin and blood of psoriasis patients. The Journal of investigative dermatology. 2014;134(9):2351-60. Epub 2014/03/25.

95. Wolk K, Haugen HS, Xu W, Witte E, Waggie K, Anderson M, et al. IL-22 and IL-20 are key mediators of the epidermal alterations in psoriasis while IL-17 and IFN-gamma are not. J Mol Med (Berl). 2009;87(5):523-36. Epub 2009/03/31.

96. Boniface K, Bernard FX, Garcia M, Gurney AL, Lecron JC, Morel F. IL-22 inhibits epidermal differentiation and induces proinflammatory gene expression and migration of human keratinocytes. J Immunol. 2005;174(6):3695-702. Epub 2005/03/08.

97. Schumann K, Lammermann T, Bruckner M, Legler DF, Polleux J, Spatz JP, et al. Immobilized chemokine fields and soluble chemokine gradients cooperatively shape migration patterns of dendritic cells. Immunity. 2010;32(5):703-13. Epub 2010/05/18.

98. Rot A, von Andrian UH. Chemokines in innate and adaptive host defense: basic chemokinese grammar for immune cells. Annual review of immunology. 2004;22:891-928. Epub 2004/03/23.

99. Allavena P, Germano G, Marchesi F, Mantovani A. Chemokines in cancer related inflammation. Experimental cell research. 2011;317(5):664-73. Epub 2010/12/08.

100. Homey B, Meller S. Chemokines and other mediators as therapeutic targets in psoriasis vulgaris. Clin Dermatol. 2008;26(5):539-45. Epub 2008/08/30.

101. Mabuchi T, Chang TW, Quinter S, Hwang ST. Chemokine receptors in the pathogenesis and therapy of psoriasis. J Dermatol Sci. 2012;65(1):4-11. Epub 2011/12/20.

102. Griffith JW, Sokol CL, Luster AD. Chemokines and chemokine receptors: positioning cells for host defense and immunity. Annual review of immunology. 2014;32:659-702. Epub $2014 / 03 / 25$.

103. Bachelerie F, Ben-Baruch A, Burkhardt AM, Combadiere C, Farber JM, Graham GJ, et al. International Union of Basic and Clinical Pharmacology. [corrected]. LXXXIX. Update on the extended family of chemokine receptors and introducing a new nomenclature for atypical chemokine receptors. Pharmacological reviews. 2014;66(1):1-79. Epub 2013/11/13.

104. Rottman JB, Smith TL, Ganley KG, Kikuchi T, Krueger JG. Potential role of the chemokine receptors CXCR3, CCR4, and the integrin alphaEbeta7 in the pathogenesis of psoriasis vulgaris. Laboratory investigation; a journal of technical methods and pathology. 2001;81(3):335-47. Epub 2001/04/20.

105. Steffen S, Abraham S, Herbig M, Schmidt F, Blau K, Meisterfeld S, et al. Toll-Like Receptor-Mediated Upregulation of CXCL16 in Psoriasis Orchestrates Neutrophil Activation. The Journal of investigative dermatology. 2018;138(2):344-54. Epub 2017/09/25.

106. Oh ST, Schramme A, Tilgen W, Gutwein P, Reichrath J. Overexpression of CXCL16 in lesional psoriatic skin. Dermato-endocrinology. 2009;1(2):114-8. Epub 2010/03/13.

107. Shimaoka T, Nakayama T, Fukumoto N, Kume N, Takahashi S, Yamaguchi J, et al. Cell surface-anchored SR-PSOX/CXC chemokine ligand 16 mediates firm adhesion of CXC chemokine receptor 6-expressing cells. Journal of leukocyte biology. 2004;75(2):267-74. Epub 2003/11/25.

108. Harper EG, Guo C, Rizzo H, Lillis JV, Kurtz SE, Skorcheva I, et al. Th17 cytokines stimulate CCL20 expression in keratinocytes in vitro and in vivo: implications for psoriasis pathogenesis. J Invest Dermatol. 2009;129(9):2175-83. Epub 2009/03/20.

109. Zernecke A, Weber C. Chemokines in the vascular inflammatory response of atherosclerosis. Cardiovascular research. 2010;86(2):192-201. Epub 2009/12/17.

110. Strauss H. Zur Lehre von der neurogenen und der thyreogenen Glykosurie. Dtsch Med Wochenschr. 1897;20:309-12.

111. Benton JM, Brown PE, Church RE. The serum-cholesterol in psoriasis. Lancet. 1963;1(7281):583-4. Epub 1963/03/16.

112. McDonald CJ, Calabresi P. Thromboembolic disorders associated with psoriasis. Archives of dermatology. 1973;107(6):918. Epub 1973/06/01. 
113. Wang Y, Gao H, Loyd CM, Fu W, Diaconu D, Liu S, et al. Chronic skin-specific inflammation promotes vascular inflammation and thrombosis. The Journal of investigative dermatology. 2012;132(8):2067-75. Epub 2012/05/11.

114. Buerger C, Richter B, Woth K, Salgo R, Malisiewicz B, Diehl S, et al. Interleukin-1beta interferes with epidermal homeostasis through induction of insulin resistance: implications for psoriasis pathogenesis. The Journal of investigative dermatology. 2012;132(9):2206-14. Epub 2012/04/20.

115. Boehncke WH, Boehncke S, Tobin AM, Kirby B. The 'psoriatic march': a concept of how severe psoriasis may drive cardiovascular comorbidity. Experimental dermatology. 2011;20(4):303-7. Epub 2011/03/18.

116. Mehta NN, Yu Y, Saboury B, Foroughi N, Krishnamoorthy P, Raper A, et al. Systemic and vascular inflammation in patients with moderate to severe psoriasis as measured by [18F]fluorodeoxyglucose positron emission tomography-computed tomography (FDG-PET/CT): a pilot study. Archives of dermatology. 2011;147(9):1031-9. Epub 2011/05/18.

117. Youn SW, Kang SY, Kim SA, Park GY, Lee WW. Subclinical systemic and vascular inflammation detected by (18) F-fluorodeoxyglucose positron emission tomography/computed tomography in patients with mild psoriasis. The Journal of dermatology. 2015;42(6):559-66. Epub 2015/03/27.

118. Armstrong AW, Harskamp CT, Armstrong EJ. The association between psoriasis and obesity: a systematic review and meta-analysis of observational studies. Nutrition \& diabetes. 2012;2:e54. Epub 2012/12/05.

$119 . \quad H e n s e l e r$ T, Christophers E. Disease concomitance in psoriasis. Journal of the American Academy of Dermatology. 1995;32(6):982-6. Epub 1995/06/01.

120. Herron MD, Hinckley M, Hoffman MS, Papenfuss J, Hansen CB, Callis KP, et al. Impact of obesity and smoking on psoriasis presentation and management. Archives of dermatology. 2005;141(12):1527-34. Epub 2005/12/21.

121. Setty AR, Curhan G, Choi HK. Obesity, waist circumference, weight change, and the risk of psoriasis in women: Nurses' Health Study II. Archives of internal medicine.

2007;167(15):1670-5. Epub 2007/08/19.

122. Kumar S, Han J, Li T, Qureshi AA. Obesity, waist circumference, weight change and the risk of psoriasis in US women. Journal of the European Academy of Dermatology and Venereology : JEADV. 2013;27(10):1293-8. Epub 2012/10/13.

123. Virtue S, Vidal-Puig A. Adipose tissue expandability, lipotoxicity and the Metabolic Syndrome--an allostatic perspective. Biochimica et biophysica acta. 2010;1801(3):338-49. Epub 2010/01/09.

124. Winer S, Paltser G, Chan Y, Tsui H, Engleman E, Winer D, et al. Obesity predisposes to Th17 bias. European journal of immunology. 2009;39(9):2629-35. Epub 2009/08/08.

125. Endo Y, Asou HK, Matsugae N, Hirahara K, Shinoda K, Tumes DJ, et al. Obesity

Drives Th17 Cell Differentiation by Inducing the Lipid Metabolic Kinase, ACC1. Cell reports. 2015;12(6):1042-55. Epub 2015/08/04.

126. Coimbra S, Catarino C, Santos-Silva A. The triad psoriasis-obesity-adipokine profile. Journal of the European Academy of Dermatology and Venereology : JEADV. 2016;30(11):1876-85. Epub 2016/10/25.

127. Kanda N, Hau CS, Tada Y, Tatsuta A, Sato S, Watanabe S. Visfatin enhances CXCL8, CXCL10, and CCL20 production in human keratinocytes. Endocrinology. 2011;152(8):3155-64. Epub 2011/06/16.

128. Johnston A, Arnadottir S, Gudjonsson JE, Aphale A, Sigmarsdottir AA, Gunnarsson SI, et al. Obesity in psoriasis: leptin and resistin as mediators of cutaneous inflammation. Br J Dermatol. 2008;159(2):342-50. Epub 2008/06/13.

129. Bai F, Zheng W, Dong Y, Wang J, Garstka MA, Li R, et al. Serum levels of adipokines and cytokines in psoriasis patients: a systematic review and meta-analysis. Oncotarget.

2018;9(1):1266-78. Epub 2018/02/09.

130. Armstrong AW, Harskamp CT, Armstrong EJ. Psoriasis and metabolic syndrome: a systematic review and meta-analysis of observational studies. Journal of the American Academy of Dermatology. 2013;68(4):654-62. Epub 2013/01/31. 
131.

Alberti KG, Zimmet P, Shaw J. Metabolic syndrome--a new world-wide definition. A Consensus Statement from the International Diabetes Federation. Diabetic medicine : a journal of the British Diabetic Association. 2006;23(5):469-80. Epub 2006/05/10.

132. Organization WH. Definition, diagnosis and classification of diabetes mellitus and its complications : report of a WHO consultation. Part 1, Diagnosis and classification of diabetes mellitus. Geneva: World Health Organization, 1999.

133. Langan SM, Seminara NM, Shin DB, Troxel AB, Kimmel SE, Mehta NN, et al. Prevalence of metabolic syndrome in patients with psoriasis: a population-based study in the United Kingdom. The Journal of investigative dermatology. 2012;132(3 Pt 1):556-62. Epub 2011/11/25. 134. Cao Y. Angiogenesis modulates adipogenesis and obesity. The Journal of clinical investigation. 2007;117(9):2362-8. Epub 2007/09/06.

135. Detmar M, Brown LF, Claffey KP, Yeo KT, Kocher O, Jackman RW, et al. Overexpression of vascular permeability factor/vascular endothelial growth factor and its receptors in psoriasis. The Journal of experimental medicine. 1994;180(3):1141-6. Epub 1994/09/01.

136. Creamer D, Allen MH, Groves RW, Barker JN. Circulating vascular permeability factor/vascular endothelial growth factor in erythroderma. Lancet. 1996;348(9034):1101. Epub 1996/10/19.

137. Gupta Y, Moller S, Zillikens D, Boehncke WH, Ibrahim SM, Ludwig RJ. Genetic control of psoriasis is relatively distinct from that of metabolic syndrome and coronary artery disease. Experimental dermatology. 2013;22(8):552-3. Epub 2013/07/25.

138. Steinthorsdottir V, Thorleifsson G, Reynisdottir I, Benediktsson R, Jonsdottir T, Walters GB, et al. A variant in CDKAL1 influences insulin response and risk of type 2 diabetes. Nature genetics. 2007;39(6):770-5. Epub 2007/04/27.

139. Ogdie A, Yu Y, Haynes K, Love TJ, Maliha S, Jiang Y, et al. Risk of major cardiovascular events in patients with psoriatic arthritis, psoriasis and rheumatoid arthritis: a population-based cohort study. Annals of the rheumatic diseases. 2015;74(2):326-32. Epub 2014/10/30.

140. Gelfand JM, Dommasch ED, Shin DB, Azfar RS, Kurd SK, Wang X, et al. The risk of stroke in patients with psoriasis. The Journal of investigative dermatology. 2009;129(10):2411-8. Epub 2009/05/22.

141. Gelfand JM, Neimann AL, Shin DB, Wang X, Margolis DJ, Troxel AB. Risk of myocardial infarction in patients with psoriasis. JAMA : the journal of the American Medical Association. 2006;296(14):1735-41. Epub 2006/10/13.

142. Armstrong EJ, Harskamp CT, Armstrong AW. Psoriasis and major adverse cardiovascular events: a systematic review and meta-analysis of observational studies. Journal of the American Heart Association. 2013;2(2):e000062. Epub 2013/04/06.

143. Mehta NN, Azfar RS, Shin DB, Neimann AL, Troxel AB, Gelfand JM. Patients with severe psoriasis are at increased risk of cardiovascular mortality: cohort study using the General Practice Research Database. European heart journal. 2010;31(8):1000-6. Epub 2009/12/29.

144. Hjuler KF, Gormsen LC, Vendelbo MH, Egeberg A, Nielsen J, Iversen L. Increased global arterial and subcutaneous adipose tissue inflammation in patients with moderate-to-severe psoriasis. The British journal of dermatology. 2017;176(3):732-40. Epub 2016/10/28.

145. Fang N, Jiang M, Fan Y. Association Between Psoriasis and Subclinical Atherosclerosis: A Meta-Analysis. Medicine. 2016;95(20):e3576. Epub 2016/05/20.

146. Niessner A, Sato K, Chaikof EL, Colmegna I, Goronzy JJ, Weyand CM. Pathogensensing plasmacytoid dendritic cells stimulate cytotoxic T-cell function in the atherosclerotic plaque through interferon-alpha. Circulation. 2006;114(23):2482-9. Epub 2006/11/23.

147. Cochain C, Zernecke A. Macrophages in vascular inflammation and atherosclerosis. Pflugers Archiv : European journal of physiology. 2017;469(3-4):485-99. Epub 2017/02/09. 148. Picchi A, Gao X, Belmadani S, Potter BJ, Focardi M, Chilian WM, et al. Tumor necrosis factor-alpha induces endothelial dysfunction in the prediabetic metabolic syndrome. Circulation research. 2006;99(1):69-77. Epub 2006/06/03.

149. Xia F, Wang C, Jin Y, Liu Q, Meng Q, Liu K, et al. Luteolin protects HUVECs from TNF-alpha-induced oxidative stress and inflammation via its effects on the Nox4/ROS-NF-kappaB 
and MAPK pathways. Journal of atherosclerosis and thrombosis. 2014;21(8):768-83. Epub 2014/03/14.

150. Zhang H, Park Y, Wu J, Chen X, Lee S, Yang J, et al. Role of TNF-alpha in vascular dysfunction. Clin Sci (Lond). 2009;116(3):219-30. Epub 2009/01/03.

151. Hashmi S, Zeng QT. Role of interleukin-17 and interleukin-17-induced cytokines interleukin- 6 and interleukin- 8 in unstable coronary artery disease. Coronary artery disease. 2006;17(8):699-706. Epub 2006/11/23.

152. Stemme S, Faber B, Holm J, Wiklund O, Witztum JL, Hansson GK. T lymphocytes from human atherosclerotic plaques recognize oxidized low density lipoprotein. Proceedings of the National Academy of Sciences of the United States of America. 1995;92(9):3893-7. Epub 1995/04/25. 153. Panousis CG, Zuckerman SH. Regulation of cholesterol distribution in macrophagederived foam cells by interferon-gamma. Journal of lipid research. 2000;41(1):75-83. Epub 2000/01/11.

154. Whitman SC, Ravisankar P, Elam H, Daugherty A. Exogenous interferon-gamma enhances atherosclerosis in apolipoprotein E-/- mice. The American journal of pathology. 2000;157(6):1819-24. Epub 2000/12/07.

155. de Oliveira RT, Mamoni RL, Souza JR, Fernandes JL, Rios FJ, Gidlund M, et al. Differential expression of cytokines, chemokines and chemokine receptors in patients with coronary artery disease. International journal of cardiology. 2009;136(1):17-26. Epub 2008/07/12.

156. Braun M, Pietsch P, Felix SB, Baumann G. Modulation of intercellular adhesion molecule-1 and vascular cell adhesion molecule-1 on human coronary smooth muscle cells by cytokines. Journal of molecular and cellular cardiology. 1995;27(12):2571-9. Epub 1995/12/01. 157. Mach F, Schonbeck U, Sukhova GK, Bourcier T, Bonnefoy JY, Pober JS, et al. Functional CD40 ligand is expressed on human vascular endothelial cells, smooth muscle cells, and macrophages: implications for CD40-CD40 ligand signaling in atherosclerosis. Proceedings of the National Academy of Sciences of the United States of America. 1997;94(5):1931-6. Epub 1997/03/04. 158. Mach F, Schonbeck U, Sukhova GK, Atkinson E, Libby P. Reduction of atherosclerosis in mice by inhibition of CD40 signalling. Nature. 1998;394(6689):200-3. Epub 1998/07/22. 159. Eid RE, Rao DA, Zhou J, Lo SF, Ranjbaran H, Gallo A, et al. Interleukin-17 and interferon-gamma are produced concomitantly by human coronary artery-infiltrating $\mathrm{T}$ cells and act synergistically on vascular smooth muscle cells. Circulation. 2009;119(10):1424-32. Epub 2009/03/04.

160. Oliveira RT, Silva RM, Teo FH, Mineiro MF, Ferreira MC, Altemani A, et al. Detection of TCD4+ subsets in human carotid atheroma. Cytokine. 2013;62(1):131-40. Epub 2013/03/12.

161. Zhang L, Wang T, Wang XQ, Du RZ, Zhang KN, Liu XG, et al. Elevated frequencies of circulating Th22 cell in addition to Th17 cell and Th17/Th1 cell in patients with acute coronary syndrome. PloS one. 2013;8(12):e71466. Epub 2013/12/07.

162. Awosika O, Eleryan MG, Rengifo-Pardo M, Doherty L, Martin LW, Ehrlich A. A Case-control Study to Evaluate the Prevalence of Nonalcoholic Fatty Liver Disease Among Patients with Moderate-to-severe Psoriasis. The Journal of clinical and aesthetic dermatology. 2018;11(6):337. Epub 2018/06/27.

163. van der Voort EA, Koehler EM, Dowlatshahi EA, Hofman A, Stricker BH, Janssen HL, et al. Psoriasis is independently associated with nonalcoholic fatty liver disease in patients 55 years old or older: Results from a population-based study. Journal of the American Academy of Dermatology. 2014;70(3):517-24. Epub 2014/01/01.

164. Kulkarni NM, Jaji MS, Shetty P, Kurhe YV, Chaudhary S, Vijaykant G, et al. A novel animal model of metabolic syndrome with non-alcoholic fatty liver disease and skin inflammation. Pharmaceutical biology. 2015;53(8):1110-7. Epub 2014/11/29.

165. Mantovani A, Gisondi P, Lonardo A, Targher G. Relationship between Non-Alcoholic Fatty Liver Disease and Psoriasis: A Novel Hepato-Dermal Axis? International journal of molecular sciences. 2016;17(2):217. Epub 2016/02/11.

166. Zhang S, Huang D, Weng J, Huang Y, Liu S, Zhang Q, et al. Neutralization of Interleukin-17 Attenuates Cholestatic Liver Fibrosis in Mice. Scandinavian journal of immunology. 2016;83(2):102-8. Epub 2015/10/21. 
167.

Krueger G, Koo J, Lebwohl M, Menter A, Stern RS, Rolstad T. The impact of psoriasis on quality of life: results of a 1998 National Psoriasis Foundation patient-membership survey. Archives of dermatology. 2001;137(3):280-4. Epub 2001/03/20.

168. Dubertret L, Mrowietz U, Ranki A, van de Kerkhof PC, Chimenti S, Lotti T, et al. European patient perspectives on the impact of psoriasis: the EUROPSO patient membership survey. The British journal of dermatology. 2006;155(4):729-36. Epub 2006/09/13.

169. Dowlatshahi EA, Wakkee M, Arends LR, Nijsten T. The prevalence and odds of depressive symptoms and clinical depression in psoriasis patients: a systematic review and metaanalysis. The Journal of investigative dermatology. 2014;134(6):1542-51. Epub 2013/11/29.

170. Kannan S, Heller MM, Lee ES, Koo JY. The role of tumor necrosis factor-alpha and other cytokines in depression: what dermatologists should know. J Dermatolog Treat. 2011. Epub 2011/09/06.

171. Zou W, Feng R, Yang Y. Changes in the serum levels of inflammatory cytokines in antidepressant drug-naive patients with major depression. PloS one. 2018;13(6):e0197267. Epub 2018/06/02.

172. Chen Y, Jiang T, Chen P, Ouyang J, Xu G, Zeng Z, et al. Emerging tendency towards autoimmune process in major depressive patients: a novel insight from Th17 cells. Psychiatry research. 2011;188(2):224-30. Epub 2010/12/07.

173. Beurel E, Harrington LE, Jope RS. Inflammatory T helper 17 cells promote depressionlike behavior in mice. Biological psychiatry. 2013;73(7):622-30. Epub 2012/11/24.

174. Biomarkers and surrogate endpoints: preferred definitions and conceptual framework. Clinical pharmacology and therapeutics. 2001;69(3):89-95. Epub 2001/03/10.

$175 . \quad$ Valasek MA, Repa JJ. The power of real-time PCR. Advances in physiology education. 2005;29(3):151-9. Epub 2005/08/20.

176. Schefe JH, Lehmann KE, Buschmann IR, Unger T, Funke-Kaiser H. Quantitative realtime RT-PCR data analysis: current concepts and the novel "gene expression's CT difference" formula. J Mol Med (Berl). 2006;84(11):901-10. Epub 2006/09/15.

177. Navarro E, Serrano-Heras G, Castano MJ, Solera J. Real-time PCR detection chemistry. Clinica chimica acta; international journal of clinical chemistry. 2015;439:231-50. Epub 2014/12/03.

178. Livak KJ, Schmittgen TD. Analysis of relative gene expression data using real-time quantitative PCR and the 2(-Delta Delta C(T)) Method. Methods. 2001;25(4):402-8. Epub 2002/02/16. 179. Adan A, Alizada G, Kiraz Y, Baran Y, Nalbant A. Flow cytometry: basic principles and applications. Critical reviews in biotechnology. 2017;37(2):163-76. Epub 2016/01/16.

180. Anderson KS, Petersson S, Wong J, Shubbar E, Lokko NN, Carlstrom M, et al. Elevation of serum epidermal growth factor and interleukin 1 receptor antagonist in active psoriasis vulgaris. The British journal of dermatology. 2010;163(5):1085-9. Epub 2010/08/19.

181. Sandberg M, Frykman A, Ernerudh J, Berg G, Matthiesen L, Ekerfelt C, et al. Cord blood cytokines and chemokines and development of allergic disease. Pediatric allergy and immunology : official publication of the European Society of Pediatric Allergy and Immunology. 2009;20(6):519-27. Epub 2009/01/30.

182. Hedrick MN, Lonsdorf AS, Hwang ST, Farber JM. CCR6 as a possible therapeutic target in psoriasis. Expert Opin Ther Targets. 2010;14(9):911-22. Epub 2010/07/16.

183. Goebeler M, Toksoy A, Spandau U, Engelhardt E, Brocker EB, Gillitzer R. The C-X-C chemokine Mig is highly expressed in the papillae of psoriatic lesions. The Journal of pathology. 1998;184(1):89-95. Epub 1998/05/16.

184. Flier J, Boorsma DM, van Beek PJ, Nieboer C, Stoof TJ, Willemze R, et al. Differential expression of CXCR3 targeting chemokines CXCL10, CXCL9, and CXCL11 in different types of skin inflammation. The Journal of pathology. 2001;194(4):398-405. Epub 2001/08/28.

185. Cole KE, Strick CA, Paradis TJ, Ogborne KT, Loetscher M, Gladue RP, et al. Interferon-inducible $\mathrm{T}$ cell alpha chemoattractant (I-TAC): a novel non-ELR CXC chemokine with potent activity on activated T cells through selective high affinity binding to CXCR3. The Journal of experimental medicine. 1998;187(12):2009-21. Epub 1998/06/24.

186. Groom JR, Luster AD. CXCR3 ligands: redundant, collaborative and antagonistic functions. Immunology and cell biology. 2011;89(2):207-15. Epub 2011/01/12. 
187.

Rosenblum JM, Shimoda N, Schenk AD, Zhang H, Kish DD, Keslar K, et al. CXC chemokine ligand (CXCL) 9 and CXCL10 are antagonistic costimulation molecules during the priming of alloreactive T cell effectors. J Immunol. 2010;184(7):3450-60. Epub 2010/03/03.

188. Wuest T, Farber J, Luster A, Carr DJ. CD4+ T cell migration into the cornea is reduced in CXCL9 deficient but not CXCL10 deficient mice following herpes simplex virus type 1 infection. Cellular immunology. 2006;243(2):83-9. Epub 2007/02/14.

189. Belperio JA, Keane MP, Burdick MD, Lynch JP, 3rd, Xue YY, Li K, et al. Critical role for CXCR3 chemokine biology in the pathogenesis of bronchiolitis obliterans syndrome. J Immunol. 2002;169(2):1037-49. Epub 2002/07/05.

190. Yoneyama H, Narumi S, Zhang Y, Murai M, Baggiolini M, Lanzavecchia A, et al. Pivotal role of dendritic cell-derived CXCL10 in the retention of T helper cell 1 lymphocytes in secondary lymph nodes. The Journal of experimental medicine. 2002;195(10):1257-66. Epub 2002/05/22.

191. Ozawa M, Terui T, Tagami H. Localization of IL-8 and complement components in lesional skin of psoriasis vulgaris and pustulosis palmaris et plantaris. Dermatology. 2005;211(3):24955. Epub 2005/10/06.

192. Duan H, Koga T, Kohda F, Hara H, Urabe K, Furue M. Interleukin-8-positive neutrophils in psoriasis. Journal of dermatological science. 2001;26(2):119-24. Epub 2001/05/30.

193. Teranishi Y, Mizutani H, Murata M, Shimizu M, Matsushima K. Increased spontaneous production of IL-8 in peripheral blood monocytes from the psoriatic patient: relation to focal infection and response to treatments. Journal of dermatological science. 1995;10(1):8-15. Epub 1995/07/01. 194. Homey B, Dieu-Nosjean MC, Wiesenborn A, Massacrier C, Pin JJ, Oldham E, et al. Up-regulation of macrophage inflammatory protein-3 alpha/CCL20 and CC chemokine receptor 6 in psoriasis. J Immunol. 2000;164(12):6621-32. Epub 2000/06/08.

$195 . \quad$ Wongpiyabovorn J, Suto H, Ushio H, Izuhara K, Mitsuishi K, Ikeda S, et al. Upregulation of interleukin-13 receptor alpha1 on human keratinocytes in the skin of psoriasis and atopic dermatitis. Journal of dermatological science. 2003;33(1):31-40. Epub 2003/10/07.

196. Li B, Tsoi LC, Swindell WR, Gudjonsson JE, Tejasvi T, Johnston A, et al. Transcriptome analysis of psoriasis in a large case-control sample: RNA-seq provides insights into disease mechanisms. The Journal of investigative dermatology. 2014;134(7):1828-38. Epub 2014/01/21.

197. Swindell WR, Xing X, Stuart PE, Chen CS, Aphale A, Nair RP, et al. Heterogeneity of inflammatory and cytokine networks in chronic plaque psoriasis. PloS one. 2012;7(3):e34594. Epub 2012/04/06.

198. Zalewska A, Wyczolkowska J, Dziankowska-Bartkowiak B, Sysa-Jedrzejowska A. Interleukin 4 plasma levels in psoriasis vulgaris patients. Medical science monitor : international medical journal of experimental and clinical research. 2004;10(4):CR156-62. Epub 2004/03/25.

199. Purwar R, Werfel T, Wittmann M. IL-13-stimulated human keratinocytes preferentially attract CD4+CCR4+ T cells: possible role in atopic dermatitis. The Journal of investigative dermatology. 2006;126(5):1043-51. Epub 2006/02/18.

$200 . \quad$ Bowes J, Eyre S, Flynn E, Ho P, Salah S, Warren RB, et al. Evidence to support IL-13 as a risk locus for psoriatic arthritis but not psoriasis vulgaris. Annals of the rheumatic diseases. 2011;70(6):1016-9. Epub 2011/02/26.

201. Jain S, Kaur IR, Das S, Bhattacharya SN, Singh A. T helper 1 to T helper 2 shift in cytokine expression: an autoregulatory process in superantigen-associated psoriasis progression? Journal of medical microbiology. 2009;58(Pt 2):180-4. Epub 2009/01/15.

202. Batycka-Baran A, Besgen P, Wolf R, Szepietowski JC, Prinz JC. The effect of phototherapy on systemic inflammatory process in patients with plaque psoriasis. Journal of photochemistry and photobiology B, Biology. 2016;161:396-401. Epub 2016/06/18.

203. Chen SC, de Groot M, Kinsley D, Laverty M, McClanahan T, Arreaza M, et al. Expression of chemokine receptor CXCR3 by lymphocytes and plasmacytoid dendritic cells in human psoriatic lesions. Archives of dermatological research. 2010;302(2):113-23. Epub 2009/06/12.

204. Schroder JM, Gregory H, Young J, Christophers E. Neutrophil-activating proteins in psoriasis. The Journal of investigative dermatology. 1992;98(2):241-7. Epub 1992/02/01. 
205.

Call DR, Nemzek JA, Ebong SJ, Bolgos GL, Newcomb DE, Remick DG. Ratio of local to systemic chemokine concentrations regulates neutrophil recruitment. The American journal of pathology. 2001;158(2):715-21. Epub 2001/02/13.

206. (WHO). WHO. Waist circumference and waist-hip ratio: Report of a WHO expert consultation, Geneva, December 8-11, 2008. Geneva, Switzerland: WHO, 2011.

207. Keustermans GC, Hoeks SB, Meerding JM, Prakken BJ, de Jager W. Cytokine assays: an assessment of the preparation and treatment of blood and tissue samples. Methods. 2013;61(1):107. Epub 2013/04/23.

208. Tvedt TH, Rye KP, Reikvam H, Brenner AK, Bruserud O. The importance of sample collection when using single cytokine levels and systemic cytokine profiles as biomarkers--a comparative study of serum versus plasma samples. Journal of immunological methods. 2015;418:1928. Epub 2015/02/01.

209. Boehncke S, Salgo R, Garbaraviciene J, Beschmann H, Hardt K, Diehl S, et al. Effective continuous systemic therapy of severe plaque-type psoriasis is accompanied by amelioration of biomarkers of cardiovascular risk: results of a prospective longitudinal observational study. Journal of the European Academy of Dermatology and Venereology : JEADV. 2011;25(10):1187-93. Epub 2011/01/19.

210. Kanelleas A, Liapi C, Katoulis A, Stavropoulos P, Avgerinou G, Georgala S, et al. The role of inflammatory markers in assessing disease severity and response to treatment in patients with psoriasis treated with etanercept. Clinical and experimental dermatology. 2011;36(8):845-50. Epub $2011 / 07 / 28$.

211. Di Minno MN, Iervolino S, Peluso R, Di Minno A, Ambrosino P, Scarpa R. Hemostatic and fibrinolytic changes are related to inflammatory conditions in patients with psoriatic arthritis-effect of different treatments. The Journal of rheumatology. 2014;41(4):714-22. Epub 2014/02/18. 212. Buommino E, De Filippis A, Gaudiello F, Balato A, Balato N, Tufano MA, et al. Modification of osteopontin and MMP-9 levels in patients with psoriasis on anti-TNF-alpha therapy. Archives of dermatological research. 2012;304(6):481-5. Epub 2012/06/12.

213. Campanati A, Ganzetti G, Di Sario A, Damiani A, Sandroni L, Rosa L, et al. The effect of etanercept on hepatic fibrosis risk in patients with non-alcoholic fatty liver disease, metabolic syndrome, and psoriasis. Journal of gastroenterology. 2013;48(7):839-46. Epub 2012/10/16.

214. Coimbra S, Oliveira H, Reis F, Belo L, Rocha S, Quintanilha A, et al. Psoriasis therapy and cardiovascular risk factors: a 12-week follow-up study. American journal of clinical dermatology. 2010;11(6):423-32. Epub 2010/05/01.

215. Romani J, Caixas A, Carrascosa JM, Ribera M, Rigla M, Luelmo J. Effect of narrowband ultraviolet $\mathrm{B}$ therapy on inflammatory markers and body fat composition in moderate to severe psoriasis. The British journal of dermatology. 2012;166(6):1237-44. Epub 2012/02/09.

216. Kawashima K, Torii K, Furuhashi T, Saito C, Nishio E, Nishida E, et al. Phototherapy reduces serum resistin levels in psoriasis patients. Photodermatology, photoimmunology \& photomedicine. 2011;27(3):152-5. Epub 2011/05/04.

217. Coimbra S, Oliveira H, Reis F, Belo L, Rocha S, Quintanilha A, et al. Circulating adipokine levels in Portuguese patients with psoriasis vulgaris according to body mass index, severity and therapy. Journal of the European Academy of Dermatology and Venereology : JEADV. 2010;24(12):1386-94. Epub 2010/03/27.

218. Vaughan DE. PAI-1 and atherothrombosis. Journal of thrombosis and haemostasis : JTH. 2005;3(8):1879-83. Epub 2005/08/17.

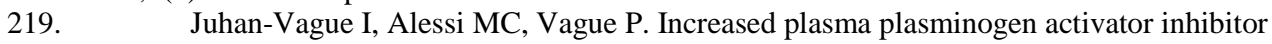
1 levels. A possible link between insulin resistance and atherothrombosis. Diabetologia. 1991;34(7):457-62. Epub 1991/07/01.

220. Orenes-Pinero E, Pineda J, Roldan V, Hernandez-Romero D, Marco P, Tello-Montoliu A, et al. Effects of Body Mass Index on the Lipid Profile and Biomarkers of Inflammation and a Fibrinolytic and Prothrombotic State. Journal of atherosclerosis and thrombosis. 2014. Epub 2015/03/05.

221. Davidovici BB, Sattar N, Prinz J, Puig L, Emery P, Barker JN, et al. Psoriasis and systemic inflammatory diseases: potential mechanistic links between skin disease and co-morbid conditions. The Journal of investigative dermatology. 2010;130(7):1785-96. Epub 2010/05/07. 
222.

Janke J, Engeli S, Gorzelniak K, Feldpausch M, Heintze U, Bohnke J, et al. Adipose tissue and circulating endothelial cell specific molecule-1 in human obesity. Hormone and metabolic research $=$ Hormon- und Stoffwechselforschung $=$ Hormones et metabolisme. 2006;38(1):28-33. Epub 2006/02/16.

223. Tok D, Ekiz F, Basar O, Coban S, Ozturk G. Serum endocan levels in patients with chronic liver disease. International journal of clinical and experimental medicine. 2014;7(7):1802-7. Epub 2014/08/16.

224. Sarrazin S, Adam E, Lyon M, Depontieu F, Motte V, Landolfi C, et al. Endocan or endothelial cell specific molecule-1 (ESM-1): a potential novel endothelial cell marker and a new target for cancer therapy. Biochimica et biophysica acta. 2006;1765(1):25-37. Epub 2005/09/20.

225. He XW, Ke SF, Bao YY, Hong WJ, Shen YG, Li C, et al. Serum levels of endocan and endoglin are associated with large-artery atherosclerotic stroke. Clinica chimica acta; international journal of clinical chemistry. 2018;478:157-61. Epub 2017/12/31.

226. Balta S, Mikhailidis DP, Demirkol S, Ozturk C, Celik T, Iyisoy A. Endocan: A novel inflammatory indicator in cardiovascular disease? Atherosclerosis. 2015;243(1):339-43. Epub 2015/10/09.

227. Cimen T, Efe TH, Akyel A, Sunman H, Algul E, Sahan HF, et al. Human Endothelial Cell-Specific Molecule-1 (Endocan) and Coronary Artery Disease and Microvascular Angina. Angiology. 2016;67(9):846-53. Epub 2016/01/09.

228. Scherpereel A, Depontieu F, Grigoriu B, Cavestri B, Tsicopoulos A, Gentina T, et al. Endocan, a new endothelial marker in human sepsis. Critical care medicine. 2006;34(2):532-7. Epub 2006/01/21.

229. Canpolat U, Kocyigit D, Yildirim A. Role of Endothelial Dysfunction and Endocan in Atherosclerosis: Point of Origin or End Point? Angiology. 2016. Epub 2016/06/17.

230. Balta I, Balta S, Demirkol S, Mikhailidis DP, Celik T, Akhan M, et al. Elevated serum levels of endocan in patients with psoriasis vulgaris: correlations with cardiovascular risk and activity of disease. The British journal of dermatology. 2013;169(5):1066-70. Epub 2013/07/31.

231. Erek Toprak A, Ozlu E, Uzuncakmak TK, Yalcinkaya E, Sogut S, Karadag AS. Neutrophil/Lymphocyte Ratio, Serum Endocan, and Nesfatin-1 Levels in Patients with Psoriasis Vulgaris Undergoing Phototherapy Treatment. Medical science monitor : international medical journal of experimental and clinical research. 2016;22:1232-7. Epub 2016/04/14.

232. Gunther C, Carballido-Perrig N, Kaesler S, Carballido JM, Biedermann T. CXCL16 and CXCR6 are upregulated in psoriasis and mediate cutaneous recruitment of human CD8+ T cells. The Journal of investigative dermatology. 2012;132(3 Pt 1):626-34. Epub 2011/11/25.

233. Wuttge DM, Zhou X, Sheikine Y, Wagsater D, Stemme V, Hedin U, et al.

CXCL16/SR-PSOX is an interferon-gamma-regulated chemokine and scavenger receptor expressed in atherosclerotic lesions. Arteriosclerosis, thrombosis, and vascular biology. 2004;24(4):750-5. Epub $2004 / 02 / 28$.

234. Minami M, Kume N, Shimaoka T, Kataoka H, Hayashida K, Akiyama Y, et al. Expression of SR-PSOX, a novel cell-surface scavenger receptor for phosphatidylserine and oxidized LDL in human atherosclerotic lesions. Arteriosclerosis, thrombosis, and vascular biology. 2001;21(11):1796-800. Epub 2001/11/10.

235. Aslanian AM, Charo IF. Targeted disruption of the scavenger receptor and chemokine CXCL16 accelerates atherosclerosis. Circulation. 2006;114(6):583-90. Epub 2006/08/02.

236. Ma A, Pan X, Xing Y, Wu M, Wang Y, Ma C. Elevation of serum CXCL16 level correlates well with atherosclerotic ischemic stroke. Archives of medical science : AMS. 2014;10(1):47-52. Epub 2014/04/05.

237. Jovanovic I, Zivkovic M, Djuric T, Popovic M, Alavantic D, Stankovic A. CXCL16 in Vascular Pathology Research: from Macro Effects to microRNAs. Journal of atherosclerosis and thrombosis. 2015;22(10):1012-24. Epub 2015/08/21.

238. Bechard D, Scherpereel A, Hammad H, Gentina T, Tsicopoulos A, Aumercier M, et al. Human endothelial-cell specific molecule-1 binds directly to the integrin CD11a/CD18 (LFA-1) and blocks binding to intercellular adhesion molecule-1. J Immunol. 2001;167(6):3099-106. Epub 2001/09/07. 
239

Sigurdardottir G, Ekman AK, Stahle M, Bivik C, Enerback C. Systemic treatment and narrowband ultraviolet B differentially affect cardiovascular risk markers in psoriasis. Journal of the American Academy of Dermatology. 2014;70(6):1067-75. Epub 2014/03/25.

240. Suzuki H, Miyagaki T, Otobe S, Nakajima R, Oka T, Takahashi N, et al. Increased endocan expression in lesional skin and decreased endocan expression in sera in atopic dermatitis. The Journal of dermatology. 2017;44(12):1392-5. Epub 2017/07/18.

241. Kendall RL, Wang G, Thomas KA. Identification of a natural soluble form of the vascular endothelial growth factor receptor, FLT-1, and its heterodimerization with KDR. Biochemical and biophysical research communications. 1996;226(2):324-8. Epub 1996/09/13.

242. Canavese M, Altruda F, Ruzicka T, Schauber J. Vascular endothelial growth factor (VEGF) in the pathogenesis of psoriasis--a possible target for novel therapies? Journal of dermatological science. 2010;58(3):171-6. Epub 2010/05/01.

243. Roudnicky F, Poyet C, Wild P, Krampitz S, Negrini F, Huggenberger R, et al. Endocan is upregulated on tumor vessels in invasive bladder cancer where it mediates VEGF-A-induced angiogenesis. Cancer research. 2013;73(3):1097-106. Epub 2012/12/18.

244. Petrovsky N, McNair P, Harrison LC. Diurnal rhythms of pro-inflammatory cytokines: regulation by plasma cortisol and therapeutic implications. Cytokine. 1998;10(4):307-12. Epub 1998/06/09.

245. Peake JM, Della Gatta P, Suzuki K, Nieman DC. Cytokine expression and secretion by skeletal muscle cells: regulatory mechanisms and exercise effects. Exercise immunology review. 2015;21:8-25. Epub 2015/04/01.

246. Brown M, McClean CM, Davison GW, Brown JCW, Murphy MH. The acute effects of walking exercise intensity on systemic cytokines and oxidative stress. European journal of applied physiology. 2018. Epub 2018/07/17.

247. Reihmane D, Jurka A, Tretjakovs P, Dela F. Increase in IL-6, TNF-alpha, and MMP-9, but not sICAM-1, concentrations depends on exercise duration. European journal of applied physiology. 2013;113(4):851-8. Epub 2012/09/20.

248. Fischer T, Alsins J, Berne B. Ultraviolet-action spectrum and evaluation of ultraviolet lamps for psoriasis healing. International journal of dermatology. 1984;23(10):633-7. Epub $1984 / 12 / 01$.

249. Urbanski A, Schwarz T, Neuner P, Krutmann J, Kirnbauer R, Kock A, et al. Ultraviolet light induces increased circulating interleukin-6 in humans. The Journal of investigative dermatology. 1990;94(6):808-11. Epub 1990/06/01.

250. Walters IB, Burack LH, Coven TR, Gilleaudeau P, Krueger JG. Suberythemogenic narrow-band UVB is markedly more effective than conventional UVB in treatment of psoriasis vulgaris. Journal of the American Academy of Dermatology. 1999;40(6 Pt 1):893-900. Epub $1999 / 06 / 12$.

251. Wainwright NJ, Dawe RS, Ferguson J. Narrowband ultraviolet B (TL-01) phototherapy for psoriasis: which incremental regimen? The British journal of dermatology. 1998;139(3):410-4. Epub 1998/10/10.

252. Guckian M, Jones CD, Vestey JP, Cooper EJ, Dawe R, Gibbs NK, et al. Immunomodulation at the initiation of phototherapy and photochemotherapy. Photodermatology, photoimmunology \& photomedicine. 1995;11(4):163-9. Epub 1995/08/01.

253. Sigmundsdottir H, Johnston A, Gudjonsson JE, Valdimarsson H. Narrowband-UVB irradiation decreases the production of pro-inflammatory cytokines by stimulated T cells. Archives of dermatological research. 2005;297(1):39-42. Epub 2005/05/13.

254. Barr RM, Walker SL, Tsang W, Harrison GI, Ettehadi P, Greaves MW, et al. Suppressed alloantigen presentation, increased TNF-alpha, IL-1, IL-1Ra, IL-10, and modulation of TNF-R in UV-irradiated human skin. The Journal of investigative dermatology. 1999;112(5):692-8. Epub 1999/05/08.

255. Enk CD, Sredni D, Blauvelt A, Katz SI. Induction of IL-10 gene expression in human keratinocytes by UVB exposure in vivo and in vitro. J Immunol. 1995;154(9):4851-6. Epub $1995 / 05 / 01$.

256. Walters IB, Ozawa M, Cardinale I, Gilleaudeau P, Trepicchio WL, Bliss J, et al. Narrowband (312-nm) UV-B suppresses interferon gamma and interleukin (IL) 12 and increases IL-4 
transcripts: differential regulation of cytokines at the single-cell level. Archives of dermatology. 2003;139(2):155-61. Epub 2003/02/18.

257. Krutmann J, Hönigsmann, H., Elmets, C.A. Dermatological Phototherapy and Photodiagnostic Methods. Second Edition ed. Berlin Heidelberg: Springer-Verlag; 2009.

258. Gibbs NK. Narrowband UV-B phototherapy clears psoriasis through a combination of local and systemic effects. Archives of dermatology. 2003;139(5):665; author reply -6. Epub $2003 / 05 / 21$.

259. Dawe RS, Cameron H, Yule S, Man I, Ibbotson SH, Ferguson J. UV-B phototherapy clears psoriasis through local effects. Archives of dermatology. 2002;138(8):1071-6. Epub 2002/08/08.

260. Arakawa A, Siewert K, Stohr J, Besgen P, Kim SM, Ruhl G, et al. Melanocyte antigen triggers autoimmunity in human psoriasis. The Journal of experimental medicine. 2015;212(13):220312. Epub 2015/12/02.

261. Lande R, Botti E, Jandus C, Dojcinovic D, Fanelli G, Conrad C, et al. The antimicrobial peptide LL37 is a T-cell autoantigen in psoriasis. Nature communications. 2014;5:5621. Epub $2014 / 12 / 04$.

262. Sigurdardottir SL, Thorleifsdottir RH, Valdimarsson H, Johnston A. The role of the palatine tonsils in the pathogenesis and treatment of psoriasis. The British journal of dermatology. 2013;168(2):237-42. Epub 2012/08/21.

263. Beer HD, Contassot E, French LE. The inflammasomes in autoinflammatory diseases with skin involvement. The Journal of investigative dermatology. 2014;134(7):1805-10. Epub 2014/03/07.

264. Jung N, Hellmann M, Hoheisel R, Lehmann C, Haase I, Perniok A, et al. An open-label pilot study of the efficacy and safety of anakinra in patients with psoriatic arthritis refractory to or intolerant of methotrexate (MTX). Clinical rheumatology. 2010;29(10):1169-73. Epub 2010/06/10.

265. Mansouri B, Kivelevitch D, Campa M, Menter A. Palmoplantar pustular psoriasis unresponsive to the interleukin-1beta antagonist canakinumab. Clinical and experimental dermatology. 2016;41(3):324-6. Epub 2015/09/08.

266. Tauber M, Viguier M, Alimova E, Petit A, Liote F, Smahi A, et al. Partial clinical response to anakinra in severe palmoplantar pustular psoriasis. The British journal of dermatology. 2014;171(3):646-9. Epub 2014/04/02.

267. Viguier M, Guigue P, Pages C, Smahi A, Bachelez H. Successful treatment of generalized pustular psoriasis with the interleukin-1-receptor antagonist Anakinra: lack of correlation with IL1RN mutations. Annals of internal medicine. 2010;153(1):66-7. Epub 2010/07/14.

268. Tzanetakou V, Kanni T, Giatrakou S, Katoulis A, Papadavid E, Netea MG, et al. Safety and Efficacy of Anakinra in Severe Hidradenitis Suppurativa: A Randomized Clinical Trial. JAMA dermatology. 2016;152(1):52-9. Epub 2015/11/19.

269. Russo V, Alikhan A. Failure of Anakinra in a Case of Severe Hidradenitis Suppurativa. Journal of drugs in dermatology : JDD. 2016;15(6):772-4. Epub 2016/06/09.

270. Sun NZ, Ro T, Jolly P, Sayed CJ. Non-response to Interleukin-1 Antagonist

Canakinumab in Two Patients with Refractory Pyoderma Gangrenosum and Hidradenitis Suppurativa. The Journal of clinical and aesthetic dermatology. 2017;10(9):36-8. Epub 2018/01/19.

271. Tervaniemi MH, Katayama S, Skoog T, Siitonen HA, Vuola J, Nuutila K, et al. NODlike receptor signaling and inflammasome-related pathways are highlighted in psoriatic epidermis. Scientific reports. 2016;6:22745. Epub 2016/03/16.

272. Salskov-Iversen ML, Johansen C, Kragballe K, Iversen L. Caspase-5 expression is upregulated in lesional psoriatic skin. The Journal of investigative dermatology. 2011;131(3):670-6. Epub 2010/12/31.

273. Zhang H, Fu R, Guo C, Huang Y, Wang H, Wang S, et al. Anti-dsDNA antibodies bind to TLR4 and activate NLRP3 inflammasome in lupus monocytes/macrophages. Journal of translational medicine. 2016;14(1):156. Epub 2016/06/03.

274. Kim SK, Choe JY, Lee GH. Enhanced expression of NLRP3 inflammasome-related inflammation in peripheral blood mononuclear cells in Sjogren's syndrome. Clinica chimica acta; international journal of clinical chemistry. 2017;474:147-54. Epub 2017/10/03. 
275. Piancone F, Saresella M, Marventano I, La Rosa F, Santangelo MA, Caputo D, et al. Monosodium Urate Crystals Activate the Inflammasome in Primary Progressive Multiple Sclerosis. Frontiers in immunology. 2018;9:983. Epub 2018/05/22.

276. Arbore G, West EE, Spolski R, Robertson AAB, Klos A, Rheinheimer C, et al. T helper 1 immunity requires complement-driven NLRP3 inflammasome activity in CD4(+) T cells. Science. 2016;352(6292):aad1210. Epub 2016/06/18.

277. Gambichler T, Zhang Y, Hoxtermann S, Kreuter A. Natural killer cells and B lymphocytes in peripheral blood of patients with psoriasis. The British journal of dermatology. 2013;168(4):894-6. Epub 2012/09/28.

278. Lu J, Ding Y, Yi X, Zheng J. CD19+ B cell subsets in the peripheral blood and skin lesions of psoriasis patients and their correlations with disease severity. Brazilian journal of medical and biological research $=$ Revista brasileira de pesquisas medicas e biologicas. 2016;49(9):e5374. Epub 2016/08/18.

279. Guidelli GM, Fioravanti A, Rubegni P, Feci L. Induced psoriasis after rituximab therapy for rheumatoid arthritis: a case report and review of the literature. Rheumatology international. 2013;33(11):2927-30. Epub 2012/11/09.

280. Chang YS, Lee HT, Chen WS, Hsiao KH, Chen MH, Tsai CY, et al. Treatment of psoriasis with rituximab. Journal of the American Academy of Dermatology. 2012;66(5):e184-5. Epub 2012/04/18.

281. Jimenez-Boj E, Stamm TA, Sadlonova M, Rovensky J, Raffayova H, Leeb B, et al. Rituximab in psoriatic arthritis: an exploratory evaluation. Annals of the rheumatic diseases. 2012;71(11):1868-71. Epub 2012/07/27.

282. Yanaba K, Kamata M, Ishiura N, Shibata S, Asano Y, Tada Y, et al. Regulatory B cells suppress imiquimod-induced, psoriasis-like skin inflammation. Journal of leukocyte biology. 2013;94(4):563-73. Epub 2013/05/01.

283. Balato N, Napolitano M, Ayala F, Patruno C, Megna M, Tarantino G. Nonalcoholic fatty liver disease, spleen and psoriasis: New aspects of low-grade chronic inflammation. World journal of gastroenterology. 2015;21(22):6892-7. Epub 2015/06/17.

284. Gotoh K, Inoue M, Masaki T, Chiba S, Shimasaki T, Ando H, et al. A novel antiinflammatory role for spleen-derived interleukin-10 in obesity-induced inflammation in white adipose tissue and liver. Diabetes. 2012;61(8):1994-2003. Epub 2012/06/01.

$285 . \quad$ Hayashi M, Yanaba K, Umezawa Y, Yoshihara Y, Kikuchi S, Ishiuji Y, et al. IL-10producing regulatory B cells are decreased in patients with psoriasis. Journal of dermatological science. 2016;81(2):93-100. Epub 2015/11/29.

286. Chistiakov DA, Orekhov AN, Bobryshev YV. Immune-inflammatory responses in atherosclerosis: Role of an adaptive immunity mainly driven by $\mathrm{T}$ and B cells. Immunobiology. 2016;221(9):1014-33. Epub 2016/06/06.

287. Caligiuri G, Nicoletti A, Poirier B, Hansson GK. Protective immunity against atherosclerosis carried by B cells of hypercholesterolemic mice. The Journal of clinical investigation. 2002;109(6):745-53. Epub 2002/03/20.

288. Emami H, Singh P, MacNabb M, Vucic E, Lavender Z, Rudd JH, et al. Splenic metabolic activity predicts risk of future cardiovascular events: demonstration of a cardiosplenic axis in humans. JACC Cardiovascular imaging. 2015;8(2):121-30. Epub 2015/01/13. 289. Hjuler KF, Gormsen LC, Vendelbo MH, Egeberg A, Nielsen J, Iversen L. Systemic Inflammation and Evidence of a Cardio-splenic Axis in Patients with Psoriasis. Acta dermatovenereologica. 2018;98(4):390-5. Epub 2018/01/13.

290. Thomas J, Kupper M, Batra R, Jargosch M, Atenhan A, Baghin V, et al. Is the humoral immunity dispensable for the pathogenesis of psoriasis? Journal of the European Academy of Dermatology and Venereology : JEADV. 2018. Epub 2018/06/02.

291. Czarnowicki T, Gonzalez J, Bonifacio KM, Shemer A, Xiangyu P, Kunjravia N, et al. Diverse activation and differentiation of multiple B-cell subsets in patients with atopic dermatitis but not in patients with psoriasis. The Journal of allergy and clinical immunology. 2016;137(1):118-29 e5. Epub 2015/10/07. 
292.

Sbidian E, Chaimani A, Garcia-Doval I, Do G, Hua C, Mazaud C, et al. Systemic pharmacological treatments for chronic plaque psoriasis: a network meta-analysis. The Cochrane database of systematic reviews. 2017;12:CD011535. Epub 2017/12/23.

293. Di Meglio P, Perera GK, Nestle FO. The multitasking organ: recent insights into skin immune function. Immunity. 2011;35(6):857-69. Epub 2011/12/27.

294. de Oliveira PS, Cardoso PR, Lima EV, Pereira MC, Duarte AL, Pitta Ida R, et al. IL17A, IL-22, IL-6, and IL-21 Serum Levels in Plaque-Type Psoriasis in Brazilian Patients. Mediators of inflammation. 2015;2015:819149. Epub 2015/09/10.

$295 . \quad C h$ abra S, Narang T, Joshi N, Goel S, Sawatkar G, Saikia B, et al. Circulating T-helper 17 cells and associated cytokines in psoriasis. Clinical and experimental dermatology. 2016;41(7):80610. Epub 2016/08/03.

296. Krueger JG, Brunner PM. Interleukin-17 alters the biology of many cell types involved in the genesis of psoriasis, systemic inflammation and associated comorbidities. Experimental dermatology. 2018;27(2):115-23. Epub 2017/11/21.

297. Moran B, Sweeney CM, Hughes R, Malara A, Kirthi S, Tobin AM, et al. Hidradenitis Suppurativa Is Characterized by Dysregulation of the Th17:Treg Cell Axis, Which Is Corrected by Anti-TNF Therapy. The Journal of investigative dermatology. 2017;137(11):2389-95. Epub $2017 / 06 / 28$.

298. Vekic DA, Frew J, Cains GD. Hidradenitis suppurativa, a review of pathogenesis, associations and management. Part 1. The Australasian journal of dermatology. 2018. Epub 2018/01/23.

299. Lima AL, Karl I, Giner T, Poppe H, Schmidt M, Presser D, et al. Keratinocytes and neutrophils are important sources of proinflammatory molecules in hidradenitis suppurativa. The British journal of dermatology. 2016;174(3):514-21. Epub 2015/10/06.

$300 . \quad$ Matusiak L, Szczech J, Bieniek A, Nowicka-Suszko D, Szepietowski JC. Increased interleukin (IL)-17 serum levels in patients with hidradenitis suppurativa: Implications for treatment with anti-IL-17 agents. Journal of the American Academy of Dermatology. 2017;76(4):670-5. Epub 2017/01/04.

301. Li X, Zhang Y, Xia M, Gulbins E, Boini KM, Li PL. Activation of Nlrp3 inflammasomes enhances macrophage lipid-deposition and migration: implication of a novel role of inflammasome in atherogenesis. PloS one. 2014;9(1):e87552. Epub 2014/01/30.

302. Stienstra R, Joosten LA, Koenen T, van Tits B, van Diepen JA, van den Berg SA, et al. The inflammasome-mediated caspase-1 activation controls adipocyte differentiation and insulin sensitivity. Cell metabolism. 2010;12(6):593-605. Epub 2010/11/27.

303. Vandanmagsar B, Youm YH, Ravussin A, Galgani JE, Stadler K, Mynatt RL, et al. The NLRP3 inflammasome instigates obesity-induced inflammation and insulin resistance. Nature medicine. 2011;17(2):179-88. Epub 2011/01/11.

304. Madec S, Rossi C, Chiarugi M, Santini E, Salvati A, Ferrannini E, et al. Adipocyte P2X7 receptors expression: a role in modulating inflammatory response in subjects with metabolic syndrome? Atherosclerosis. 2011;219(2):552-8. Epub 2011/10/08. 


\section{Papers}

The papers associated with this thesis have been removed for copyright reasons. For more details about these see:

http://urn.kb.se/resolve?urn=urn:nbn:se:liu:diva-151988 